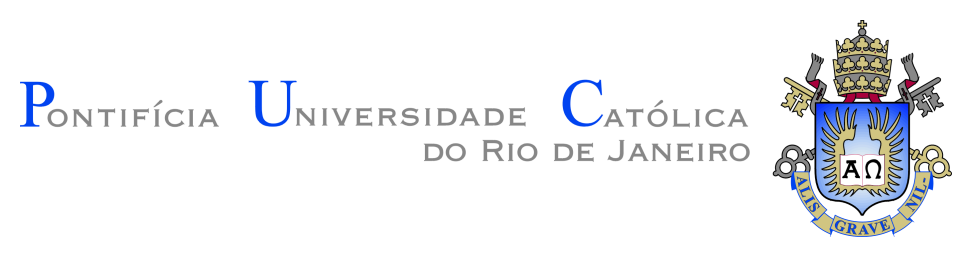

lago Arcas da Fonseca

\title{
Aplicações da Equação do Calor na Indústria do Petróleo
}

Dissertação de Mestrado

Dissertação apresentada como requisito parcial para obtenção do grau de Mestre pelo Programa de Pós-graduação em Matemáticado Departamento de Matemáticado Centro Técnico Científicoda PUC-Rio.

Orientador Prof. Alessandro Alla Co-orientador: Prof. Abelardo Borges Barreto Jr. 
lago Arcas da Fonseca

\section{Aplicações da Equação do Calor na Indústria do Petróleo}

Dissertação apresentada como requisito parcial para obtenção do grau de Mestre pelo Programa de Pós-graduação em Matemáticado Departamento de Matemáticado Centro Técnico Científicoda PUC-Rio. Aprovada pela Comissão Examinadora abaixo assinada.

Prof. Alessandro Alla

Orientador Departamento de Matemática - DMAT/PUC-Rio

Prof. Abelardo Borges Barreto Jr. Co-orientador Departamento de Matemática - PUC-Rio

Prof. Helio Cortes Vieira Lopes Departamento de Informática - PUC-Rio

Prof Lis Ingrid Roque Lopes Custódio Instituto de Matemática e Estatística - UERJ

Prof. Sinésio Pesco

Departamento de Matemática - PUC-Rio 
Todos os direitos reservados. É proibida a reprodução total ou parcial do trabalho sem autorização da universidade, do autor e do orientador.

\section{lago Arcas da Fonseca}

Graduado em Matemática Bacharelado (2015) e Licenciatura (2019) pela Universidade Federal Fluminense (UFF-Niterói). Durante a graduação foi monitor do Projeto Geometria Analítica: Iniciando Alunos à Docência (2013), Projeto Álgebra I (2015) e Projeto Álgebra Linear II (2017). Participou do Programa de Iniciação Científica da UFF: Cálculo Diferencial Segundo F-G-C-H (2014) e do IMPA: Introdução a Geometria Diferencial (2015). Começou em 2018 o Mestrado em Matemática Aplicada pela Pontifícia Universidade Católica do Rio de Janeiro (Puc-Rio), durante o mestrado foi Professor do Magistério Superior Substituto associado ao Departamento de Matemática da Universidade Federal Fluminense (UFF-Volta Redonda) em 2018.

Ficha Catalográfica

Arcas da Fonseca, lago

Aplicações da Equação do Calor na Indústria do Petróleo / lago Arcas da Fonseca; orientador: Alessandro Alla; coorientador: Abelardo Borges Barreto Jr.. - Rio de janeiro: PUC-Rio, Departamento de Matemática, 2020.

v., 74 f: il. color. ; $30 \mathrm{~cm}$

Dissertação (mestrado) - Pontifícia Universidade Católica do Rio de Janeiro, Departamento de Matemática.

Inclui bibliografia

1. Matemática Aplicada - Teses. 2. Equações Diferenciais Parciais - Teses. 3. Análise Numérica - Teses. 4. Métodos Computacionais para Indústria do Petróleo - Teses. 5. Diferenças finitas;. 6. Método Newton-Krylov Sem-Jacobiano;. 7. Simulação numérica de reservatórios;. 8. Escoamento bifásico de água e óleo.. I. Alla, Alessandro. II. Borges Barreto Jr., Abelardo. III. Pontifícia Universidade Católica do Rio de Janeiro. Departamento de Matemática. IV. Título. 
Dedico esse trabalho a Deus, Jesus, minha família, namorada e amigos. Obrigado por estarem comigo nos caminhos da minha existência. 


\section{Agradecimentos}

Agradeço a Deus por ter me criado, e sempre estado comigo, me dando forças através de infinitos meios e circunstâncias para que eu possa suportar a parte que me cabe na obra da Sua criação.

Agradeço a Jesus por ser o amigo de sempre, pelas oportunidades e exemplos que me dá todos os dias para que eu possa me tornar uma pessoa melhor, seguindo seus passos.

Agradeço a minha família por darem meu mundo material e moral, por me ensinarem o valor do estudo, por sempre apoiar e incentivar meus sonhos. Eu não seria o que sou hoje se não fosse por vocês. Vocês são ótimos pais e familiares.

Agradeço a minha namorada, por sempre me apoiar e incentivar em todos os momentos, pela compreensão, carinho e amor.

Agradeço aos meus amigos por todos os conselhos e apoios que me dão, por me ensinarem que é preciso dar um passo de cada vez, e que devagar também se chega longe.

Agradeço ao chefe do departmento de matemática da UFF-VR, por sua gentileza e compreensão enquanto eu estava como professor substituto no departamento, me proporcionando turmas para lecionar em horários diferentes das minhas disciplinas do mestrado.

Agradeço a PUC-Rio por sua ótima estrutura e funcionários, aos meus orientadores que estiveram comigo me apoiando e a CAPES pelo apoio financeiro para realização deste trabalho.

Agradeço a todos os professores que passaram por mim e deixaram algum aprendizado comigo: desde os que me ensinaram a ler e escrever, até aos que me ensinaram a derivar, integrar e a pensar sobre Educação de maneira ampla.

O presente trabalho foi realizado com apoio da Coordenação de Aperfeiçoamento de Pessoal de Nível Superior - Brasil (CAPES) - Código de Financiamento 001. 


\section{Resumo}

Arcas da Fonseca, Iago; Alla, Alessandro; Borges Barreto Jr., Abelardo. Aplicações da Equação do Calor na Indústria do Petróleo. Rio de Janeiro, 2020. 74p. Dissertação de Mestrado Departamento de Matemática, Pontifícia Universidade Católica do Rio de Janeiro.

Neste trabalho focamos sobre alguns modelos matemáticos na área do petróleo, com o objetivo de propor um modelo inicial de simulador numérico de reservatórios. Inicialmente apresentamos uma EDP do calor não-linear com um termo fonte de calor constante, estudada para o domínio sendo uma placa plana quadrada homogênea e heterogênea, onde aplicamos soluções numéricas utilizando o método das diferenças finitas implícito. Abordamos o problema de refinamento da malha no entorno dos poços utilizando o método JFNK (Jacobian-Free Newton-Krylov), que aumenta a eficiência computacional através de uma aproximação para a matriz Jacobiana. Por fim resolvemos um sistema de EDPs não-lineares que representam o escoamento bifásico de água e óleo, constituído por equações de transporte em termos da pressão e da saturação. Fizemos simulações numéricas de alguns casos conhecidos e os resultados mostraram uma boa qualidade no nosso método.

\section{Palavras-chave}

Diferenças finitas; Método Newton-Krylov Sem-Jacobiano; Simulação numérica de reservatórios; Escoamento bifásico de água e óleo. 


\section{Abstract}

Arcas da Fonseca, Iago; Alla, Alessandro (Advisor); Borges Barreto Jr., Abelardo (Co-Advisor). Applications of Heat Equation in Oil Industry. Rio de Janeiro, 2020. 74p. Dissertação de mestrado - Departamento de Matemática, Pontifícia Universidade Católica do Rio de Janeiro.

In this work we focus on the numerical approximation of some mathematical models in the oil field. First, we present a non-linear heat equation with a constant heat source term, studied for the domain of a homogeneous and heterogeneous square domain, where we apply numerical solutions using an implicit finite difference method. We approach the problem of mesh refinement around the wells using the JFNK (JacobianFree Newton-Krylov) method, which improves the computational efficiency through an approximation to the Jacobian matrix. Finally, we solve a system of non-linear EDPs that represent the two-phase flow of water and oil, consisting of equations of transport in terms of pressure and saturation. Numerical simulations for some known cases showed accurate approximation of our method.

\section{Keywords}

Finite Difference; Jacobian-Free Newton-Krylov Method; Numerical reservoirs simulation; Water-oil biphasic flow. 


\section{Sumário}

1 Introdução 12

2 Equação do Calor com Termo Fonte em uma Placa Homogênea $\quad 15$

2.1 Aproximação Numerica 16

$\begin{array}{ll}2.1 .1 \text { Método de Newton } & 19\end{array}$

2.1.2 Método do Subespaço de Krylov 21

2.1.3 Método Newton-Krylov Sem Jacobiano 25

2.2 Experimentos Numéricos 26

2.2.1 Teste 1: Equação do Calor linear com termo fonte constante 28

2.2.2 Teste 2: Equação do Calor não-linear com termo fonte variável e constante 36

3 Equação do Calor com Termo Fonte em uma Placa Heterogênea 43

3.1 Aproximação Numérica 44

3.2 Experimentos Numéricos 49

3.2.1 Teste 3: Equação do Calor linear com termo fonte constante na placa heterogênea com condições de contorno internas $\quad 50$

3.2.2 Teste 4: Equação do Calor não-linear com termo fonte variável e constante na placa heterogênea com condições de contorno internas 53

4 Escoamento bifásico de água e óleo $\quad 60$

4.1 Equações de conservação $\quad 60$

$\begin{array}{lll}4.1 .1 & \text { Conservação de massa } & 60\end{array}$

4.1.2 Conservação da quantidade de movimento 61

4.2 Equações de Transporte 61

4.3 Domínio, condições iniciais e de contorno 62

4.4 Aproximação Numérica $\quad 63$

$\begin{array}{ll}\text { 4.4.1 Experimentos Numéricos } & 67\end{array}$

5 Conclusão $\quad 72$

$\begin{array}{ll}\text { Referências bibliográficas } & 73\end{array}$ 


\section{Lista de figuras}

Figura 2.1 Discretização do domínio $\Omega$. 16

$\begin{array}{lll}\text { Figura 2.2 Discretização do intervalo }[0, T] & 17\end{array}$

Figura 2.3 Teste 1 (Caso 1) 29

Figura 2.4 Curvas de nível do Teste 1 (Caso 1) 29

Figura 2.5 Variação $\|\mathcal{E}(k)\|$ do Teste 1 (Caso 1) 29

Figura 2.6 Teste 1 (Caso 2) 30

Figura 2.7 Curvas de nível do Teste 1 (Caso 2) 30

Figura 2.8 Variação $\|\mathcal{E}(k)\|$ do Teste 1 (Caso 2) 31

Figura 2.9 Teste 1 (Caso 3) 32

Figura 2.10 Curvas de nível do Teste 1 (Caso 3) 32

Figura 2.11 Variação $\|\mathcal{E}(k)\|$ do Teste 1 (Caso 3) 32

Figura 2.12 Teste 1 (Caso 4) 33

Figura 2.13 Curvas de nível do Teste 1 (Caso 4) 33

Figura 2.14 Variação $\|\mathcal{E}(k)\|$ do Teste 1 (Caso 4) 34

Figura 2.15 Teste 1 (Caso 5) 34

Figura 2.16 Curvas de nível do Teste 1 (Caso 5) 35

Figura 2.17 Variação $\|\mathcal{E}(k)\|$ do Teste 1 (Caso 5) 35

Figura 2.18 Teste 2 (Caso 1) 36

Figura 2.19 Curvas de nível do Teste 2 (Caso 1) 36

Figura 2.20 Variação $\|\mathcal{E}(k)\|$ do Teste 2 (Caso 1) 37

Figura 2.21 Teste 2 (Caso 2) 37

Figura 2.22 Curvas de nível do Teste 2 (Caso 2) 38

Figura 2.23 Variação $\|\mathcal{E}(k)\|$ do Teste 2 (Caso 2) 38

Figura 2.24 Teste 2 (Caso 3) 39

Figura 2.25 Curvas de nível do Teste 2 (Caso 3) 39

Figura 2.26 Variação $\|\mathcal{E}(k)\|$ do Teste 2 (Caso 3) 39

Figura 2.27 Teste 2 (Caso 4) 40

Figura 2.28 Curvas de nível do Teste 2 (Caso 4) 40

Figura 2.29 Variação $\|\mathcal{E}(k)\|$ do Teste 2 (Caso 4) 40

Figura 2.30 Teste 2 (Caso 5) 41

Figura 2.31 Curvas de nível do Teste 2 (Caso 5) 41

Figura 2.32 Variação $\|\mathcal{E}(k)\|$ do Teste 2 (Caso 5) 42

Figura 3.1 Placa heterogênea com condições de contorno internas. 43

Figura 3.2 Discretização da placa heterogênea com $n=3$. 45

$\begin{array}{lll}\text { Figura 3.3 Teste } 3 \text { (Caso 6) } & 50\end{array}$

Figura 3.4 Curvas de nível do Teste 3 (Caso 6) 50

Figura 3.5 Teste 3 (Caso 7) 51

Figura 3.6 Curvas de nível do Teste 3 (Caso 7) 51

Figura 3.7 Teste 3 (Caso 8) 52

Figura 3.8 Curvas de nível do Teste 3 (Caso 8) 52

Figura 3.9 Teste 3 (Caso 9) 53

Figura 3.10 Curvas de nível do Teste 3 (Caso 9) 53

Figura 3.11 Teste 4 (Caso 6) 54

Figura 3.12 Curvas de nível do Teste 4 (Caso 6) 54 
Figura 3.13 Variação $\|\mathcal{E}(k)\|$ do Teste 4 (Caso 6) 54

Figura 3.14 Teste 4 (Caso 7) 55

Figura 3.15 Curvas de nível do Teste 4 (Caso 7) 55

Figura 3.16 Variação $\|\mathcal{E}(k)\|$ do Teste 4 (Caso 7) 56

Figura 3.17 Teste 4 (Caso 8) 56

Figura 3.18 Curvas de nível do Teste 4 (Caso 8) 57

Figura 3.19 Variação $\|\mathcal{E}(k)\|$ do Teste 4 (Caso 8) 57

Figura 3.20 Teste 4 (Caso 9) 58

Figura 3.21 Curvas de nível do Teste 4 (Caso 9) 58

Figura 3.22 Variação $\|\mathcal{E}(k)\|$ do Teste 4 (Caso 9) 58

$\begin{array}{lll}\text { Figura 4.1 Pressão do óleo (Caso 10) } & 68\end{array}$

$\begin{array}{lll}\text { Figura 4.2 Saturação da água (Caso 10) } & 69\end{array}$

$\begin{array}{lll}\text { Figura 4.3 Pressão do óleo (Caso 11) } & 69\end{array}$

Figura 4.4 Saturação da água (Caso 11) 69

$\begin{array}{lll}\text { Figura 4.5 } & \text { Pressão do óleo (Caso 12) } & 70\end{array}$

Figura 4.6 Saturação da água (Caso 12) 70

Figura 4.7 Pressão do óleo (Caso 13) 71

$\begin{array}{lll}\text { Figura 4.8 Saturação da água (Caso 13) } & 71\end{array}$ 
O ser humano não morre quando seu coração deixa de bater, morre quando de alguma maneira deixa de se sentir importante.

Augusto Cury, O vendedor de Sonhos. 


\section{Introdução}

Atualmente a matemática aplicada se faz presente fortemente na sociedade, um dos motivos é por conta da dificuldade de se resolver problemas matemáticos analiticamente. Busca-se então uma solução numérica aproximada desses problemas. Somando-se a isso, surgem naturalmente problemas industriais, desafiando e fazendo com que cresça ainda mais a matemática aplicada, que se mostra uma potencial ferramenta para soluções desses problemas, como pode ser observado em Friedman (1).

Cursos de matemática industrial começaram a surgir nas universidades, fazendo com que a matemática se aproxime cada vez mais da indústria, o que incentiva e é produtivo para o desenvolvimento de ambas. Esse fato se deve a crescente demanda do mercado industrial. Assim as universidades começaram a buscar meios de implementar esses cursos, como pode ser visto em Friedman e Lavery (2), onde os autores dão instruções de como se iniciar um curso de matemática industrial nas universidades.

No Brasil, o primeiro curso de graduação em matemática industrial foi oferecido no ano 2000 pela Universidade Federal do Paraná (UFPR), e depois o curso surgiu na Universidade Federal do Ceará (UFC), Fundação Getúlio Vargas (FGV), Universidade Federal do Espírito Santo (UFES), entre outras.

Uma forte ligação que podemos ver entre a matemática aplicada e a indústria está relacionada a Engenharia de Petróleo, pois muitos modelos matemáticos são criados para dar informações importantes sobre jazidas petrolíferas, como: reservatórios, poços, exploração, localização, produção, perfuração, entre outros. Muitos livros são escritos sobre o assunto, e disciplinas de graduação surgiram nessas áreas. Uma referência é o livro de Abou-Kassem et al. em (3), onde os autores ensinam a construir um simulador de reservatórios a partir do estudo de modelos matemáticos.

Ocorre que a modelagem de muitos problemas da engenharia e das ciências da natureza de um modo geral envolvem equações diferenciais parciais - EDPs, e quanto maior a proximidade dos problemas em relação ao mundo real, a teoria matemática para resolvê-los se torna mais difícil, dado que suas modelagens são feitas por sistemas de EDPs não-lineares, onde a resolução por métodos analíticos é bastante complicada, nem mesmo sendo possível, 
atualmente, em certos casos. Como uma alternativa a essa situação, surgem os métodos numéricos, que contribuem na resolução desses problemas, fornecendo soluções aproximadas.

Sendo assim, a motivação do nosso trabalho é contribuir para a aproximação entre a matemática e a indústria, procurando aperfeiçoar procedimentos já existentes e solucionar os novos problemas que surgem. Particulamente nosso objetivo será voltado para o estudo de algumas aplicações da EDP do calor na indústria do petróleo.

Inicialmente buscamos a solução numérica da EDP do calor não-linear em duas dimensões com um termo fonte de calor constante e um variável, usando o método das diferenças finitas apresentado em Leveque (4). Em termos bem gerais, podemos pensar nos termos fontes de calor da seguinte maneira: quando os termos fontes de calor constante são positivos, representam poços produtores, produzindo óleo a uma vazão constante, e quando são negativos representam poços injetores, injetando água a uma vazão constante. $\mathrm{E}$ os termos fonte de calor variável representam poços produzindo a uma vazão variável. Utilizamos o MatLab como ferramenta para aproximar nosso problema.

A presente dissertação está organizada em cinco capítulos, onde o primeiro capítulo consiste dessa introdução.

O segundo capítulo traz a resolução da EDP do calor não-linear com termos fontes, cujo domínio é uma placa plana quadrada homogênea, ou seja feita de um único material, logo toda a placa possui condutividade térmica constante. Discretizamos a equação e estudamos métodos numéricos de resolução como o método de Newton, em Faires e Burden (5), do Subespaço de Krylov, em Liesen e Strakos (6) e JFNK (Jacobian-Free Newton-Krylov), em Knoll e Keyes (7). Optamos por utilizar o último método para aplicar ao problema, pois ele nos permite uma aproximação eficiente para a matriz jacobiana e aumentar a dimensão do problema. Tanto para o caso de fontes de calor constantes, como para o caso de fontes de calor variável, foram realizados testes com diferentes posicionamentos e intensidades dessas fontes. Ao final foram estudados cinco casos para cada tipo de fonte (constante ou variável).

O terceiro capítulo também traz a resolução da EDP do calor não-linear com termos fontes, porém com o domínio sendo uma placa plana quadrada heterogênea, logo a placa não é mais feita de um único material, e assim a conduvidade térmica não é mais constante em toda a placa como no capítulo anterior, fazendo que o problema não tenha solução analítica. Tratamos a placa heterogênea como sendo divida em quatro regiões onde cada uma possui um valor de condutividade térmica diferente, e colocamos condições de contorno 
internas entre essas quatro regiões. Inicialmente discretizamos as quatro condições de contorno internas da placa, e estudamos as modificações que elas produzem na EDP do calor. Organizamos diferentes posicionamentos para as fontes do termo fonte de calor constante obtendo quatro novos casos. Realizamos experimentos numéricos baseados em dois testes: no primeiro resolvemos a EDP do calor para os quatro casos obtidos e no segundo resolvemos as mesmas equações porém adicionamos o termo fonte de calor variável. Discutimos e comparamos os resultados obtidos. No quarto capítulo tratamos mais diretamente de uma aplicação da EDP do calor na indústria do petróleo, estudando um sistema de EDPs, que representa um escoamento bifásico de água e óleo, em termos da pressão do óleo e saturação da água com coeficientes de difusividade constantes. Inicialmente discretizamos as equações do sistema e o resolvemos numericamente pelo método das diferenças finitas e o método IMPES (Implicit Pressure Explicit Saturation), em Kou e Sun (8), onde tratamos as equações desacopladas, resolvendo implicitamente para a pressão do óleo e explicitamente para a saturação da água. Organizamos diferentes posicionamentos para a injeção de água e produção de óleo e realizamos experimentos numéricos de alguns casos conhecidos, cujos resultados mostraram a qualidade no nosso método.

No quinto capítulo apresentamos a conclusão do trabalho. 


\section{Equação do Calor com Termo Fonte em uma Placa Homo- gênea}

Nesse capítulo estudaremos a equação diferencial parcial do calor em duas dimensões, como ponto de partida para no Capítulo 4 estudarmos o escoamento bifásico de água e óleo. Vamos tomar o domínio representado por uma placa plana $\Omega=[0, L] \times[0, L] \subset \mathbb{R}^{2}$ no formato de um quadrado de lado $L \in \mathbb{R}, L>0$, feita de um único material com condutividade térmica constante $\sigma \in \mathbb{R}, \sigma>0$.

Denotaremos a temperatura no ponto $(x, y) \in \Omega$, no instante de tempo $t$, por $U((x, y), t)$, assim $U: \Omega \times[0, T] \longrightarrow \mathbb{R}^{2}$, onde $T \in \mathbb{R}, T>0$ representa o tempo final.

Nossa placa $\Omega$, através de sua fronteira $\partial \Omega$, troca calor com o meio externo. Essa condição escrita matematicamente se expressa como a condição de contorno do tipo Neumann $\partial_{n} U=0$, para $(x, y) \in \partial \Omega$.

Além disso $\Omega$ estará submetida a uma fonte de calor constante $q$ e uma fonte de calor variável $s$ que varia de acordo com a temperatura da placa, onde $q: \Omega \longrightarrow \mathbb{R}^{2}$ e $s: \Omega \longrightarrow \mathbb{R}^{2}$

Nessas condições, dado que a placa $\Omega$ possui uma temperatura inicial $U((x, y), 0)=f(x, y)$, está submetida a uma fonte de calor constante $q$, e a uma fonte de calor variável $s(U)$, a sua temperatura em um determinado instante de tempo $t$, é determinada pela equação do calor (2-1).

$$
\begin{cases}U_{t}=\sigma \Delta U+s(U)+q, & (x, y) \in \Omega, t \in[0, T] \\ U((x, y), 0)=f(x, y), & (x, y) \in \Omega \\ \partial_{n} U=0, & (x, y) \in \partial \Omega, t \in[0, T]\end{cases}
$$

Onde $\Delta U=U_{x x}+U_{y y}$ é o laplaciano de $U$. Em Evans (9) está demonstrado a existência e unicidade da solução da equação (2-1), porém como essa equação é não-linear e bidimensional, a visualização de sua solução não é algo simples de se obter, principalmente para domínios heterogêneos (assunto abordado no Capítulo 3), onde não há solução analítica. Por isso nossa motivação está em resolvê-la numericamente. Para tal, vamos usar o Método das Diferenças Finitas apresentado em Leveque (4). Dessa forma precisamos discretizar o espaço e tempo, e depois aproximar numericamente a derivada espacial e temporal na equação do calor em (2-1). 


\section{1}

\section{Aproximação Numerica}

Para o espaço, vamos discretizar o intervalo $[0, L]$, em ambos eixos $x$ e $y$, em $n+2$ pontos com espaçamento uniforme $h$ entre eles, onde:

$$
h=\frac{L}{n+1}
$$

A discretização pode ser visualizada na Figura 2.1.

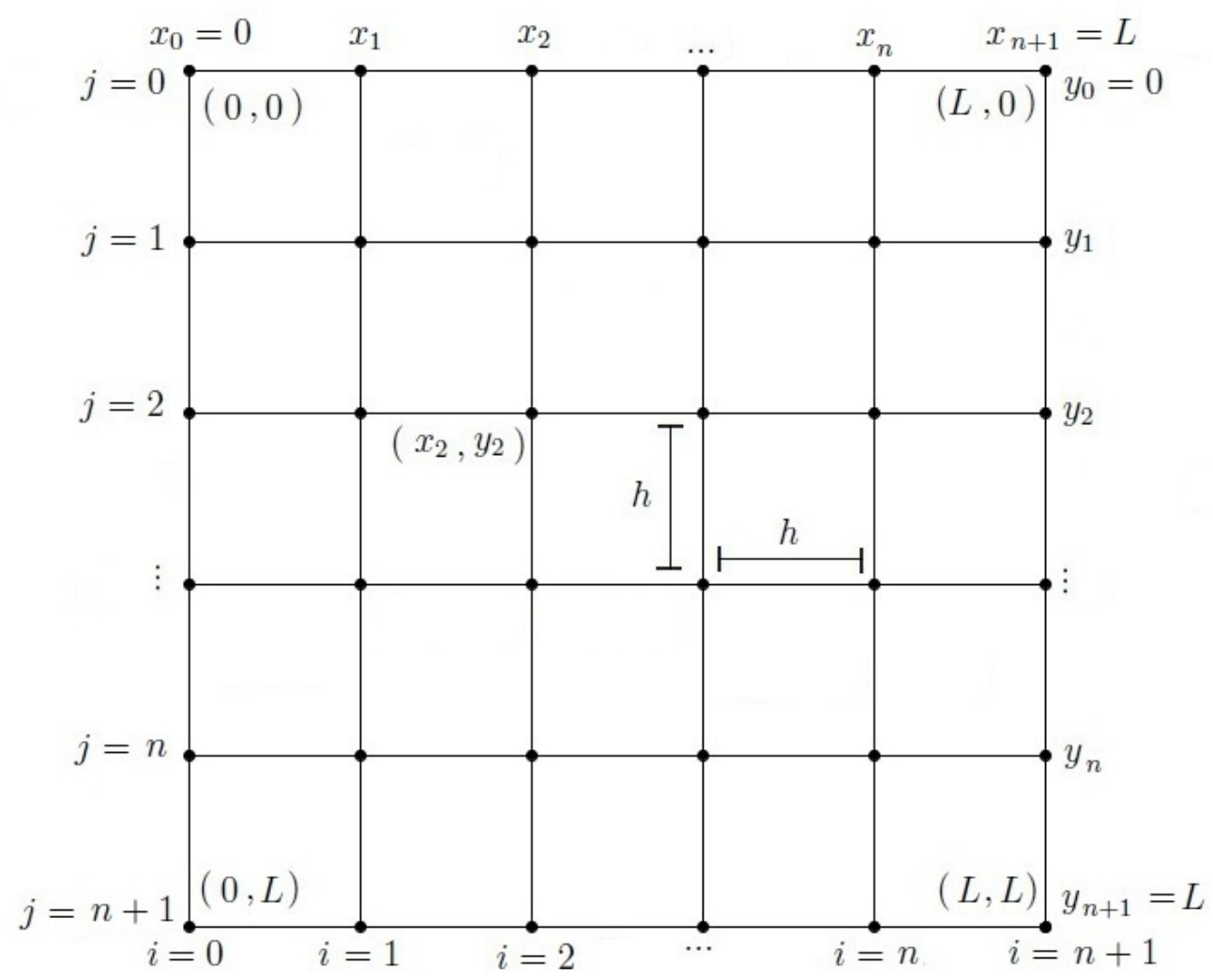

Figura 2.1: Discretização do domínio $\Omega$.

Desse modo, $x_{i}=i h$ e $y_{j}=j h$ para $0 \leq i, j \leq n+1$. No total teremos $(n+2)^{2}$ pontos $\left(x_{i}, y_{j}\right)$, e para ordená-los, percorremos os pontos da malha bidimensional na Figura 2.1 de cima para baixo, da esquerda para direita. A escolha de uma ordenação para os pontos do domínio é importante para a resolução de sistemas lineares, pois como existem diferentes ordenações possíveis, para cada uma haverá diferentes matrizes associadas, de acordo com Cuminato e Meneguette em (10).

Para o tempo, vamos discretizar o intervalo $[0, T]$ em $m+2$ pontos, com espaçamento uniforme $\Delta t$ entre eles, onde:

$$
\Delta t=\frac{T}{m+1} .
$$

A discretização pode ser visualizada na Figura 2.2. 


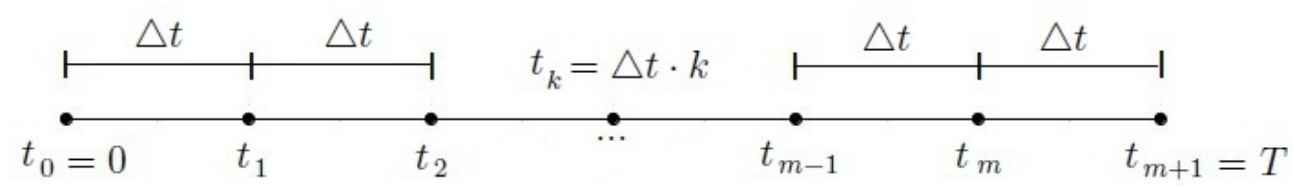

Figura 2.2: Discretização do intervalo $[0, T]$

Assim, $t_{k}=\Delta t k$ para $0 \leq k \leq m+1$. Dada essa discretização, adotaremos a notação $U_{i, j}^{k}$, que representa o valor aproximado da solução exata $U\left(\left(x_{i}, y_{j}\right), t_{k}\right)$. Logo $U_{i, j}^{k} \approx U\left(\left(x_{i}, y_{j}\right), t_{k}\right)$. O termo fonte variável $s(U)$ pode ser reescrito como $s\left(U_{i, j}^{k}\right)$, e o termo fonte constante como $q\left(x_{i}, y_{j}\right) \approx q_{i, j}$ e ambos atuam nos nós da malha bidimensional, ou seja, nos pontos $\left(x_{i}, y_{j}\right)$.

Dessa forma, podemos reescrever a condição inicial como:

$$
U_{i, j}^{0}=f\left(x_{i}, y_{j}\right), \quad 0 \leq i, j \leq n+1
$$

Como $\Omega$ tem a forma de um quadrado de lado $L$, temos que a condição de contorno do tipo Neumann na Equação (2-1) se expressa nos quatro lados desse quadrado, assumindo a forma:

$$
\begin{cases}\frac{\partial U}{\partial x}=0, & y=L \\ \frac{\partial U}{\partial x}=0, & y=0 \\ \frac{\partial U}{\partial y}=0, & x=L \\ \frac{\partial U}{\partial y}=0, & x=0\end{cases}
$$

$\mathrm{Na}$ Equação (2-5), vamos reescrever a primeira e terceira equações na forma discretizada e aproximá-las por Diferenças para Trás, obtendo:

$$
\begin{array}{ll}
\frac{\partial U_{i, n+1}^{k}}{\partial x} \simeq \frac{U_{i, n+1}^{k}-U_{i+1, n+1}^{k}}{h}=0, & 0 \leq i \leq n+1 \\
\frac{\partial U_{n+1, j}^{k}}{\partial y} \simeq \frac{U_{n+1, j}^{k}-U_{n+1, j+1}^{k}}{h}=0, & 0 \leq j \leq n+1
\end{array}
$$

E vamos reescrever a segunda e quarta equações em (2-5) na forma discretizada e aproximá-las agora por Diferenças para Frente:

$$
\begin{array}{ll}
\frac{\partial U_{i, 0}^{k}}{\partial x} \simeq \frac{U_{i+1,0}^{k}-U_{i, 0}^{k}}{h}=0, & 0 \leq i \leq n+1 \\
\frac{\partial U_{0, j}^{k}}{\partial y} \simeq \frac{U_{0, j+1}^{k}-U_{0, j}^{k}}{h}=0, & 0 \leq j \leq n+1
\end{array}
$$

Assim, das equações (2-6), (2-7), (2-8) e (2-9), as condições de Neumann em (2-5) podem ser reescritas como: 


$$
\begin{cases}U_{i, n+1}^{k}=U_{i+1, n+1}^{k}, & 0 \leq i \leq n+1 \\ U_{i, 0}^{k}=U_{i+1,0}^{k}, & 0 \leq i \leq n+1 \\ U_{n+1, j}^{k}=U_{n+1, j+1}^{k}, & 0 \leq j \leq n+1 \\ U_{0, j}^{k}=U_{0, j+1}^{k}, & 0 \leq j \leq n+1\end{cases}
$$

Onde $1 \leq k \leq m$. Vamos aproximar as derivadas de segunda ordem por Diferenças Centrais:

$$
\begin{aligned}
& U_{x x}\left(\left(x_{i}, y_{j}\right), t_{k}\right) \simeq \frac{U_{i-1, j}^{k}-2 U_{i, j}^{k}+U_{i+1, j}^{k}}{h^{2}} \\
& U_{y y}\left(\left(x_{i}, y_{j}\right), t_{k}\right) \simeq \frac{U_{i, j-1}^{k}-2 U_{i, j}^{k}+U_{i, j+1}^{k}}{h^{2}}
\end{aligned}
$$

Agora, somando (2-11) e (2-12) obtemos a aproximação:

$$
\sigma \Delta U \simeq \sigma \frac{U_{i-1, j}^{k}+U_{i, j-1}^{k}-4 U_{i, j}^{k}+U_{i+1, j}^{k}+U_{i, j+1}^{k}}{h^{2}}
$$

Usaremos o Método Implícito de Euler apresentado em Leveque (4), aproximando a primeira derivada no tempo em $U$, usando Diferenças para Trás:

$$
U_{t}\left(\left(x_{i}, y_{j}\right), t_{k}\right) \simeq \frac{U_{i, j}^{k}-U_{i, j}^{k-1}}{\Delta t}
$$

Substituindo (2-13) e (2-14) na equação do Calor (2-1), obtemos um conjunto de equações algébricas:

$$
\frac{U_{i, j}^{k}-U_{i, j}^{k-1}}{\Delta t}=\sigma \frac{U_{i-1, j}^{k}+U_{i, j-1}^{k}-4 U_{i, j}^{k}+U_{i+1, j}^{k}+U_{i, j+1}^{k}}{h^{2}}+s\left(U_{i, j}^{k}\right)+q_{i, j}
$$

Que pode ser reescrita como:

$U_{i, j}^{k-1}=-\alpha U_{i-1, j}^{k}-\alpha U_{i, j-1}^{k}+(1+4 \alpha) U_{i, j}^{k}-\alpha U_{i+1, j}^{k}-\alpha U_{i, j+1}^{k}-\Delta t s\left(U_{i, j}^{k}\right)-\Delta t q_{i, j}$, para $1 \leq i, j \leq n, 1 \leq k \leq m$ e $\alpha=\frac{\sigma \Delta t}{h^{2}}$.

Em (2-16), vamos substituir os valores para $i, j$ seguindo a ordenação de cima para baixo e da esquerda para direita, deixando $k$ fixo, assim temos $n^{2}$ equações, nessas $n^{2}$ equações vamos substituir as condições de contorno (2-10), obtendo um sistema não-linear que pode ser expresso como a equação:

$$
U^{k-1}=A U^{k}-\Delta t s\left(U^{k}\right)-\Delta t q, \quad k=1, \ldots, m,
$$

onde $U^{k}, q \in \mathbb{R}^{n^{2} \times 1}$ são as matrizes: 


$$
U^{k}=\left[\begin{array}{c}
U_{1,1}^{k} \\
U_{1,2}^{k} \\
\vdots \\
U_{1, n}^{k} \\
\vdots \\
U_{n, n}^{k}
\end{array}\right] \quad, \quad q=\left[\begin{array}{c}
q_{1,1} \\
q_{1,2} \\
\vdots \\
q_{1, n} \\
\vdots \\
q_{n, n}
\end{array}\right]
$$

e $A \in \mathbb{R}^{n^{2} \times n^{2}}$ é a matriz pentadiagonal:

$$
A=\left[\begin{array}{ccccc}
B & -\alpha I & 0 & \cdots & 0 \\
-\alpha I & C & -\alpha I & & \\
& \ddots & \ddots & \ddots & \\
& & -\alpha I & C & -\alpha I \\
0 & \cdots & 0 & -\alpha I & B
\end{array}\right]
$$

com $B, C, \in \mathbb{R}^{n \times n}$ sendo matrizes tridiagonais, onde $I$ é a matriz identidade, 0 é a matriz nula e $B, C$ são da forma:

$$
\begin{aligned}
& B=\left[\begin{array}{ccccc}
(1+2 \alpha) & -\alpha & 0 & \cdots & 0 \\
-\alpha & (1+3 \alpha) & -\alpha & & \\
& \ddots & \ddots & \ddots & \\
& & -\alpha & (1+3 \alpha) & -\alpha \\
0 & \ldots & 0 & -\alpha & (1+2 \alpha)
\end{array}\right] \\
& C=\left[\begin{array}{ccccc}
(1+3 \alpha) & -\alpha & 0 & \ldots & 0 \\
-\alpha & (1+4 \alpha) & -\alpha & & \\
& \ddots & \ddots & \ddots & -\alpha \\
0 & \ldots & 0 & -\alpha & (1+3 \alpha)
\end{array}\right]
\end{aligned}
$$

A primeira ideia que surge para resolver a equação (2-17) que é não-linear, é usar o Método de Newton.

\subsection{1}

\section{Método de Newton}

Vamos definir uma função $F: \mathbb{R}^{n^{2}} \rightarrow \mathbb{R}^{n^{2}}$

$$
F(x):=-U^{k-1}+A x-\Delta t s(x)-\Delta t q, k=1,2, \ldots, m,
$$

tal que $F\left(U^{k}\right)=0$ corresponde a solução procurada da equação $(2-17), U^{k-1}$ é conhecido, dado que $U^{0}$ é condição inicial. A matriz jacobiana da função $F$ é: 


$$
J(x)=A-\Delta t J(s(x))
$$

onde $J(s(x))$ representa a jacobiana de $s(x)$. Como trabalharemos com funções $s(x)$ onde cada componente é independente umas das outras, teremos que $J(s(x)): \mathbb{R}^{n^{2}} \rightarrow \mathbb{R}^{n^{2}}$ é uma matriz diagonal.

A linearização da função $F$ na vizinhança do ponto $x_{\lambda} \in \mathbb{R}^{n^{2}}$ é:

$$
F(x) \simeq F\left(x_{\lambda}\right)+J\left(x_{\lambda}\right)\left(x-x_{\lambda}\right)
$$

Seja o vetor $x_{\lambda+1} \in \mathbb{R}^{n^{2}}$, definido como o vetor que faz com que a linearização de $F$ seja nula, daí:

$$
F\left(x_{\lambda}\right)+J\left(x_{\lambda}\right)\left(x_{\lambda+1}-x_{\lambda}\right)=0
$$

Ou seja, sendo $\Delta x=x_{\lambda+1}-x_{\lambda}$, temos que $\Delta x$ é solução do sistema linear:

$$
J\left(x_{\lambda}\right) \Delta x=-F\left(x_{\lambda}\right)
$$

E dessa forma:

$$
x_{\lambda+1}=x_{\lambda}+\Delta x
$$

Portanto, partindo da equação (2-17) e da condição inicial $U^{0}$, determinamos $U^{1}$ através do Método de Newton e assim sucessivamente. A convergência e estabilidade do Método de Newton está demonstrada em Faires e Burden (5).

Abaixo está um pseudocódigo para o Método de Newton.

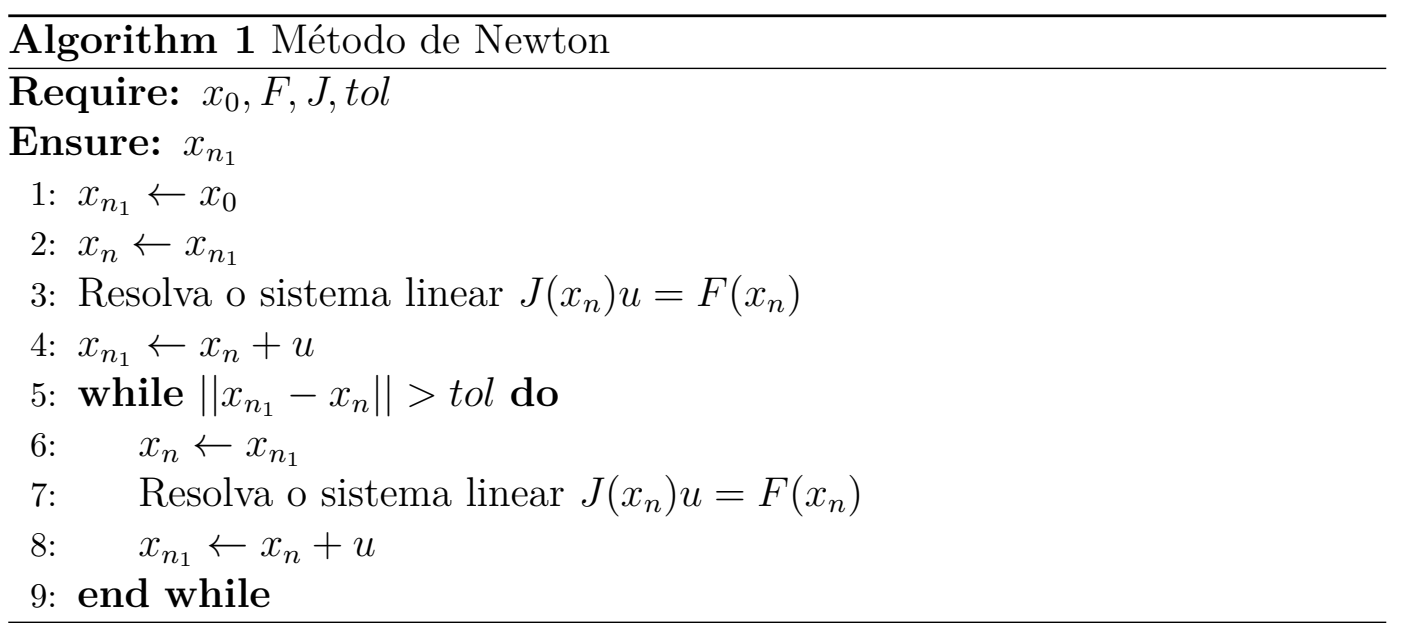

O Método de Newton é usado para sistemas não lineares, e em cada iteração ele resolve um sistema linear. Assim é natural buscarmos um modo eficiente de resolver esses sistemas lineares que surgem, como por exemplo, o Método do Subespaço de Krylov. 
Capítulo 2. Equação do Calor com Termo Fonte em uma Placa Homogênea 21

\subsection{2}

\section{Método do Subespaço de Krylov}

Sendo $M \in \mathbb{R}^{n \times n}$ e $b \in \mathbb{R}^{n \times 1}$, o Método do Subespaço de Krylov objetiva resolver o sistema linear:

$$
M x=b
$$

de modo a obter uma solução aproximada $\tilde{x}$ tal que:

$$
M \tilde{x} \approx b
$$

Para isso, primeiramente define-se o resíduo inicial:

$$
r_{0}=b-M x_{0}
$$

Onde $x_{0}$ é uma estimativa inicial para a solução do sistema linear (2-24). Dai obtém-se o subespaço de Krylov $\mathcal{K}_{\rho}$ dado por:

$$
\mathcal{K}_{\rho}\left(M, r_{0}\right)=\operatorname{span}\left(r_{0}, M r_{0}, M^{2} r_{0}, \ldots, M^{\rho-1} r_{0}\right)
$$

para $\rho \leq n$. Depois busca-se uma base para esse subespaço, uma escolha natural seria:

$$
\varphi=\left\{r_{0}, M r_{0}, M^{2} r_{0}, \ldots, M^{\rho-1} r_{0}\right\}
$$

Dessa forma, qualquer vetor $z \in \mathcal{K}_{\rho}\left(M, r_{0}\right)$ pode ser escrito como combinação linear dos elementos do espaço $\mathcal{K}_{\rho}\left(M, r_{0}\right)$ :

$$
z=\left(\xi_{\rho-1} M^{\rho-1}+\ldots+\xi_{2} M^{2}+\xi_{1} M+\xi_{0} I\right) r_{0},
$$

para $\xi_{i} \in \mathbb{R}, i=0,1, \ldots,(\rho-1)$.

Se $M$ for invertível, temos das equações (2-26) e (2-25) que:

$$
\tilde{x} \approx x_{0}+M^{-1} r_{0}
$$

Aplicando-se para a matriz $M$ o teorema de Kayley-Hamilton apresentado em Hoffman e Kunze (11), podemos obter uma expressão da sua matriz inversa $M^{-1}$, e assim:

$$
M^{-1} r_{0}=\left(\varsigma_{n-1} M^{n-1}+\ldots+\varsigma_{2} M^{2}+\varsigma_{1} M+\varsigma_{0} I\right) r_{0}
$$

onde os coeficientes $\varsigma_{i} \in \mathbb{R}$, para $i=0,1, \ldots,(n-1)$ podem ser obtidos pela equação característica de $M$. Assim, de (2-31) e (2-29) vem que:

$$
M^{-1} r_{0} \in \mathcal{K}_{\rho}\left(M, r_{0}\right)
$$

Portanto, de (2-30) e (2-32) concluímos que:

$$
\tilde{x} \in x_{0}+\mathcal{K}_{\rho}\left(M, r_{0}\right)
$$


Isso significa que devemos procurar a solução aproximada $\tilde{x}$ do sistema (2-24) no subespaço afim $x_{0}+\mathcal{K}_{\rho}\left(M, r_{0}\right)$. Para fazer isso vamos impor a condição de Galerkin:

$$
b-M x_{\rho} \perp L_{\rho}
$$

Onde $L_{\rho}$ é o espaço das restrições de dimensão $\rho$. Existem vários métodos do subespaço de Krylov que surgem através das diferentes escolhas de $L_{\rho}$. Quando escolhemos $L_{\rho}=\mathcal{K}_{\rho}\left(M, r_{0}\right)$ temos Método dos Resíduos Mínimos Generalizados (GMRES - Generalized Minimum Residual) apresentado por Saad e Schultz em (12).

Antes de iniciarmos a busca pela solução aproximada $\tilde{x}$, precisamos construir uma base adequada para o subespaço de $\operatorname{Krylov} \mathcal{K}_{\rho}\left(M, r_{0}\right)$, pois a escolha natural que indicamos em (2-28) não é boa, dado que essa sequência de vetores converge para o autovetor associado ao maior autovalor, em módulo, da matriz $M$ e assim tende a se tornar linearmente dependente quando o número de iterações é alto, LeVeque (4), porém isso não ocorre se a base for ortonormal, então uma boa ideia é ortonormalizar a base (2-28) e depois usá-la como base do subespaço de Krylov. Para isso usaremos o Método de Ortonormalização de Arnoldi, apresentado por Arnoldi em (13), que a partir de um vetor unitário:

$$
w_{1}=\frac{r_{0}}{\left\|r_{0}\right\|}
$$

Gera vetores $w_{\rho}$ através da ortonormalização de $M w_{\rho-1}$ com relação aos vetores gerados anteriormente. Abaixo temos um pseudocódigo para o Método de Ortonormalização de Arnoldi:

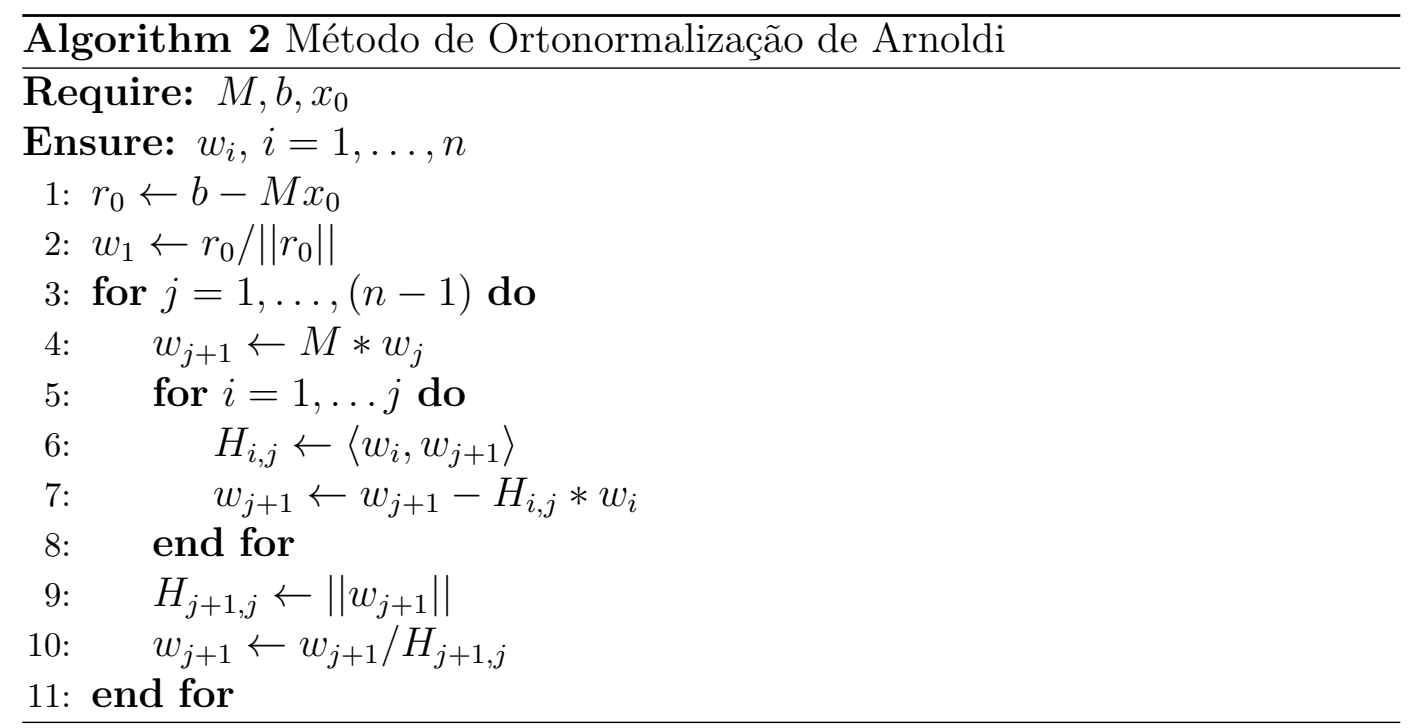

Onde a matriz $H_{\rho} \in \mathbb{R}^{\rho \times \rho}$, cujas entradas $H_{i, j}$ foram produzidas no algoritmo (2), é a matriz de Hessemberg superior $\left(H_{i, j}=0\right.$ para $\left.i>j+1\right)$, onde $\rho$ é o número de iterações feitas durante o algoritmo (2). E tomemos 
a matriz $W_{\rho} \in \mathbb{R}^{\rho \times \rho}$, como sendo $W_{\rho}=\left[\begin{array}{llll}w_{1} & w_{2} & \ldots & w_{\rho}\end{array}\right]$, cujas colunas são formadas pela base ortonormal que construímos. Repare que o algoritmo (2) atualiza o vetor $w_{j+1}$ no passo 10 da seguinte forma:

$$
H_{j+1, j} w_{j+1}=w_{j+1}
$$

Substituindo o passo 7 do algoritmo (2) no lado direito da equação (2-36) obtemos:

$$
H_{j+1, j} w_{j+1}=w_{j+1}-H_{i, j} w_{i}
$$

Ao substituirmos o passo 4 do algoritmo (2), no lado direito da equação (2-37) temos que:

$$
H_{j+1, j} w_{j+1}=M w_{j}-H_{i, j} w_{i}
$$

Após $\rho$ iterações a equação (2-38) terá a forma:

$$
H_{\rho+1, \rho} w_{\rho+1}=M w_{\rho}-H_{1, \rho} w_{1}-H_{2, \rho} w_{2}-\ldots-H_{\rho, \rho} w_{\rho}
$$

Que pode ser reescrita como:

$$
M w_{\rho}=H_{1, \rho} w_{1}+H_{2, \rho} w_{2}+\ldots+H_{\rho, \rho} w_{\rho}+H_{\rho+1, \rho} w_{\rho+1}
$$

Assim:

$$
M w_{\rho}=W_{\rho+1} \tilde{h}_{\rho}
$$

Onde $\tilde{h}_{\rho}$ representa a $\rho$-ésima coluna da matriz $H_{\rho}$ e $W_{\rho+1}$ é a matriz cujas colunas são a base ortonormal para o subespaço de $\operatorname{Krylov} \mathcal{K}_{\rho}\left(M, r_{0}\right)$. Generalizando a equação (2-41) para todos os vetores de $W_{\rho}$, surgem as matrizes $W_{\rho}$ e $H_{\rho}$ do lado esquerdo e direito, respectivamente. Assim obtemos a relação:

$$
M W_{\rho}=W_{\rho+1} H_{\rho}
$$

Agora, suponha que $x_{\rho}$ seja uma solução aproximada do sistema linear (2-24), então pela equação (2-33) podemos escrever que:

$$
x_{\rho}=x_{0}+c_{\rho}
$$

Onde $c_{\rho} \in \mathcal{K}_{\rho}\left(M, r_{0}\right)$, mas como por construção os vetores coluna de $W_{\rho}$ são uma base para $\mathcal{K}_{\rho}\left(M, r_{0}\right)$, temos:

$$
c_{\rho}=p_{1} w_{1}+\ldots p_{\rho} w_{\rho}
$$

Para $p_{i}, i=1, \ldots \rho$ escalares. Note que podemos reescrever $(2-44)$ da seguinte maneira:

$$
c_{\rho}=W_{\rho} p_{\rho}
$$

De modo que $p_{\rho}$ é um vetor coluna cujas entradas são $p_{i}, i=1, \ldots \rho$. Assim pela equação (2-43) e (2-45), temos:

$$
x_{\rho}=x_{0}+W_{\rho} p_{\rho}
$$


A Equação (2-46) é usada para encontrar a solução aproximada. O que resta então é saber como encontrar o vetor $p_{\rho}$. Para isso suponhamos sem perda de generalidade que nosso ponto inicial $x_{0}$ seja o vetor nulo, dai as equações (2-26) e (2-46) ficam respectivamente:

$$
\begin{aligned}
& r_{0}=b \\
& x_{\rho}=W_{\rho} p_{\rho}
\end{aligned}
$$

E repare que pelo fato do vetor $w_{1}$ ser a primeira coluna da matriz $W_{\rho+1}$, a Equação (2-35) pode ser reescrita como:

$$
r_{0}=\left\|r_{0}\right\| w_{1}=W_{\rho+1}\left(\left\|r_{0}\right\| e_{1}\right)
$$

Onde $e_{1}$ é o primeiro vetor da base canônica. Para o Método dos Resíduos Mínimos Generalizados, é preciso que em cada iteração $\rho$ o resíduo seja mínimo, dai vem o nome do método, ou seja:

$$
\left\|r_{\rho}\right\|=\min _{x_{\rho} \in \mathcal{K}_{\rho}\left(M, r_{0}\right)}\left\|b-M x_{\rho}\right\|
$$

Vamos substituir as equações (2-47) em (2-49):

$$
\left\|r_{\rho}\right\|=\min _{p_{\rho} \in \mathbb{R}^{\rho}}\left\|r_{0}-M W_{\rho} p_{\rho}\right\|
$$

Agora, substituindo (2-48) e (2-42) em (2-50), obtemos:

$$
\left\|r_{\rho}\right\|=\min _{p_{\rho} \in \mathbb{R}^{\rho}}\left\|W_{\rho+1}\left(\left\|r_{0}\right\| e_{1}\right)-W_{\rho+1} H_{\rho} p_{\rho}\right\|
$$

Para que $\left\|r_{\rho}\right\|$ seja mínimo, devemos ter que o lado direito ta equação (2-51) seja próximo de zero, ou seja:

$$
W_{\rho+1} H_{\rho} p_{\rho} \approx W_{\rho+1}\left(\left\|r_{0}\right\| e_{1}\right)
$$

Note que $W_{\rho+1}$ é uma matriz ortogonal por construção, dai $W_{\rho+1}^{-1}=W_{\rho+1}^{T}$, então multiplicando ambos lados da equação (2-52) por $W_{\rho+1}^{T}$ a esquerda, temos que:

$$
H_{\rho} p_{\rho} \approx\left\|r_{0}\right\| e_{1}
$$

Note que (2-53) é um sistema linear simples de ser resolvido porque $H_{\rho}$ é a matriz de Hessenberg superior, Golub e Loan em (14). Ao resolver esse sistema obtemos então o vetor $p_{\rho}$ como queríamos, e para encontrar a solução aproximada do sitema linear (2-24) basta substituir o valor de $p_{\rho}$ na equação $(2-46)$.

Portanto, para obtermos um pseudocódigo do Método dos Resíduos Mínimos Generalizados, basta que acrescentemos antes do fim no algoritmo (2), depois do passo 10, os comandos: 


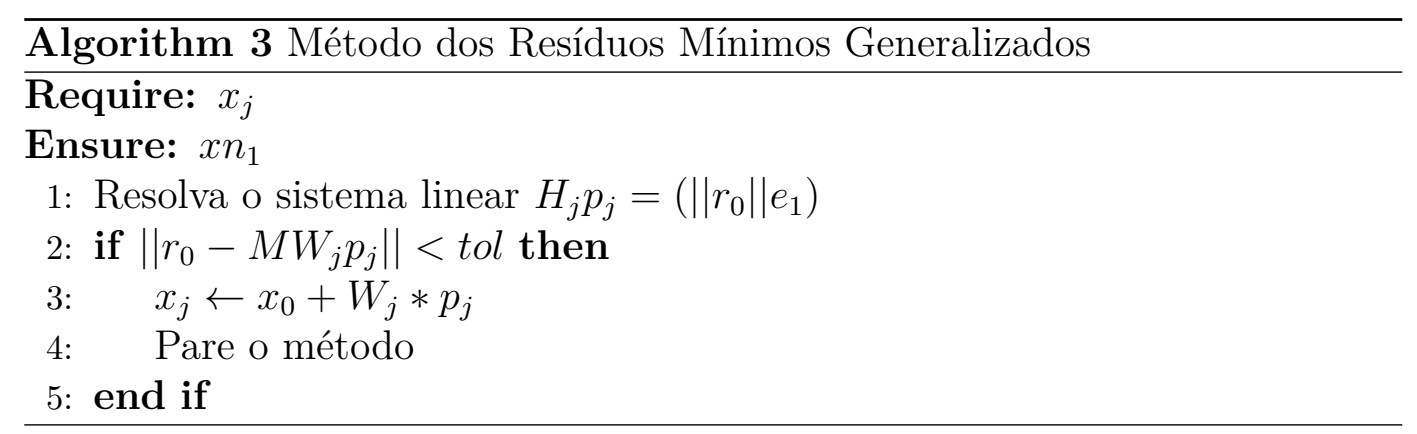

Onde $W_{j}=\left[\begin{array}{lll}w_{1} & \ldots & w_{j}\end{array}\right]$. Ou seja, calculamos o vetor que minimiza o resíduo, depois se o resíduo for menor do que uma tolerância escolhida, encontramos a solução aproximada e paramos o método. A convergência e estabilidade do Método GMRES está feita em Liesen e Strakos (6).

Esse modo de resolver sistemas lineares é bem eficiente, e assim é natural a ideia de um código que envolva o Método de Newton e o GMRES: onde o GMRES é usado para resolver os sistemas lineares nas iterações do Método de Newton, porém ainda precisaríamos calcular toda a matriz jacobiana $J$, o que pode ser bem caro computacionalmente dependendo da expressão da função $F$. Objetivando contornar esse problema surgiu o Método Newton-Krylov Sem Jacobiano (JFNK - Jacobian-Free Newton-Krylov), Knoll e Keyes (7).

\subsection{3}

\section{Método Newton-Krylov Sem Jacobiano}

No Método Newton-Krylov Sem Jacobiano, não é preciso calcular toda a matriz jacobiana, o que torna o muito eficiente computacionalmente. Vamos tomar a Equação (2-22), e nela aplicar o método GMRES, desse modo sendo $\Delta x_{0}$ um chute inicial teremos o resíduo inicial como:

$$
r_{0}=-F(x)-J(x) \Delta x_{0}
$$

Onde $F$ representa o sistema não-linear. Assim, o subespaço de Krylov nesse caso é:

$$
\mathcal{K}_{\rho}\left(J, r_{0}\right)=\operatorname{span}\left(r_{0}, J r_{0}, J^{2} r_{0}, \ldots, J^{\rho-1} r_{0}\right)
$$

Vimos que o objetivo do método GMRES é, em cada iteração $\rho$, minimizar o resíduo $\left\|J(x) \Delta x_{\rho}+F(x)\right\|$, e temos pela Equação (2-33), que $\Delta x_{\rho}$ pode ser escrito da seguinte maneira:

$$
\Delta x_{\rho}=\Delta x_{0}+\sum_{i=0}^{\rho-1} d_{i}\left(J^{i}\right) r_{0}
$$

Onde $d_{i}, i=0,1, \ldots,(\rho-1)$ são os escalares que minimizam o resíduo. Repare no lado direito da Equação (2-56), que não é necessária toda a matriz jacobiana, apenas precisamos do produto da matriz jacobiana por um vetor. 
Assim podemos obter uma aproximação para esse produto através de uma expansão de Taylor de primeira ordem, Knoll e Keyes (7), obtendo assim:

$$
J v \approx \frac{F(x-v \epsilon)-F(x)}{\epsilon}
$$

Onde $\epsilon$ é uma pequena perturbação. A Equação (2-57) representa a derivada direcional da função $F$ no ponto $x$ na direção do vetor $v$, essa é a ideia central do método JFNK. A demonstração da convergência do método pode ser encontrada em Brown e Saad (15).

A ideia para um pseudocódigo do método JFNK então é usar o método GMRES junto com o método de Newton e a aproximação da jacobiana como na equação (2-57), o nosso chute inicial $\Delta x_{0}$ será o chute inicial para o Método de Newton. Abaixo está um pseudocódigo para o Método Newton-Krylov Sem Jacobiano.

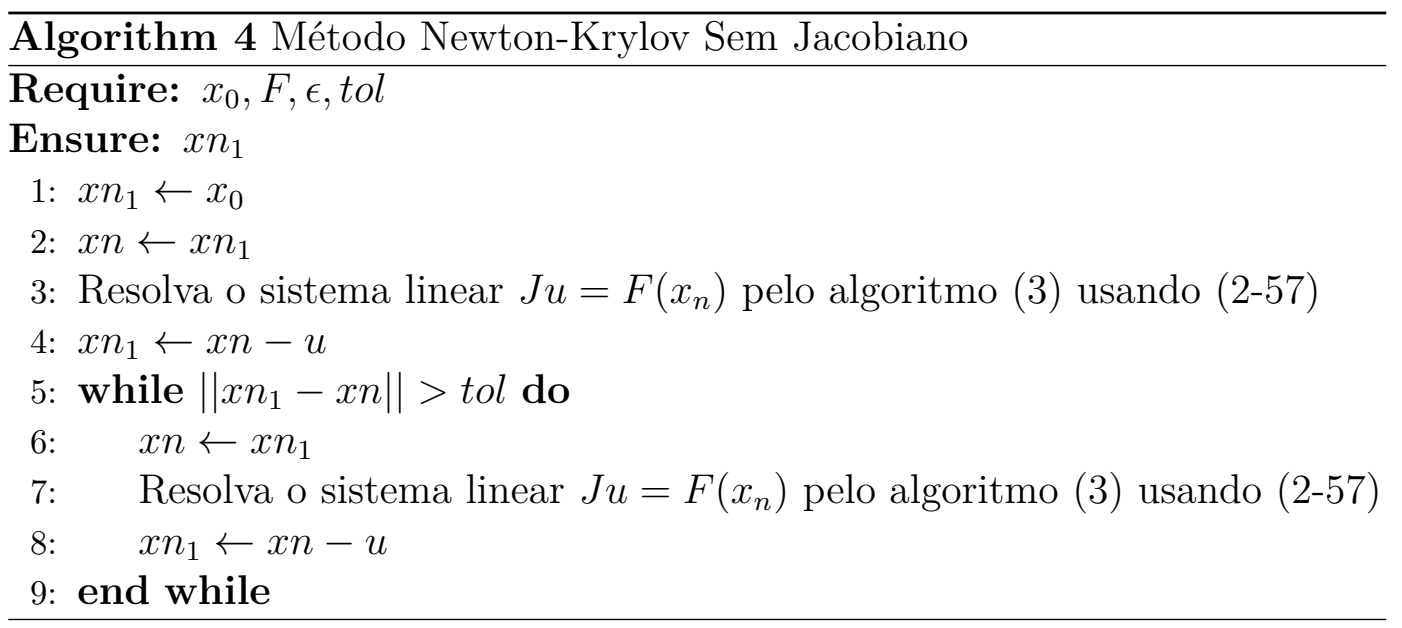

Usaremos o Método Newton-Krylov Sem Jacobiano para resolver as EDP do calor não linear, por causa de sua eficiência, e porque com ele conseguimos aumentar o número de pontos na discretização do domínio, aumentando assim a dimensão do problema e não perdendo a eficiência computacional, dado que precisamos de uma malha muito fina para melhor obtermos informações.

\section{2}

\section{Experimentos Numéricos}

Faremos dois tipos de testes: No Teste 1 resolveremos as equações somente com o termo fonte constante, ou seja $s(U)=0$; e com o Teste 2 abordaremos as equações que possuem o termo fonte constante e variável.

Em cada teste estudamos as equações com diferentes tipos de termos fonte constante, junto com suas respectivas curvas de nível. A cor azul e amarela indicam baixa e alta temperatura, respectivamente. Quanto mais 
forte ou mais fraca é a tonalidade da cor, mais intensa ou mais amena é a temperatura que ela representa.

Usamos cinco casos para o termo fonte constante, são eles:

Caso 1:

$$
q(x, y)= \begin{cases}5, & (x, y)=(0.5,0.5) \\ 0, & \text { c.c. }\end{cases}
$$

Caso 2:

$$
q(x, y)= \begin{cases}-5, & (x, y)=(0.1,0.1) \\ 5, & (x, y)=(0.9,0.9) \\ 0, & \text { c.c. }\end{cases}
$$

Caso 3:

$$
q(x, y)= \begin{cases}-10, & (x, y)=(0.1,0.1) \\ 5, & (x, y)=(0.9,0.9) \\ 0, & \text { c.c. }\end{cases}
$$

Caso 4:

$$
q(x, y)= \begin{cases}-1, & (x, y)=(0.1,0.1) \\ -1, & (x, y)=(0.1,0.9) \\ 4, & (x, y)=(0.5,0.5) \\ -1, & (x, y)=(0.9,0.1) \\ -1, & (x, y)=(0.9,0.9) \\ 0, & \text { c.c. }\end{cases}
$$

Caso 5:

$$
q(x, y)= \begin{cases}2, & (x, y)=(0.1,0.1) \\ 1, & (x, y)=(0.1,0.9) \\ -10, & (x, y)=(0.5,0.5) \\ 3, & (x, y)=(0.9,0.1) \\ 4, & (x, y)=(0.9,0.9) \\ 0, & \text { c.c. }\end{cases}
$$

Para calcular a variação entre as soluções de cada caso analisado nos testes, procedemos como na Equação $A .18$ do apêndice em Leveque (4). Onde primeiro, em cada iteração definimos:

$$
\mathcal{E}(k)=U^{k+1}-U^{k}
$$

Depois, para cada iteração calculamos o quanto uma solução difere da outra:

$$
\|\mathcal{E}(k)\|=\left(h \sum_{i=1}^{n^{2}}\left\|U^{k+1}-U^{k}\right\|^{2}\right)^{1 / 2}
$$

Para avaliarmos se a solução chega ou não ao equilíbrio usamos o critério de parada, na obtenção das soluções, para quando: $\|\mathcal{E}(k)\|<10^{-6}$ ou o número de interações for maior do que $10^{4}$. Se ocorre o primeiro caso temos que a 
solução chega ao equilíbrio, e se ocorrer o segundo caso temos que a solução não chega ao equilíbrio.

Quando a solução não chega ao equilíbrio, fixamos o tempo final para $T=5$. Caso contrário, usamos como tempo final o tempo em que ela chega ao equilíbrio, ou seja quando $\|\mathcal{E}(k)\|<10^{-6}$.

Para cada caso fizemos um gráfico semi-log da variação pelo tempo, $\|\mathcal{E}(k)\| \times t$. Quando a solução chega ao equilíbrio a variação decresce até $10^{-6}$, como esperado pelo critério de parada, isso significa que a solução para de se desenvolver com o passar do tempo. E quando a solução não chega ao equilíbrio, a variação fica constante a partir de determinado momento, ou seja a solução não para de se desenvolver com o passar do tempo.

Esse padrão foi usado para todos os experimentos numéricos no Capítulo 2 e 3 .

\subsection{1}

\section{Teste 1: Equação do Calor linear com termo fonte constante}

Nesse caso, fazendo $s(U)=0$ em (2-1), teremos a equação:

$$
\begin{cases}U_{t}=\sigma \Delta U+q, & (x, y) \in \Omega, t \in[0, T] \\ U((x, y), 0)=f(x, y), & (x, y) \in \Omega \\ \partial_{n} U=0, & (x, y) \in \partial \Omega\end{cases}
$$

Repare que agora temos uma equação linear. Pela equação (2-16) segue:

$$
U_{i, j}^{k-1}=-\alpha U_{i-1, j}^{k}-\alpha U_{i, j-1}^{k}+(1+4 \alpha) U_{i, j}^{k}-\alpha U_{i+1, j}^{k}-\alpha U_{i, j+1}^{k}-\Delta t q_{i, j}
$$

Para $1 \leq i, j \leq n, 1 \leq k \leq m$ e $\alpha=\frac{\sigma \Delta t}{h^{2}}$

Que produz o sistema linear, que escreveremos da seguinte maneira:

$$
A U^{k}=U^{k-1}+\Delta t q, \quad 1 \leq k \leq m
$$

Como nesse caso a equação é linear, então não precisaremos do Método de Newton.

Para a resolução da Equação (2-65), tomaremos como condição inicial $U^{0}$ a função $f(x, y)=0$.

Vamos agora estudar cinco casos abordando diferentes funções $q$, que representa o termo fonte de calor constante, e que ao mesmo tempo pode representar também um poço de produção de petróleo (se a fonte for positiva) ou uma injeção de água (se a fonte for negativa) no reservatório de petróleo que no caso seria toda a placa $\Omega$.

Em todos os casos abaixo usamos os dados: $L=1, f(x, y)=0, \sigma=$ $0.1, \Delta x=0.01, \Delta t=0.025$ e a dimensão do problema é $n^{2}=99^{2}=9801$. 
Capítulo 2. Equação do Calor com Termo Fonte em uma Placa Homogênea 29

O tempo final para cada caso foi analisado separadamente.

Caso 1: Usamos a fonte de calor constante como em (2-58). A Figura 2.3 apresenta a evolução da solução obtida em quatro diferentes tempos, através de um gráfico de temperatura por posição. A Figura 2.4 ilustra as correspondentes curvas de nível e a Figura 2.5 o gráfico $\|\mathcal{E}(k)\| \times t$ em escala logarítmica.
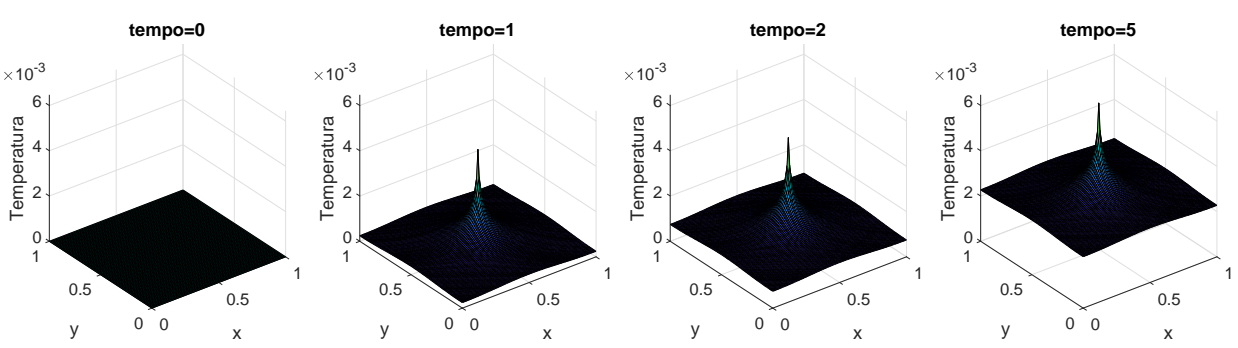

Figura 2.3: Teste 1 (Caso 1)
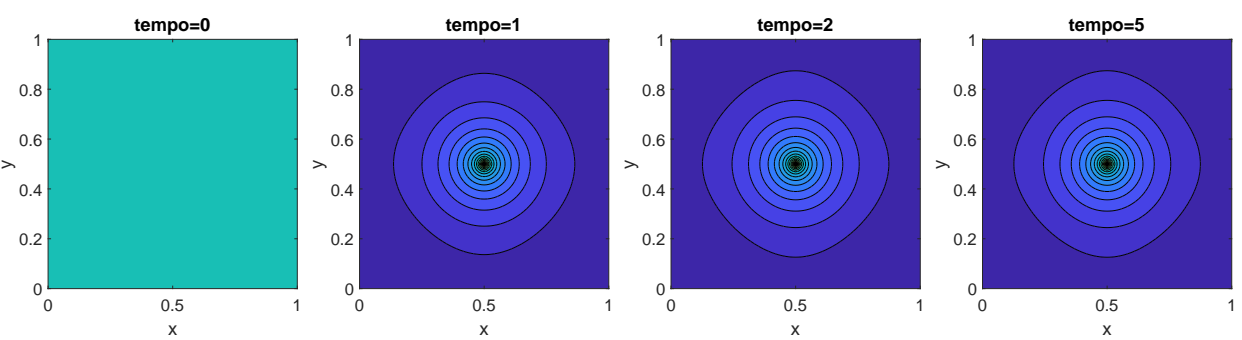

Figura 2.4: Curvas de nível do Teste 1 (Caso 1)

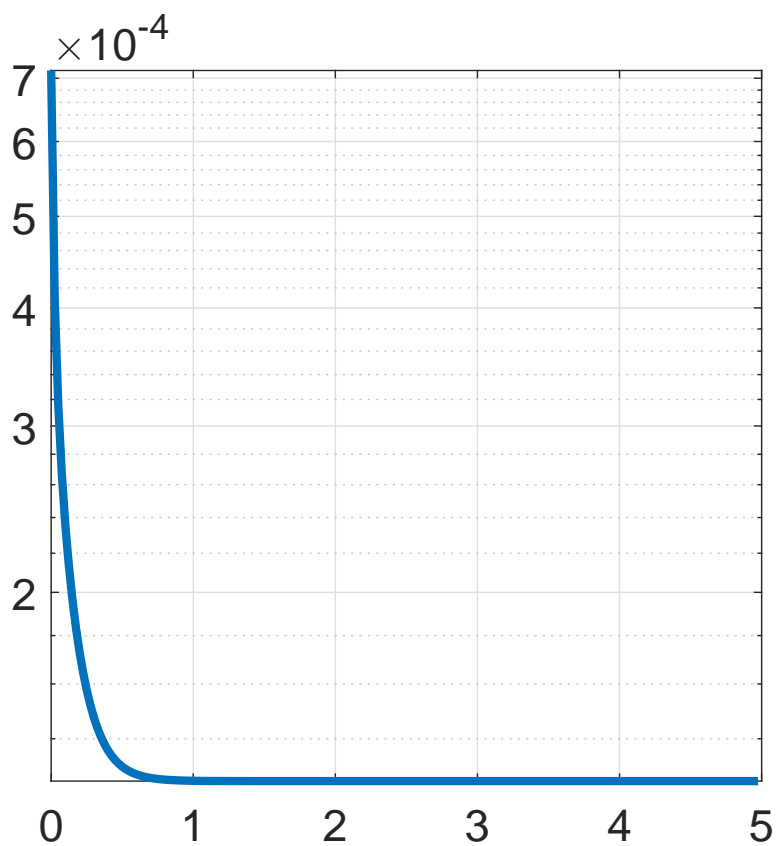

Figura 2.5: Variação $\|\mathcal{E}(k)\|$ do Teste 1 (Caso 1) 
Repare que a condição inicial está sendo satisfeita, e a solução está de acordo com a física do problema, pois como há uma fonte de calor no centro da placa esquentando-a, isso faz com que toda a placa vá aumentando de temperatura, ficando porém com o centro sempre mais quente, como pode ser notado na Figura (2.3), até atingir seu valor máximo de 0.0065 . O valor mínimo da temperatura alcançada pela placa foi 0, como esperado. Como a soma das fontes do termo fonte de calor $q$ não é nula, a solução nesse caso não chega ao equilíbrio, como pode ser percebido na Figura 2.5, pois a variação $\|\mathcal{E}(k)\|$ fica constante.

Caso 2: Usamos a fonte de calor constante como em (2-59). A Figura 2.6 apresenta a evolução da solução obtida em quatro diferentes tempos, através de um gráfico de temperatura por posição. A Figura 2.7 ilustra as correspondentes curvas de nível e a Figura 2.8 o gráfico $\|\mathcal{E}(k)\| \times t$ em escala logarítmica.
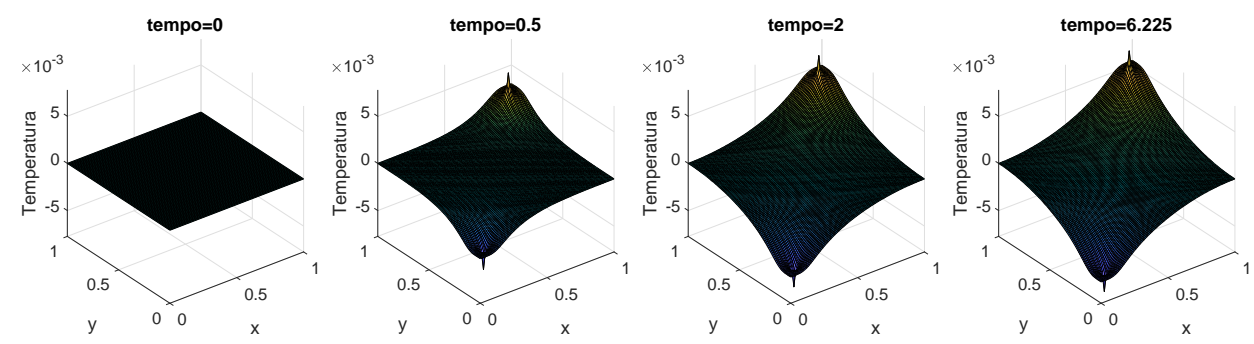

Figura 2.6: Teste 1 (Caso 2)
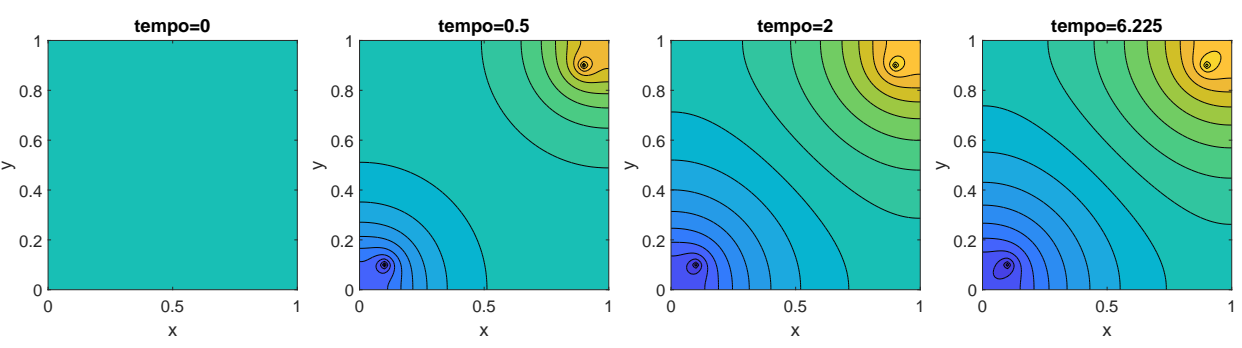

Figura 2.7: Curvas de nível do Teste 1 (Caso 2) 


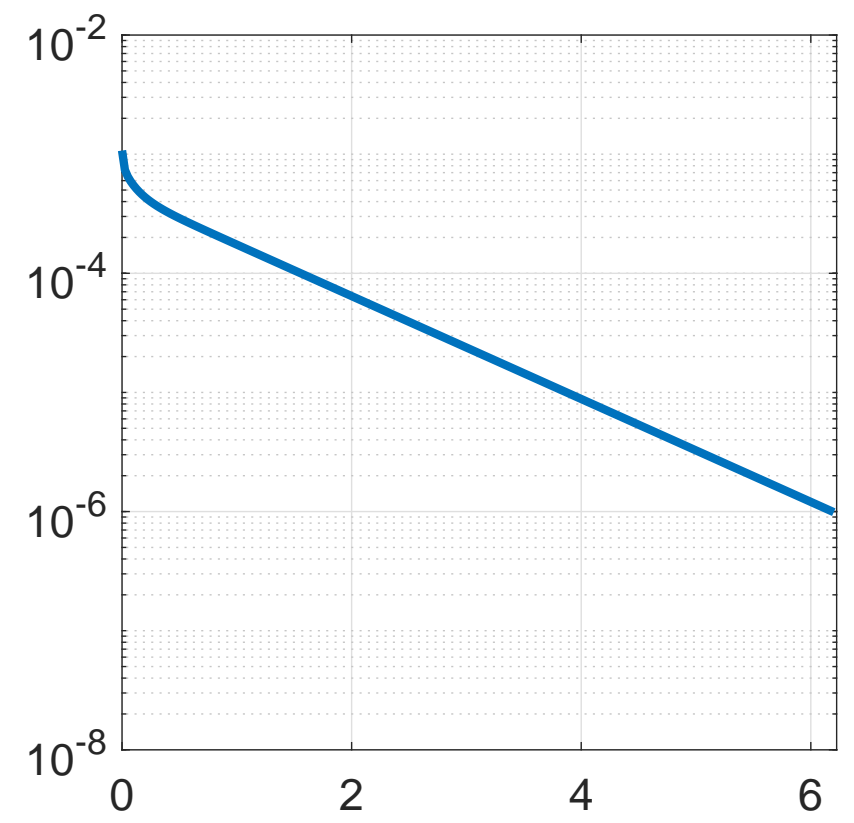

Figura 2.8: Variação $\|\mathcal{E}(k)\|$ do Teste 1 (Caso 2)

Nesse caso temos em dois extremos simétricos, fontes de calor também simétricas. E isso faz com que nas proximidades de cada um desses extremos, predomine respectivamente a temperatura fria próxima de $(0.1,0.1)$ e quente próxima de $(0.9,0.9)$. Com o passar do tempo, essas temperaturas tendem a se propagar para toda a placa, como pode ser visto na Figura 2.7. A temperatura máxima atingida pela placa foi 0.0077 e a mínima -0.0077, ambas iguais em módulo, o que era esperado, dada a simetria da placa e das fontes de calor. Note que nesse caso, como a soma das fontes do termos fonte de calor $q$ é nula, então a solução chega ao equilíbrio, como podemos ver na Figura 2.8, pois agora a variação $\|\mathcal{E}(k)\|$ é decrescente, e repare que a tolerância de $10^{-6}$ que impusemos é respeitada.

Caso 3: Usamos a fonte de calor constante como em (2-60). A Figura 2.9 apresenta a evolução da solução obtida em quatro diferentes tempos, através de um gráfico de temperatura por posição. A Figura 2.10 ilustra as correspondentes curvas de nível e a Figura 2.11 o gráfico $\|\mathcal{E}(k)\| \times t$ em escala logarítmica. 

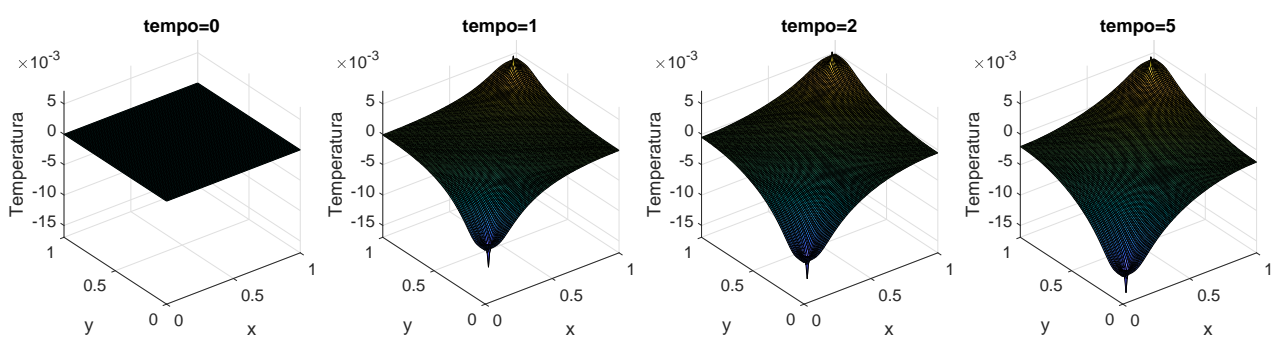

Figura 2.9: Teste 1 (Caso 3)
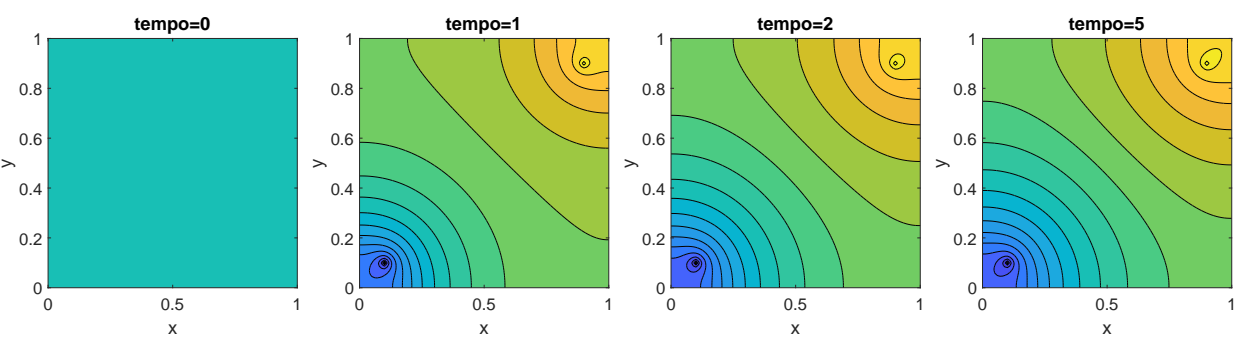

Figura 2.10: Curvas de nível do Teste 1 (Caso 3)

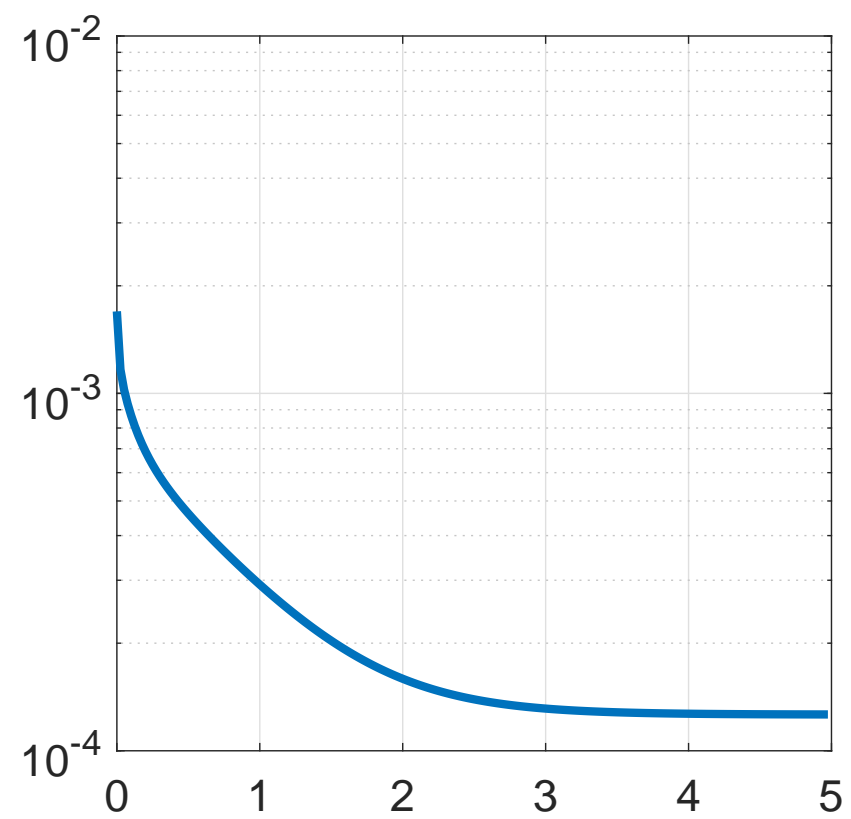

Figura 2.11: Variação $\|\mathcal{E}(k)\|$ do Teste 1 (Caso 3)

Agora temos um caso parecido com o anterior, mas com fontes de calor de módulos diferentes. Incialmente o processo é muito semelhante, ficando mais frio perto da temperatura negativa e mais quente perto da positiva, e ambas temperaturas se propagando pela placa, mas com o passar do tempo a temperatura da placa atige seu máximo em determinado tempo mas depois começa a diminuir. Rerepare na Figura 2.9 que a temperatura em $T=5$ é menor do que em $T=2$. Isso ocorre porque a fonte de calor negativa é maior, 
Capítulo 2. Equação do Calor com Termo Fonte em uma Placa Homogênea 33

em módulo, do que a positiva, se propagando pela placa por mais tempo e com mais intensidade. Veja também a diferença das curvas de nível em $T=5$ na Figura 2.10: há mais curvas de nível na região da temperatura fria do que na quente. E em relação ao caso anterior, na Figura 2.7, também em $T=5$, há mais curvas de nível na região da temperatura quente do que nesse caso. A temperatura mínima atingida foi -0.0169 , menor que a do caso anterior, como esperado. A temperatura máxima atingida foi 0.0071, também menor que a do caso anterior. E como a soma das fontes do termo fonte de calor $q$ não é nula, a solução não chega ao equilíbrio, como mostra a Figura 2.11 onde a variação fica constante.

Caso 4: Usamos a fonte de calor constante como em (2-61). A Figura 2.12 apresenta a evolução da solução obtida em quatro diferentes tempos, através de um gráfico de temperatura por posição. A Figura 2.13 ilustra as correspondentes curvas de nível e a Figura 2.14 o gráfico $\|\mathcal{E}(k)\| \times t$ em escala logarítmica.
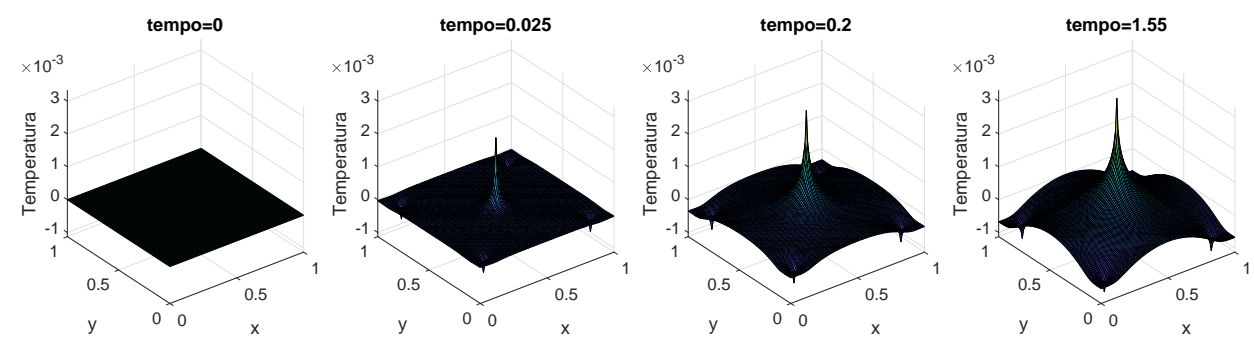

Figura 2.12: Teste 1 (Caso 4)
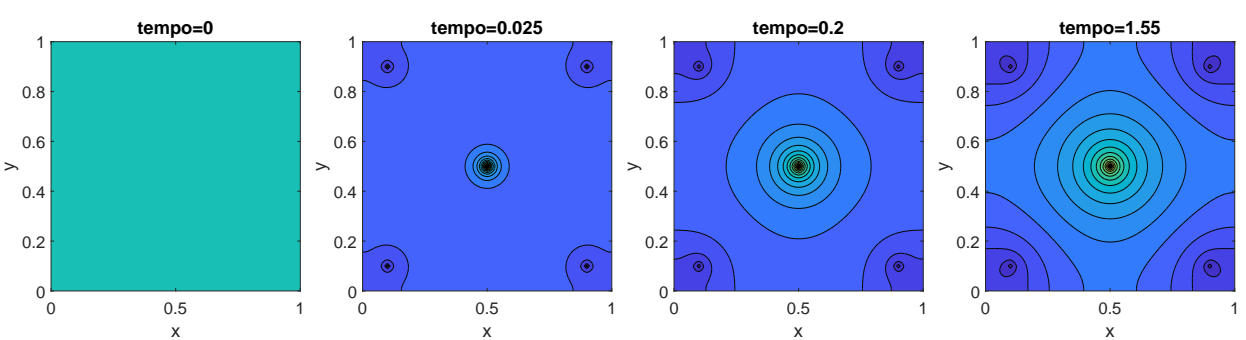

Figura 2.13: Curvas de nível do Teste 1 (Caso 4) 


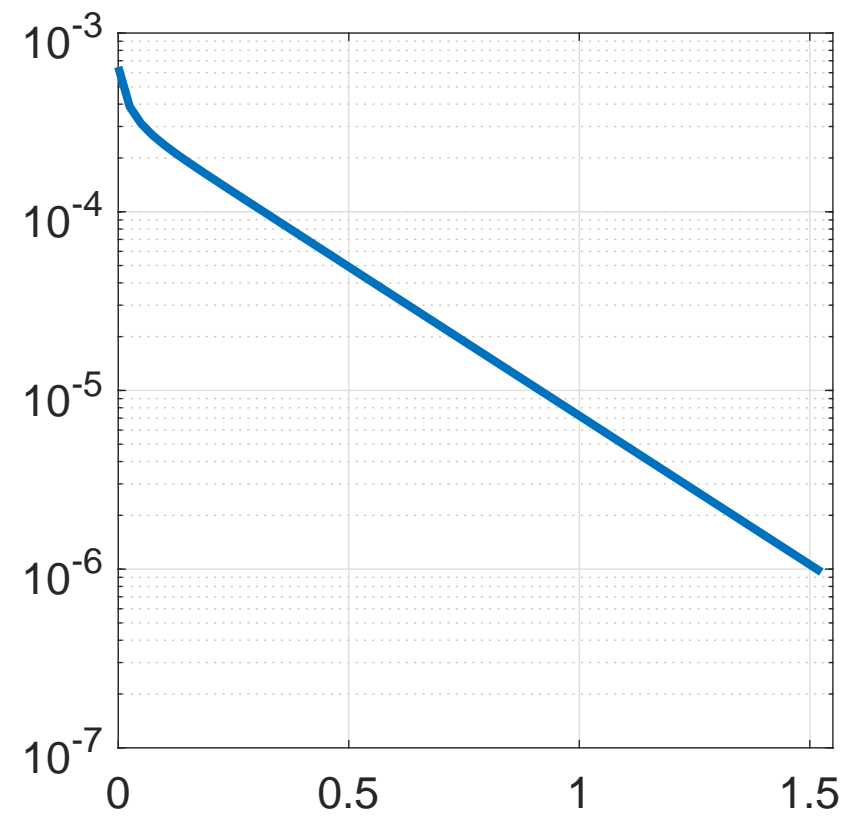

Figura 2.14: Variação $\|\mathcal{E}(k)\|$ do Teste 1 (Caso 4)

Por conta das fontes de calor, as regiões próximas as quatro extemidades da placa vão esfriando, e a região central esquentando. Como a soma das temperaturas do termo fonte de calor $q$ é zero, isso faz com que a solução chegue ao equílibrio, o que pode ser notado na Figura 2.14, respeitando a tolerância de $10^{-6}$ que impusemos. A solução obtida é um resultado esperado, pois esse caso representa um esquema conhecido como five-spot, como é ilustrado em Rosa et al. (16), onde a temperatura central representa um poço produtor, e as quatro temperaturas nos extremos, poços injetores. A temperatura máxima atingida pela placa foi 0.0033 e a mínima -0.0011 .

Caso 5: Usamos a fonte constante como em (2-62). A Figura 2.15 apresenta a evolução da solução obtida em quatro diferentes tempos, através de um gráfico de temperatura por posição. A Figura 2.16 ilustra as correspondentes curvas de nível e a Figura 2.17 o gráfico $\|\mathcal{E}(k)\| \times t$ em escala logarítmica.
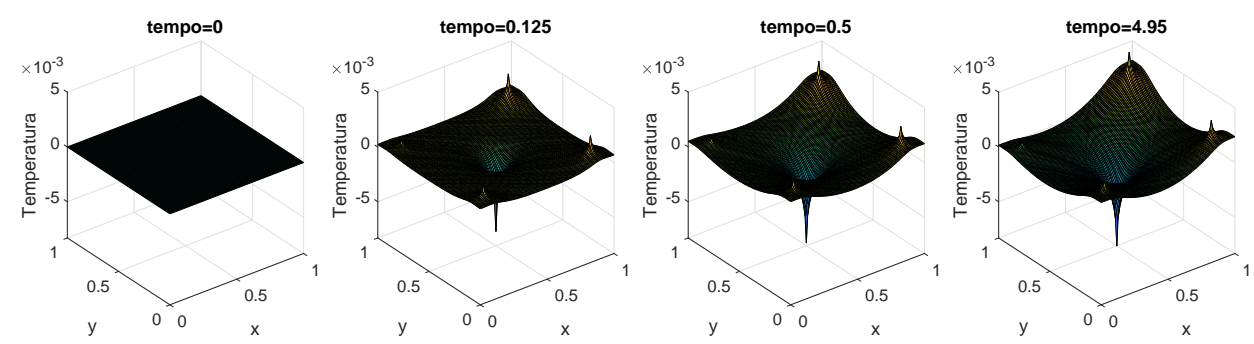

Figura 2.15: Teste 1 (Caso 5) 

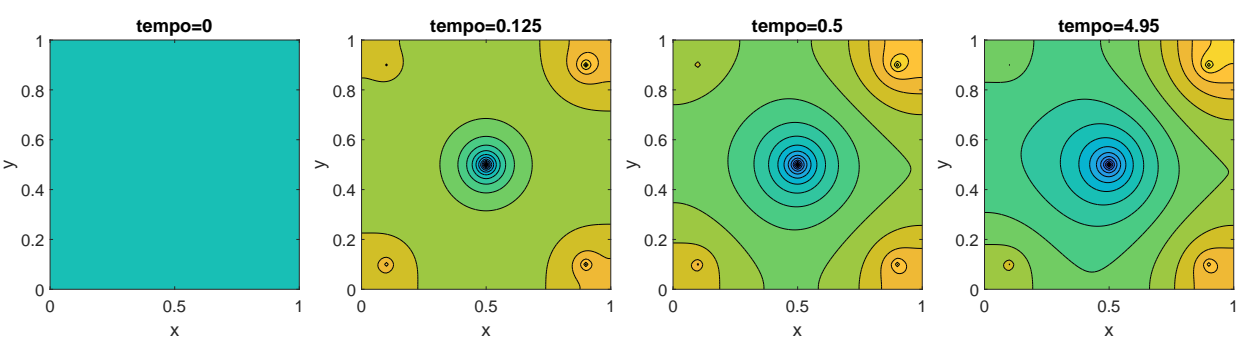

Figura 2.16: Curvas de nível do Teste 1 (Caso 5)

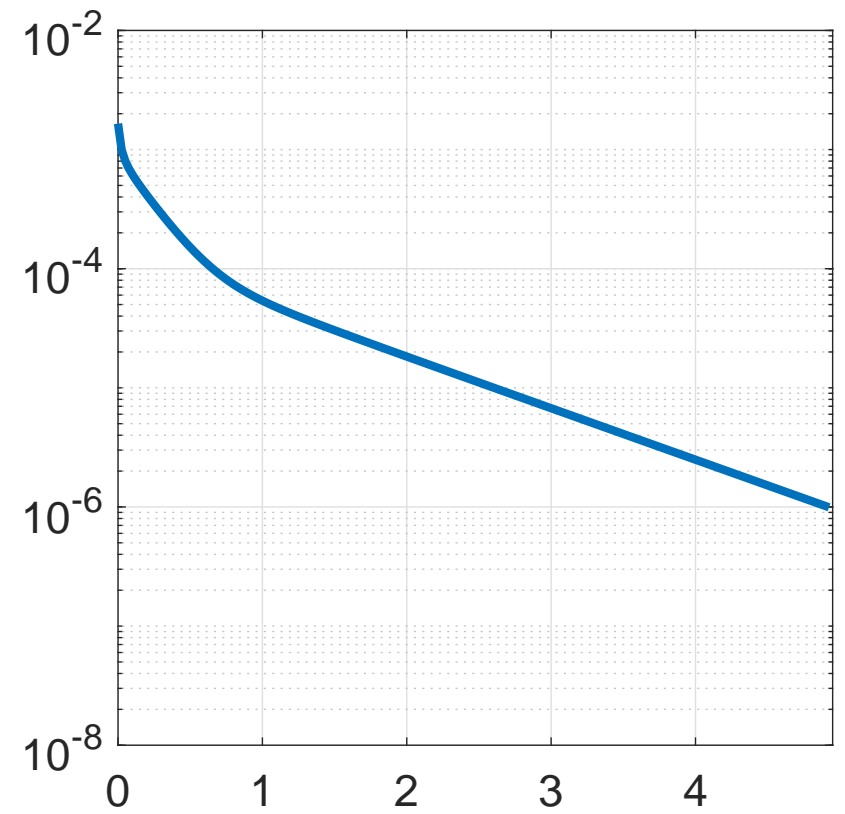

Figura 2.17: Variação $\|\mathcal{E}(k)\|$ do Teste 1 (Caso 5)

No centro da placa está um termo fonte de calor esfriando-a, e nas quatro extremidades há termos fonte de calor esquentando-a, com temperaturas diferentes. Naturalmente, com o passar do tempo as temperaturas tendem a se propagar pela placa, porém como as extremidades do lado direito esquentam mais do que as do lado esquerdo, o frio que inicialmente está centralizado, começa a se propagar pelo lado esquerdo porque nesse lado as extremidades esquentam menos, dando esse aspecto inclinado no gráfico da solução, como pode ser observado na Figura 2.15, e que pode ser também observado na Figura 2.19 com as curvas de niveis centrais um pouco deslocadas para a esquerda. A temperatura máxima atingida pela placa foi 0.005 e a mínima -0.0083 . Repare que como as temperaturas do termo fonte nesse caso são maiores do que as do anterior, o máximo e o mínimo, em módulo, também são maiores. A solução encontrada alcança o equilíbrio, como pode ser visto na Figura 2.17, dado que a soma das fontes do termo fonte de calor $q$ é nula. 
Capítulo 2. Equação do Calor com Termo Fonte em uma Placa Homogênea 36

\subsection{2}

\section{Teste 2: Equação do Calor não-linear com termo fonte variável e constante}

Agora vamos trabalhar com a equação apresentada no início, ou seja uma equação do calor 2D com termo fonte variável e termo fonte constante.

Em todos os casos usamos os dados $L=1, s(U)=\sin (\pi U), f(x, y)=$ $0, \sigma=0.05, \Delta x=0.01, \Delta t=0.025$ e a dimensão do problema é $n^{2}=99^{2}=$ 9801.

Caso 1: Usamos a fonte de calor constante como em (2-58). A Figura 2.18 apresenta a evolução da solução obtida em quatro diferentes tempos, através de um gráfico de temperatura por posição. A Figura 2.19 ilustra as correspondentes curvas de nível e a Figura 2.20 o gráfico $\|\mathcal{E}(k)\| \times t$ em escala logarítmica.
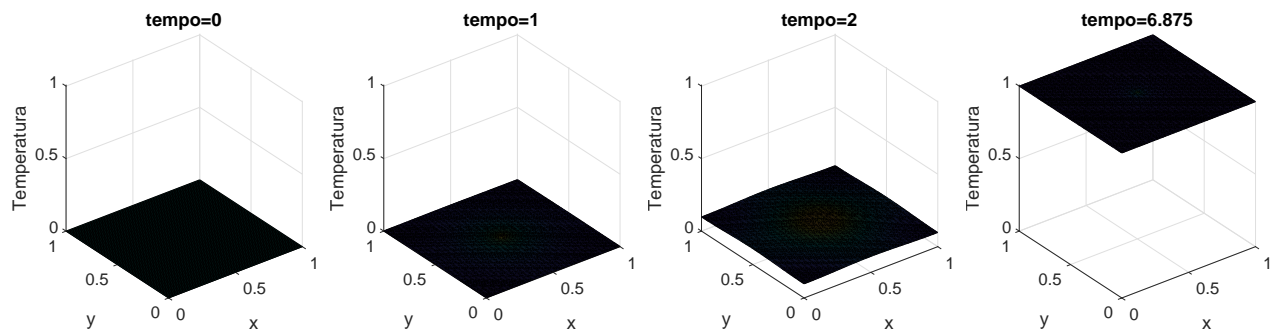

Figura 2.18: Teste 2 (Caso 1)
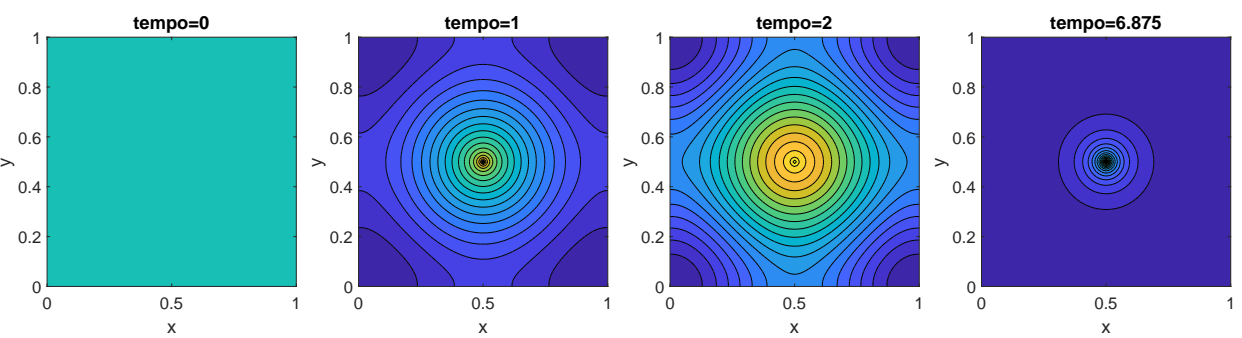

Figura 2.19: Curvas de nível do Teste 2 (Caso 1) 


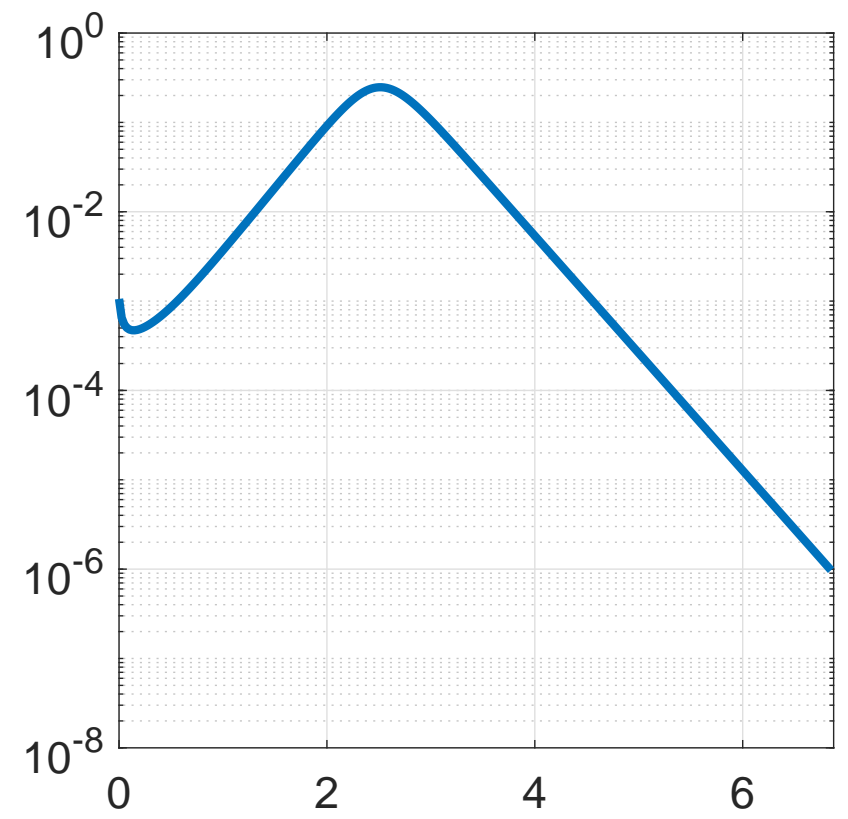

Figura 2.20: Variação $\|\mathcal{E}(k)\|$ do Teste 2 (Caso 1)

Pode-se observar uma grande diferença produzida pelo efeito da fonte variável $s$ em relação a esse mesmo caso no Teste 1 , dado que antes rapidamente se formava um bico na região central onde está posicionada a fonte de calor constante, mas agora isso não ocorre, como podemos observar na Figura 2.18. A solução fica no seu movimento natural crescimento, tendo seu valor máximo de 1.0068, bem maior do que no Teste 1 , e o valor mínimo de 0 como era esperado. Outra diferença é que a solução chega ao equilíbrio, como pode ser percebido na Figura 2.20 onde a variação decresce respeitando a tolerância de $10^{-6}$, enquanto que no Teste 1 a solução nesse caso não chega ao equilíbrio, isso se dá pelo efeito da fonte variável $s$.

Caso 2: Usamos a fonte de calor constante como em (2-59). A Figura 2.21 apresenta a evolução da solução obtida em quatro diferentes tempos, através de um gráfico de temperatura por posição. A Figura 2.22 ilustra as correspondentes curvas de nível e a Figura 2.23 o gráfico $\|\mathcal{E}(k)\| \times t$ em escala logarítmica.
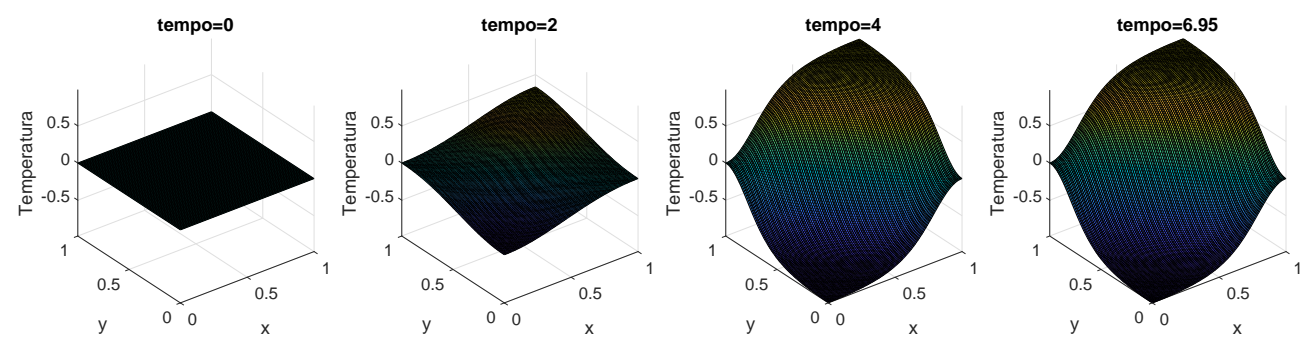

Figura 2.21: Teste 2 (Caso 2) 

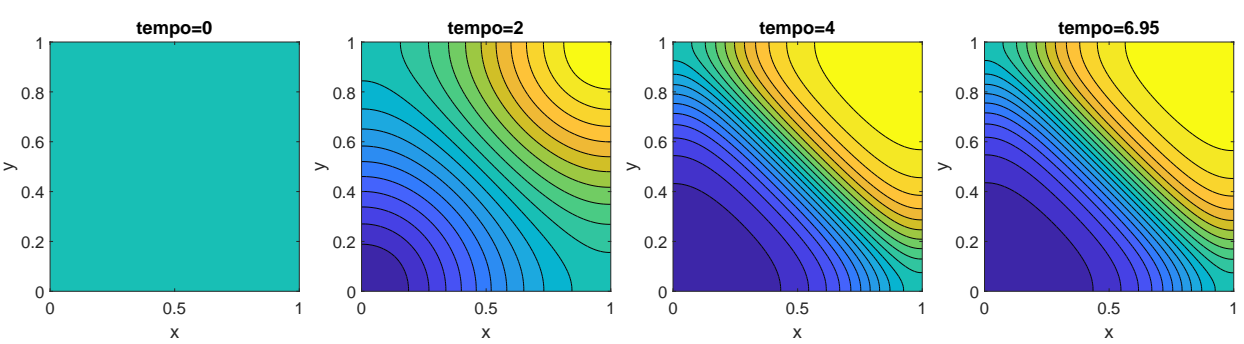

Figura 2.22: Curvas de nível do Teste 2 (Caso 2)

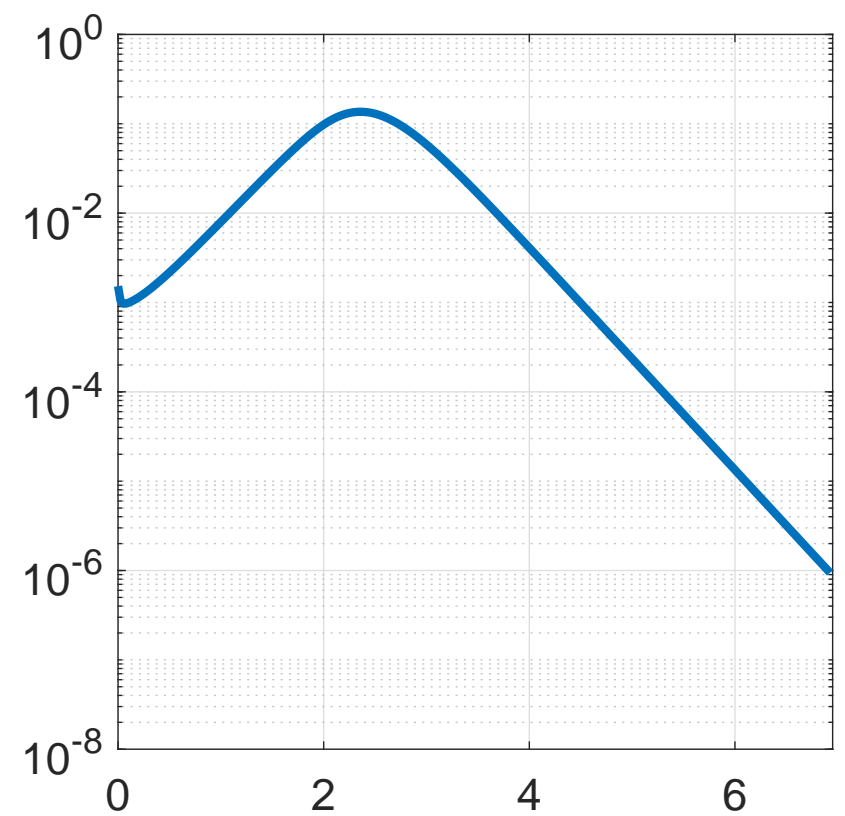

Figura 2.23: Variação $\|\mathcal{E}(k)\|$ do Teste 2 (Caso 2)

Note que a solução se encontra bastante curvada como podemos observar na Figura 2.21, diferentemete da solução desse mesmo caso no Teste 1, esse é o efeito que o termo fonte variável $s$, sendo a função seno, exerce sobre a solução. Repare também que não se formam os bicos na solução, muito comuns no Teste 1, produzidos pela fonte de calor constante. Agora eles não se formam pelo efeito do termo fonte variável $s$. O equilíbrio é alcançado nesse caso, dado que a variação decresce como se percebe na Figura 2.23. A temperatura máxima alcançada pela placa foi 0.9826 e a mínima -0.9826 , valores iguais em módulo, o que era esperado, dada a simetria da placa e das fontes de calor constante.

Caso 3: Usamos a fonte de calor constante como em (2-60). A Figura 2.24 apresenta a evolução da solução obtida em quatro diferentes tempos, através de um gráfico de temperatura por posição. A Figura 2.25 ilustra as correspondentes curvas de nível e a Figura 2.26 o gráfico $\|\mathcal{E}(k)\| \times t$ em escala logarítmica. 

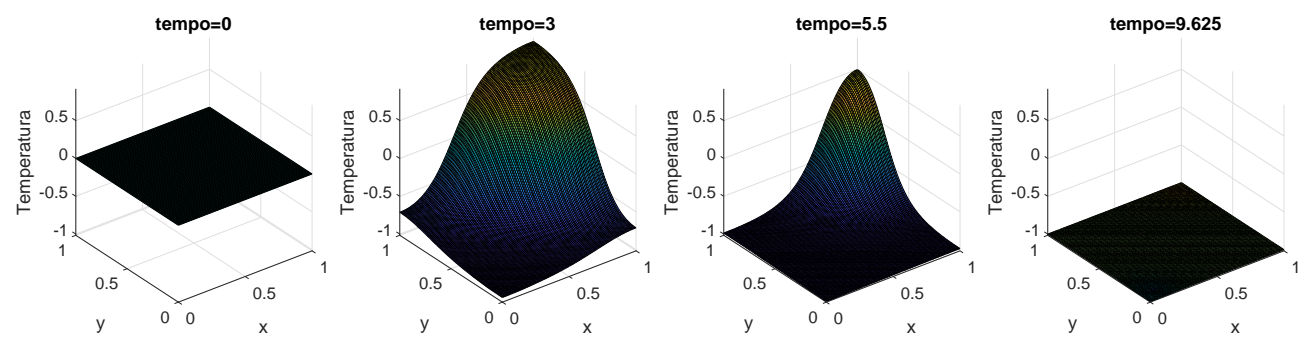

Figura 2.24: Teste 2 (Caso 3)
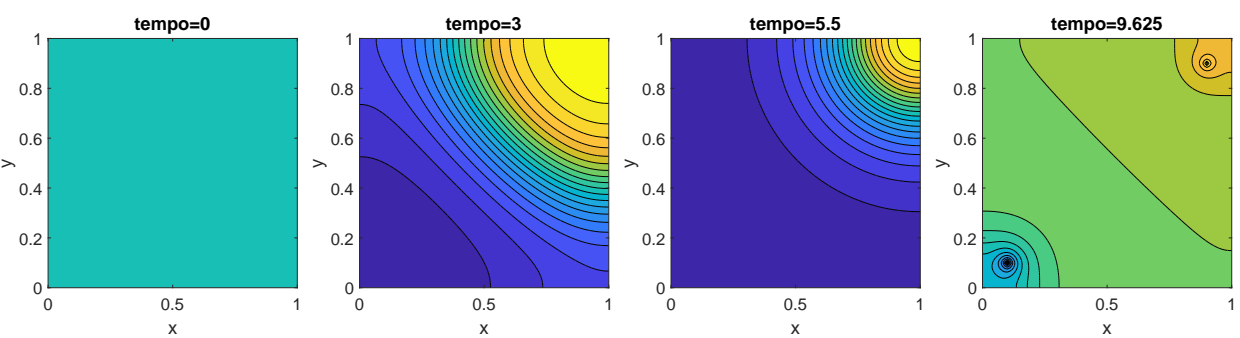

Figura 2.25: Curvas de nível do Teste 2 (Caso 3)

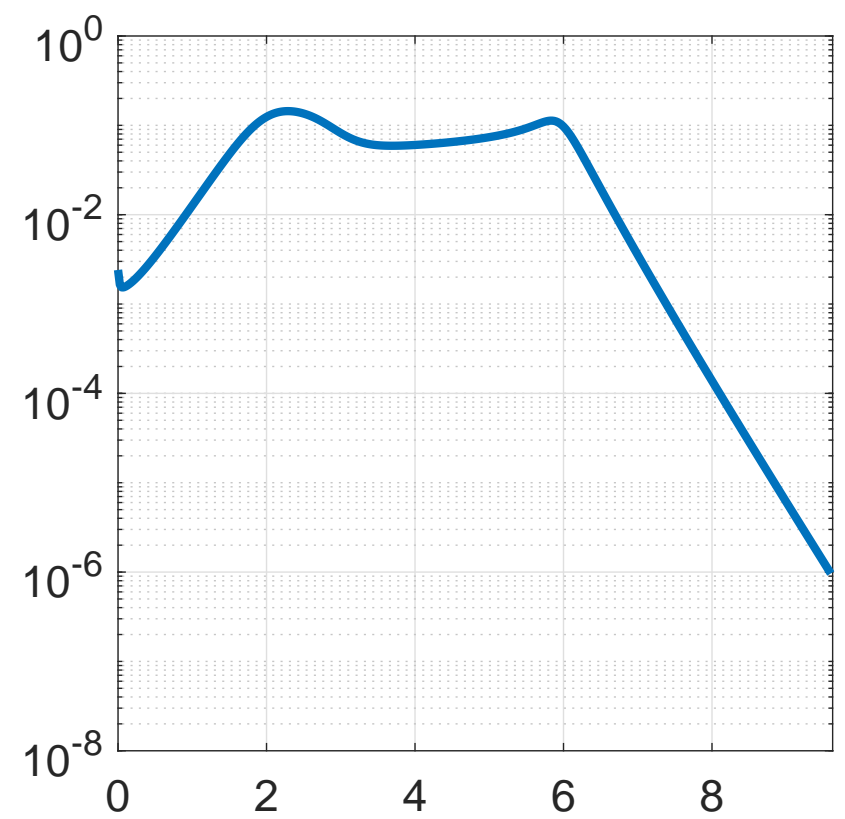

Figura 2.26: Variação $\|\mathcal{E}(k)\|$ do Teste 2 (Caso 3)

Nesse caso a solução chega ao equilíbrio, como pode ser notado nas Figuras 2.24 e 2.26, fato que não ocorre nesse caso no Teste 1, e também não há bicos na solução, isses fatos decorrem do efeito da função seno na fonte de calor variável $s$, que é continua e suaviza esses bicos, fazendo com que eles não apareçam na solução. A temperatura máxima alcançada pela placa foi 0.9132 e a mínima -1.0152, como era esperado o valor mínimo em módulo é maior do que o máximo, dado que a fonte de calor constante negativa é maior 
Capítulo 2. Equação do Calor com Termo Fonte em uma Placa Homogênea 40

em módulo do que a positiva, e ambas as temperaturas são maiores em módulo do que as atingidas pela solução desse caso no Teste 1 .

Caso 4: Usamos a fonte de calor constante como em (2-61). A Figura 2.27 apresenta a evolução da solução obtida em quatro diferentes tempos, através de um gráfico de temperatura por posição. A Figura 2.28 ilustra as correspondentes curvas de nível e a Figura 2.29 o gráfico $\|\mathcal{E}(k)\| \times t$ em escala logarítmica.
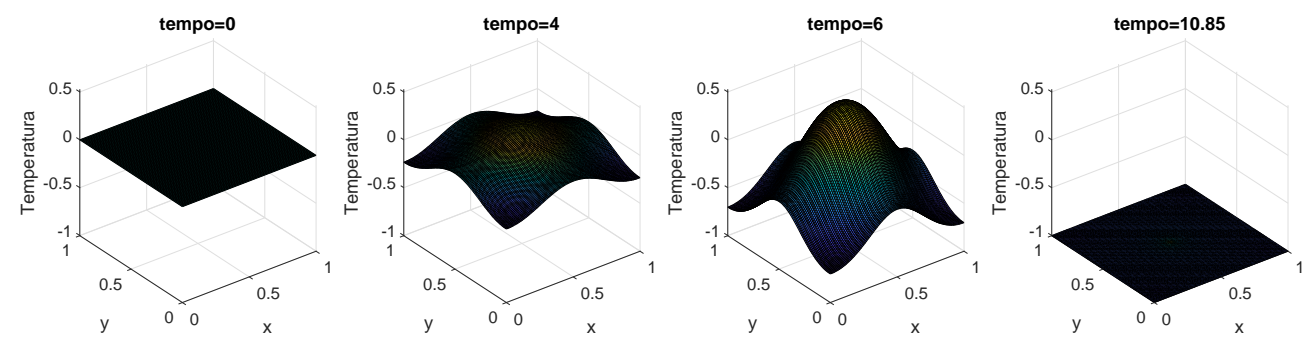

Figura 2.27: Teste 2 (Caso 4)
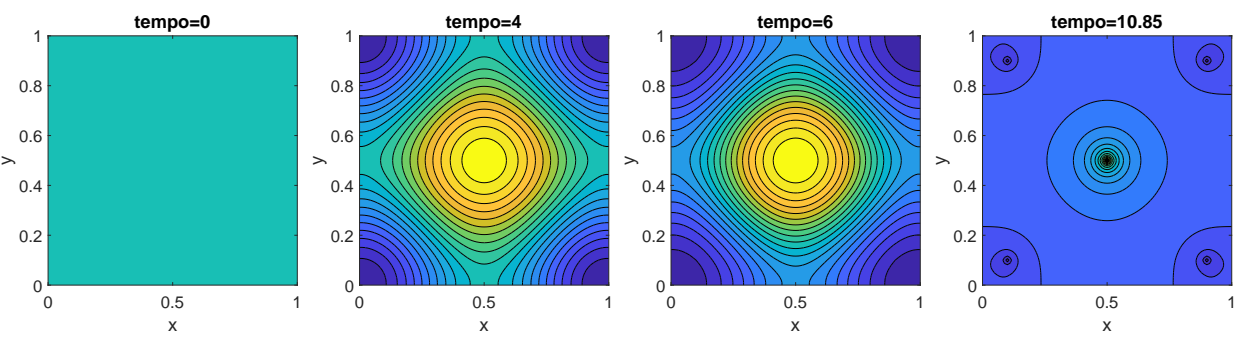

Figura 2.28: Curvas de nível do Teste 2 (Caso 4)

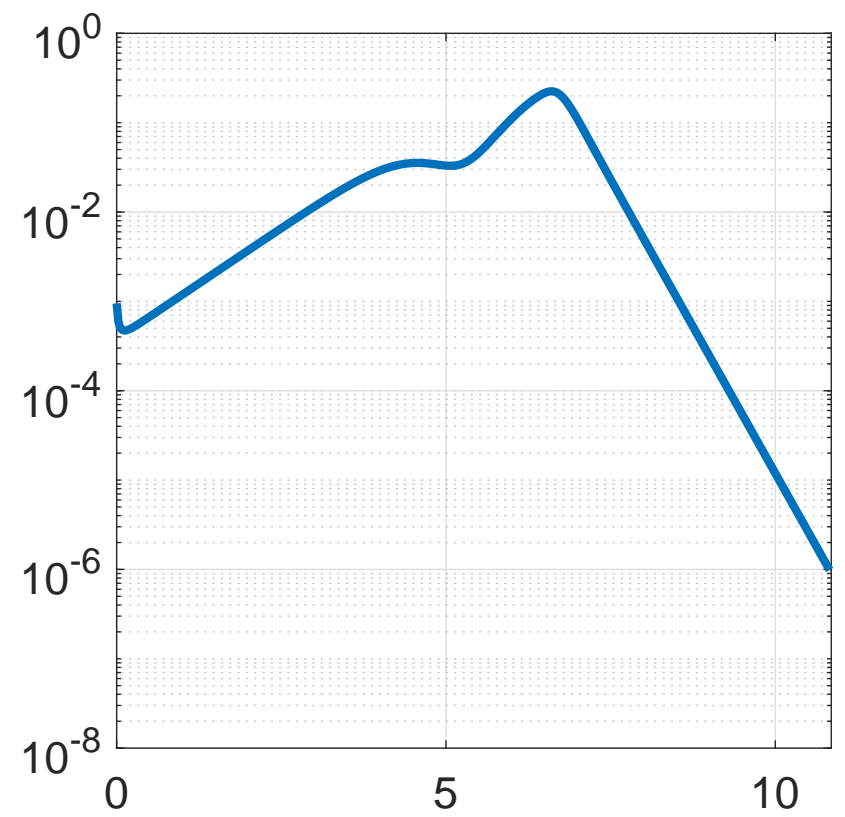

Figura 2.29: Variação $\|\mathcal{E}(k)\|$ do Teste 2 (Caso 4) 
Repare como a solução se curva bastante e não possui bicos, como pode ser visto nas Figuras 2.27 e 2.28, essas são conseguências do efeito da função seno na fonte de calor variável $s$. A temperatura máxima alcançada pela placa foi 0.5235 e a mínima -1.0015, ambos maiores em módulo do que as temperaturas máximas e mínimas desse mesmo caso no Teste 1. A solução chega ao equilíbrio, como pode ser visto na Figura 2.29, dado que a variação decresce, respeitadando a tolerância de $10^{-6}$ que foi imposta.

Caso 5: Usamos a fonte de calor constante como em (2-62). A Figura 2.30 apresenta a evolução da solução obtida em quatro diferentes tempos, através de um gráfico de temperatura por posição. A Figura 2.31 ilustra as correspondentes curvas de nível e a Figura 2.32 o gráfico $\|\mathcal{E}(k)\| \times t$ em escala logarítmica.
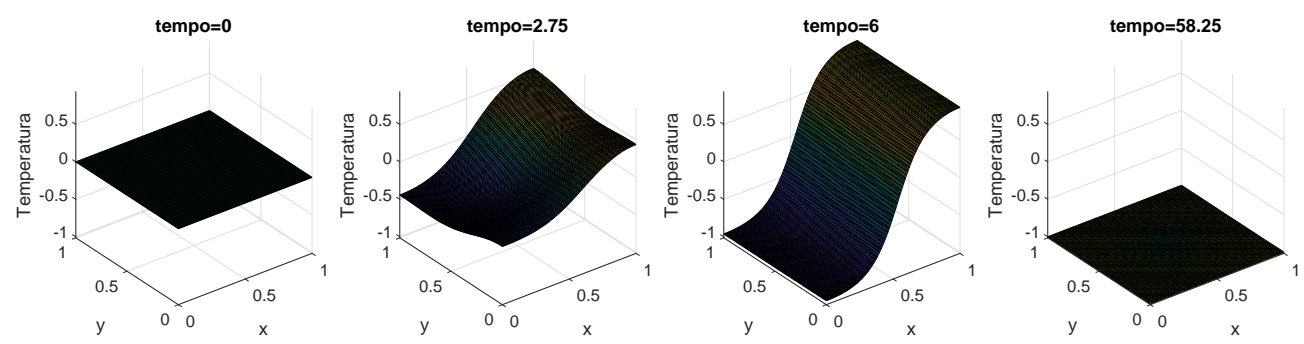

Figura 2.30: Teste 2 (Caso 5)
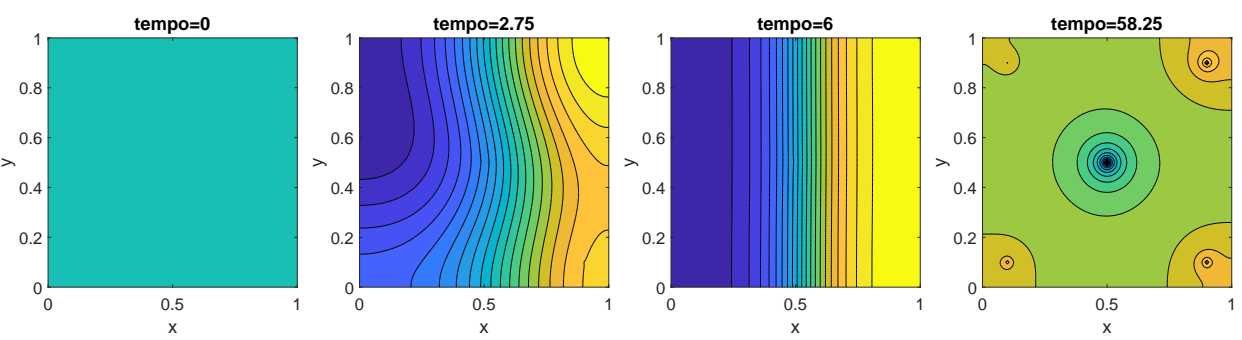

Figura 2.31: Curvas de nível do Teste 2 (Caso 5) 


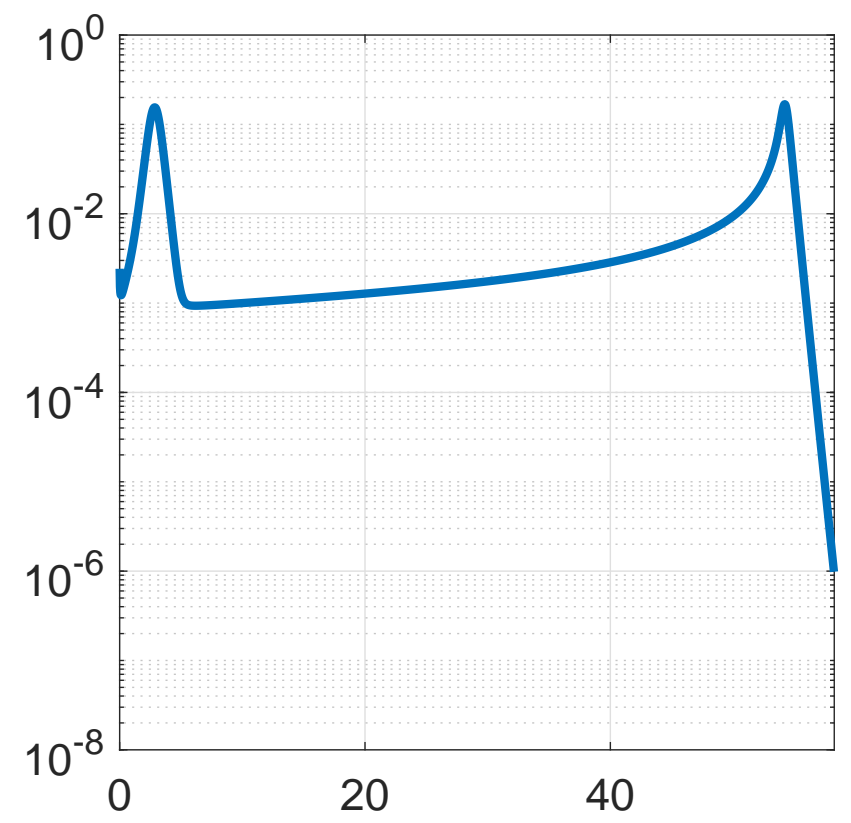

Figura 2.32: Variação $\|\mathcal{E}(k)\|$ do Teste 2 (Caso 5)

Como as maiores fontes de calor constantes positivas estão do lado direito da placa, inicialmente ela vai tomando essa forma inclinada no decorrer do tempo, sem bicos como era esperado, depois a solução vai decaindo até chegar ao equilíbrio, como pode ser visto na Figura 2.30. A variação é decrescente, respeitando a tolerância de de $10^{-6}$ como podemos observar na Figura 2.32. A temperatura máxima alcançada pela placa foi 0.9344 e a mínima -1.0135 , ambos valores maiores em módulo do que a temperatura máxima e mínima alcançada por esse mesmo caso no Teste 1.

Para o Teste 1, a partir dos resultados obtidos percebemos um fato interessante: quando a soma das fontes de calor do termo fonte constate é nula, então a solução chega ao equilíbrio. Quando não, ela não chega. Diferentemente do Teste 2 , onde todas as soluções chegaram ao equilíbrio, isso ocorre pelo efeito que a fonte de calor variável, que é uma função contínua, exerce nas soluções. 
3

\section{Equação do Calor com Termo Fonte em uma Placa Hetero- gênea}

Nesse capítulo estudaremos a equação diferencial parcial do calor em duas dimensões, onde o domínio será representado por uma placa plana heterôgenea $\Omega=[0,1] \times[0,1] \subset \mathbb{R}^{2}$, no formato de um quadrado de lado $L=1$. Agora o valor da condutividade térmica $\sigma$ é variável, e a placa $\Omega$ é dividida simétricamente em quatro regiões $\Omega_{i}, i=1, \ldots, 4$ feitas de materiais diferentes, como podemos ver na Figura 3.1.

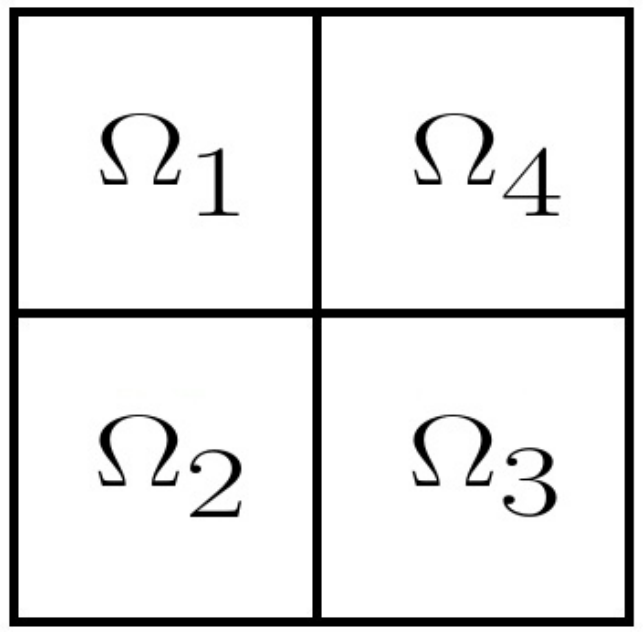

Figura 3.1: Placa heterogênea com condições de contorno internas.

Onde:

$$
\Omega= \begin{cases}\Omega_{1}, & 0 \leq x \leq 0.5,0.5 \leq y \leq 1 \\ \Omega_{2}, & 0 \leq x \leq 0.5,0 \leq y \leq 0.5 \\ \Omega_{3}, & 0.5 \leq x \leq 1,0 \leq y \leq 0.5 \\ \Omega_{4}, & 0.5 \leq x \leq 1,0.5 \leq y \leq 1\end{cases}
$$

Sendo $\sigma_{i} \in \mathbb{R}$ o valor da condutividade térmica da região $\Omega_{i}$. Além disso, como podemos ver na Figura 3.1, $\Omega$ possui quatro condições de contorno nas fronteiras dessas regiões, dadas pelas equações: 


$$
\begin{cases}\frac{1}{\sigma_{1}} U_{y}=\frac{1}{\sigma_{2}} U_{y}, & 0 \leq x \leq 0.5, y=0.5 \\ \frac{1}{\sigma_{2}} U_{x}=\frac{1}{\sigma_{3}} U_{x}, & x=0.5,0 \leq y \leq 0.5 \\ \frac{1}{\sigma_{4}} U_{y}=\frac{1}{\sigma_{3}} U_{y}, & 0.5 \leq x \leq 1, y=0.5 \\ \frac{1}{\sigma_{1}} U_{x}=\frac{1}{\sigma_{4}} U_{x}, & x=0.5,0.5 \leq y \leq 1\end{cases}
$$

Vamos discretizar a placa heterogênea $\Omega=\cup \Omega_{i}, i=1, \ldots, 4$ como no capítulo anterior, de modo que as Equações (3-2) serão usadas nos pontos da discretização que estiverem nas fronteiras internas da placa.

Portanto, temos a formulação do seguinte problema:

$$
\begin{cases}U_{t}=\sigma \Delta U+s(U)+q, & (x, y) \in \Omega, t \in[0, T] \\ U((x, y), 0)=f(x, y), & (x, y) \in \Omega, \\ \partial_{n} U=0, & (x, y) \in \partial \Omega, t \in[0, T], \\ \frac{1}{\sigma_{1}} U_{y}=\frac{1}{\sigma_{2}} U_{y}, & 0 \leq x \leq 0.5, y=0.5, \\ \frac{1}{\sigma_{2}} U_{x}=\frac{1}{\sigma_{3}} U_{x}, & x=0.5,0 \leq y \leq 0.5, \\ \frac{1}{\sigma_{4}} U_{y}=\frac{1}{\sigma_{3}} U_{y}, & 0.5 \leq x \leq 1, y=0.5, \\ \frac{1}{\sigma_{1}} U_{x}=\frac{1}{\sigma_{4}} U_{x}, & x=0.5,0.5 \leq y \leq 1 .\end{cases}
$$

Precisamos então discretizar as equações em (3-2) para poder resolver esse novo problema numéricamente.

\section{1}

\section{Aproximação Numérica}

Como vimos no capítulo anterior, a discretização da equação do calor em (3-3) tem a forma:

$$
U^{k-1}=A U^{k}-\Delta t s\left(U^{k}\right)-\Delta t q, \quad k=1, \ldots, m
$$

No problema atual, somente irá mudar a matriz $A \in \mathbb{R}^{n^{2} \times n^{2}}$, por causa da nova placa heterogênea, pois agora cada região tem um valor de $\sigma$ diferente e temos condições de contorno internas. Para melhor entendermos essas mudanças vejamos a Figura 3.2, com a placa discretizada para $n=3$. 


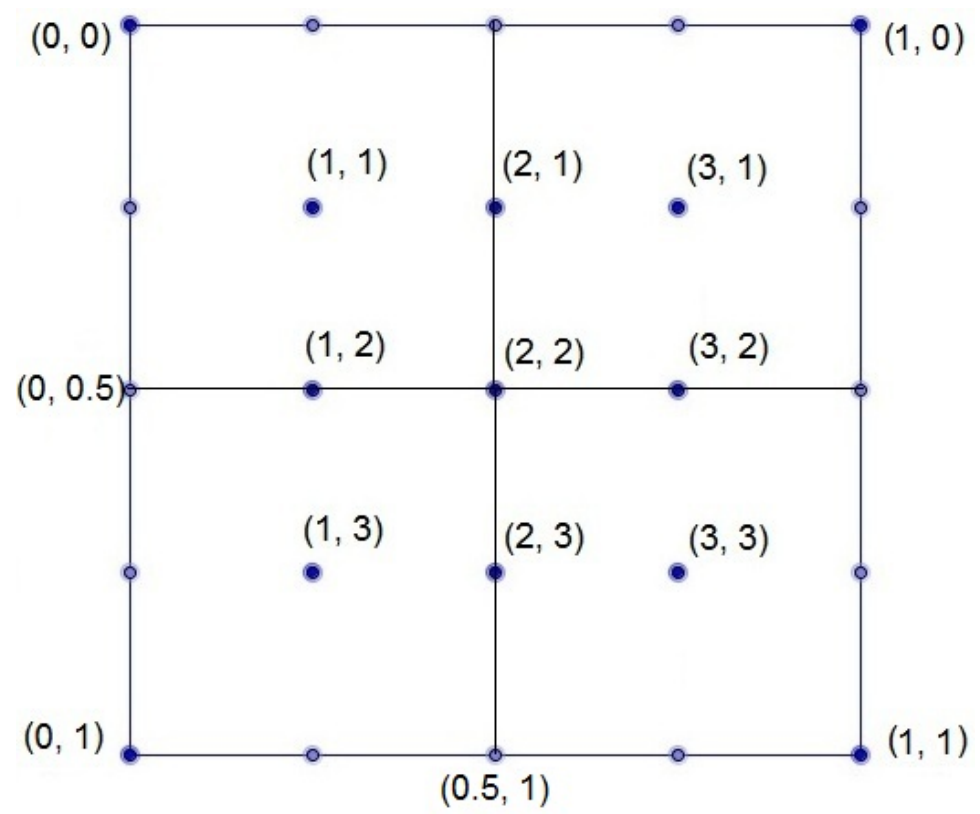

Figura 3.2: Discretização da placa heterogênea com $n=3$.

$\mathrm{Na}$ discretização, cada coluna de pontos interiores produz um bloco matricial na matriz $A$. Repare que mesmo para valores maiores de $n$, sempre temos três tipos de colunas: a coluna de pontos central, onde $x=0.5$, as colunas de pontos anteriores a coluna central e a colunas de pontos posteriores a coluna central. E todas as colunas de pontos sofrerão modificações causadas pelas condições de contorno internas, principalmente a coluna central, visto que todos os seus pontos estão sobre duas condições de contorno internas. Essa percepção ajudará a entender a forma da matriz $A$.

Vamos aproximar as Equações (3-2) por Diferença para Frente no lado esquerdo, e por Diferença para Trás no lado direito, consideramos assim que o fluxo de calor flui do lado esquerdo para o direito.

Note que a primeira e terceira equações em (3-2) são parecidas, mudando apenas a constante $\sigma$. Por isso vamos discretizar ambas ao mesmo tempo, usando os índices $\beta$ e $\gamma$. Assim, temos:

$$
\frac{1}{\sigma_{\beta}} \frac{U_{i, j+1}^{k}-U_{i, j}^{k}}{h}=\frac{1}{\sigma_{\gamma}} \frac{U_{i, j}^{k}-U_{i, j-1}^{k}}{h}
$$

Daí segue:

$$
\frac{1}{\sigma_{\gamma}} U_{i, j-1}^{k}-\frac{\sigma_{\beta}+\sigma_{\gamma}}{\sigma_{\beta} \sigma_{\gamma}} U_{i, j}^{k}+\frac{1}{\sigma_{\beta}} U_{i, j+1}^{k}=0
$$

Onde para a primeira equação em (3-2) temos $\beta=1, \gamma=2$ e para a terceira equação temos $\beta=4, \gamma=3$.

Tomando $\beta=1, \gamma=2$ em (3-6), temos a equação: 


$$
\frac{1}{\sigma_{2}} U_{i, j-1}^{k}-\frac{\sigma_{1}+\sigma_{2}}{\sigma_{1} \sigma_{2}} U_{i, j}^{k}+\frac{1}{\sigma_{1}} U_{i, j+1}^{k}=0
$$

Ao fixarmos $k$ e variarmos $i, j$, obtemos as matrizes tridiagonais $D, F, V \in$ $\mathbb{R}^{n \times n}$ :

$$
\begin{aligned}
D & =\left[\begin{array}{ccccc}
(1+2 \alpha) & -\alpha & 0 & \cdots & 0 \\
-\alpha & (1+3 \alpha) & -\alpha & & \\
& \ddots & \ddots & \ddots & \\
& \frac{1}{\sigma_{2}} & -\frac{\sigma_{1}+\sigma_{2}}{\sigma_{1} \sigma_{2}} & \frac{1}{\sigma_{1}} & \\
& \ddots & \ddots & \ddots & \\
& & -\alpha & (1+3 \alpha) & -\alpha \\
0 & \ldots & 0 & -\alpha & (1+2 \alpha)
\end{array}\right] \\
F & =\left[\begin{array}{ccccc}
(1+3 \alpha) & -\alpha & 0 & \cdots & 0 \\
-\alpha & (1+4 \alpha) & -\alpha & & \\
& \ddots & \ddots & \ddots & \\
& \frac{1}{\sigma_{2}} & -\frac{\sigma_{1}+\sigma_{2}}{\sigma_{1} \sigma_{2}} & \frac{1}{\sigma_{1}} & \\
& \ddots & \ddots & \ddots & \\
& & -\alpha & (1+4 \alpha) & -\alpha \\
0 & \cdots & 0 & -\alpha & (1+3 \alpha)
\end{array}\right]
\end{aligned}
$$

De modo que $\alpha=\alpha(x, y)=\frac{\sigma(x, y) \Delta t}{h^{2}}$, pois como $\sigma$ é constante por partes, $\alpha$ também é.

As matrizes $D$ e $V$ são geradas pela primeira coluna de pontos na discretização, sendo $D$ a primeira matriz na diagonal principal da matriz $A$, com a matriz $V$ no seu lado direito. E as matrizes $F$ e $V$ são referentes a segunda coluna de pontos na discretização até a coluna anterior a coluna central em $x=0.5$, com a matriz $V$ estando ao lado esquerdo e direito da matriz $F$. A matriz $V$ tem a forma:

$$
V=\left[\begin{array}{ccccc}
-\alpha & 0 & 0 & \cdots & 0 \\
0 & -\alpha & 0 & & \\
& \ddots & \ddots & \ddots & \\
& 0 & 0 & 0 & \\
& \ddots & \ddots & \ddots & \\
& & 0 & -\alpha & 0 \\
0 & \cdots & 0 & 0 & -\alpha
\end{array}\right]
$$

Agora, ao tomarmos $\beta=4, \gamma=3$ em (3-6), temos a equação: 


$$
\frac{1}{\sigma_{3}} U_{i, j-1}^{k}-\frac{\sigma_{4}+\sigma_{3}}{\sigma_{4} \sigma_{3}} U_{i, j}^{k}+\frac{1}{\sigma_{4}} U_{i, j+1}^{k}=0
$$

Ao fixarmos $k$ e variarmos $i, j$, obtemos as matrizes tridiagonais $E, G, V \in \mathbb{R}^{n \times n}:$

$$
\begin{gathered}
E=\left[\begin{array}{ccccc}
(1+2 \alpha) & -\alpha & 0 & \cdots & 0 \\
-\alpha & (1+3 \alpha) & -\alpha & & \\
& \ddots & \ddots & \ddots & \\
& \frac{1}{\sigma_{3}} & -\frac{\sigma_{3}+\sigma_{4}}{\sigma_{3} \sigma_{4}} & \frac{1}{\sigma_{4}} & \\
& \ddots & \ddots & \ddots & \\
& & -\alpha & (1+3 \alpha) & -\alpha \\
0 & \cdots & 0 & -\alpha & (1+2 \alpha)
\end{array}\right] \\
G=\left[\begin{array}{ccccc}
(1+3 \alpha) & -\alpha & 0 & \cdots & 0 \\
-\alpha & (1+4 \alpha) & -\alpha & & \\
& \ddots & \ddots & \ddots & \\
& \frac{1}{\sigma_{3}} & -\frac{\sigma_{3}+\sigma_{4}}{\sigma_{3} \sigma_{4}} & \frac{1}{\sigma_{4}} & \\
& \ddots & \ddots & \ddots & (1+3 \alpha)
\end{array}\right]
\end{gathered}
$$

Onde as matrizes $E$ e $V$ são geradas pela última coluna de pontos na discretização, $E$ sendo a última matriz na diagonal principal da matriz $A$, com a matriz $V$ no seu lado esquerdo. E as matrizes $G$ e $V$ são referentes a segunda coluna de pontos na discretização depois da coluna central até a coluna anterior a última coluna de pontos, com a matriz $V$ estando ao lado esquerdo e direito da matriz $G$. A matriz $V$ é a mesma que foi definida anteriormente.

Note também que a segunda e quarta equações em (3-2) são parecidas, mudando apenas a constante $\sigma$. Portanto, discretizaremos ambas juntas, usando os índices $\eta$ e $\mu$, assim obtemos:

$$
\frac{1}{\sigma_{\eta}} \frac{U_{i+1, j}^{k}-U_{i, j}^{k}}{h}=\frac{1}{\sigma_{\mu}} \frac{U_{i, j}^{k}-U_{i-1, j}^{k}}{h},
$$

Que resulta em:

$$
\frac{1}{\sigma_{\mu}} U_{i-1, j}^{k}-\frac{\sigma_{\eta}+\sigma_{\mu}}{\sigma_{\eta} \sigma_{\mu}} U_{i, j}^{k}+\frac{1}{\sigma_{\eta}} U_{i+1, j}^{k}=0
$$

Onde para a segunda equação em (3-2) temos $\eta=2, \mu=3$ e para a quarta equação temos $\eta=1, \mu=4$.

Para tratar do ponto central, usaremos a soma da primeira e quarta equações discretizadas, resultando em: 


$$
\frac{1}{\sigma_{2}} U_{i, j-1}^{k}+\frac{1}{\sigma_{4}} U_{i-1, j}^{k}-\left(\frac{\sigma_{1}+\sigma_{2}}{\sigma_{1} \sigma_{2}}+\frac{\sigma_{1}+\sigma_{4}}{\sigma_{1} \sigma_{4}}\right) U_{i, j}^{k}+\frac{1}{\sigma_{1}} U_{i, j+1}^{k}+\frac{1}{\sigma_{1}} U_{i+1, j}^{k}=0 .
$$

As equações (3-10) e (3-11), são referentes aos pontos da discretização que estão na coluna central em $x=0.5$, assim elas geram a matriz central da diagonal principal da matriz $A$, e suas matrizes laterais. Portanto, ao fixarmos $k$ e variarmos $i, j$, obtemos as matrizes tridiagonais $P, Q, R \in \mathbb{R}^{n \times n}$ :

$$
Q=\left[\begin{array}{ccccc}
-\frac{\sigma_{1}+\sigma_{4}}{\sigma_{1} \sigma_{4}} & 0 & 0 & \cdots & 0 \\
0 & -\frac{\sigma_{1}+\sigma_{4}}{\sigma_{1} \sigma_{4}} & 0 & & \\
& \ddots & \ddots & \ddots & \\
& \frac{1}{\sigma_{2}} & -\left(\frac{\sigma_{1}+\sigma_{2}}{\sigma_{1} \sigma_{2}}+\frac{\sigma_{1}+\sigma_{4}}{\sigma_{1} \sigma_{4}}\right) & \frac{1}{\sigma_{1}} & \\
& \ddots & \ddots & \ddots & \\
0 & \cdots & 0 & -\frac{\sigma_{2}+\sigma_{3}}{\sigma_{2} \sigma_{3}} & 0 \\
& & 0 & 0 & -\frac{\sigma_{2}+\sigma_{3}}{\sigma_{2} \sigma_{3}}
\end{array}\right]
$$

$$
P=\left[\begin{array}{ccccc}
\frac{1}{\sigma_{4}} & 0 & 0 & \cdots & 0 \\
0 & \frac{1}{\sigma_{4}} & 0 & & \\
& \ddots & \ddots & \ddots & \\
& 0 & \frac{1}{\sigma_{4}} & 0 & \\
& \ddots & \ddots & \ddots & \\
& & 0 & \frac{1}{\sigma_{3}} & 0 \\
0 & \cdots & 0 & 0 & \frac{1}{\sigma_{3}}
\end{array}\right], R=\left[\begin{array}{ccccc}
\frac{1}{\sigma_{1}} & 0 & 0 & \cdots & 0 \\
0 & \frac{1}{\sigma_{1}} & 0 & & \\
& \ddots & \ddots & \ddots & \\
& 0 & \frac{1}{\sigma_{1}} & 0 & \\
& \ddots & \ddots & \ddots & \\
& & 0 & \frac{1}{\sigma_{2}} & 0 \\
0 & \cdots & 0 & 0 & \frac{1}{\sigma_{2}}
\end{array}\right]
$$

Onde $Q$ é a matriz central na diagonal da matriz $A$, com $P$ e $R$ sendo matrizes que ficam do seu lado esquerdo e direito respectivamente.

Assim a matriz $A \in \mathbb{R}^{n^{2} \times n^{2}}$ tem a forma:

$$
A=\left[\begin{array}{ccccc}
D & V & 0 & \cdots & 0 \\
V & F & V & & \\
& \ddots & \ddots & \ddots & \\
& P & Q & R & \\
& \ddots & \ddots & \ddots & \\
& & V & G & V \\
0 & \cdots & 0 & V & E
\end{array}\right]
$$

Com $D, E, V, F, G, P, Q, R \in \mathbb{R}^{n \times n}$ sendo matrizes tridiagonais, onde $0 \in \mathbb{R}^{n \times n}$ é a matriz nula. 


\section{2}

\section{Experimentos Numéricos}

Nessa seção serão apresentados dois testes como experimentos numéricos, resolvendo a equação do calor (3-3) com o domínio sendo a nova placa $\Omega=\cup \Omega_{i}$, $i=1, \ldots, 4$ heterogênea. Nesses testes usaremos os seguintes valores de $\sigma$ :

$$
\sigma_{1}=0.1 \quad \sigma_{2}=0.0125 \quad \sigma_{3}=0.05 \quad \sigma_{4}=0.025
$$

Dando sequência a numeração para os testes iniciada no capítulo dois, teremos agora os Testes 3 e 4 . No Teste 3 teremos somente o termo fonte constante e no Teste 4 o termo fonte constante e variável. Nos Testes 3 e 4 usamos quatro novos casos para o termo fonte constante, são eles:

Caso 6:

$$
q(x, y)= \begin{cases}-2, & (x, y)=(0.25,0.25) \\ 2, & (x, y)=(0.75,0.75) \\ 0, & \text { c.c. }\end{cases}
$$

Caso 7:

$$
q(x, y)= \begin{cases}-1, & (x, y)=(0.25,0.75) \\ -3, & (x, y)=(0.75,0.25) \\ 4, & (x, y)=(0.75,0.75) \\ 0, & \text { c.c. }\end{cases}
$$

Caso 8:

$$
q(x, y)=\left\{\begin{array}{lc}
1, & (x, y)=(0.25,0.75) \\
1, & (x, y)=(0.25,0.25) \\
1, & (x, y)=(0.75,0.25) \\
1, & (x, y)=(0.75,0.75) \\
0, & \text { c.c. }
\end{array}\right.
$$

Caso 9:

$$
q(x, y)= \begin{cases}5, & (x, y)=(0.25,0.75) \\ -5, & (x, y)=(0.25,0.25) \\ 5, & (x, y)=(0.75,0.25) \\ -5, & (x, y)=(0.75,0.75) \\ 0, & \text { c.c. }\end{cases}
$$

Usaremos a mesma condição do capítulo anterior para analisar a variação da solução, determinando se ela chega ao equilíbrio ou não. Porém, agora com a placa heterogênea, mesmo com a soma das fontes do termo fonte de calor sendo zero, não chegaremos ao equilíbrio, pois temos regiões com diferentes valores de condutividade térmica. Desse modo nenhum caso do Teste 3 chegou 
ao equilíbrio.

No Teste 4, pelo efeito da fonte de calor variável que é uma função contínua, todas as soluções chegam ao equilíbrio, mesmo com a placa sendo heterôgenea.

\subsection{1}

\section{Teste 3: Equação do Calor linear com termo fonte constante na placa heterogênea com condições de contorno internas}

Em todos os casos usamos os dados: $L=1, f(x, y)=0, \Delta x=0.01, \Delta t=$ 0.025 e a dimensão do problema é $n^{2}=99^{2}=9801$. O tempo para cada caso foi analisado separadamente.

Caso 6: Usamos a fonte de calor constante como em (3-12). A Figura 3.3 apresenta a evolução da solução obtida em quatro diferentes tempos, através de um gráfico de temperatura por posição. E a Figura 3.4 ilustra as correspondentes curvas de nível.
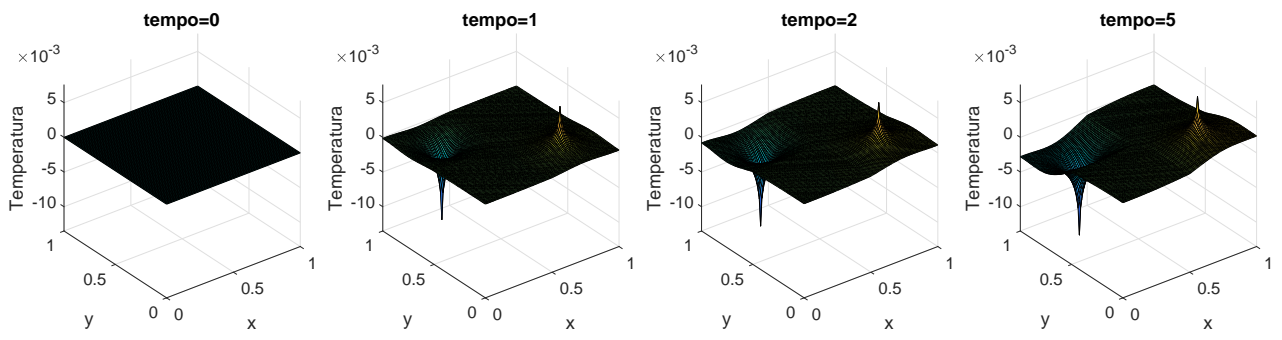

Figura 3.3: Teste 3 (Caso 6)
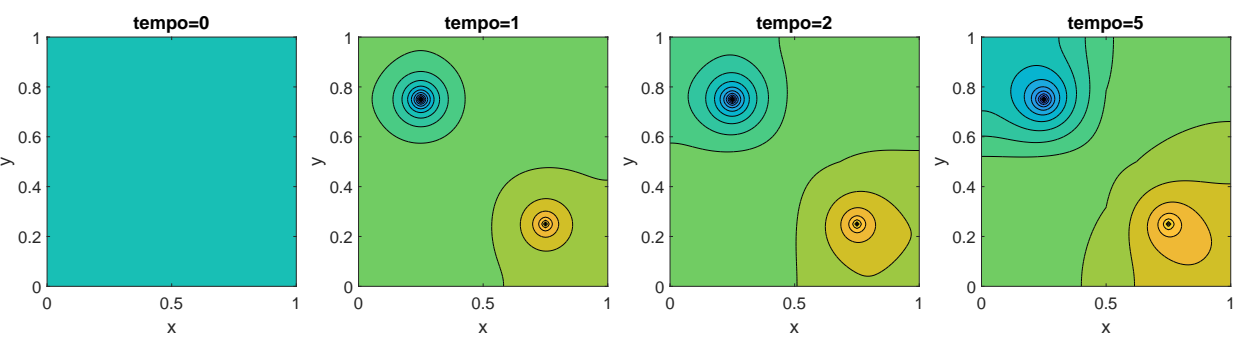

Figura 3.4: Curvas de nível do Teste 3 (Caso 6)

Repare que as condições de contorno internas na placa, fazem com que as suas regiões interfiram menos umas nas outras, isso pode ser visualizado nas Figuras 3.3 e 3.4, onde as regiões $\Omega_{1}$ e $\Omega_{3}$, que possuem fontes de calor, não interferem muito nas regiões $\Omega_{2}$ e $\Omega_{4}$, que não possuem fontes de calor. A temperatura máxima alcançada pela placa foi 0.0075 e a mínima de -0.0135 , era esperado que o valor mínimo fosse maior em módulo do que o valor máximo, 
dado que a fonte de calor negativa está na região $\Omega_{1}$, de maior valor de $\sigma$ do que a região $\Omega_{3}$, onde está a fonte de calor positiva.

Caso 7: Usamos a fonte de calor constante como em (3-13). A Figura 3.5 apresenta a evolução da solução obtida em quatro diferentes tempos, através de um gráfico de temperatura por posição. E a Figura 3.6 ilustra as correspondentes curvas de nível.
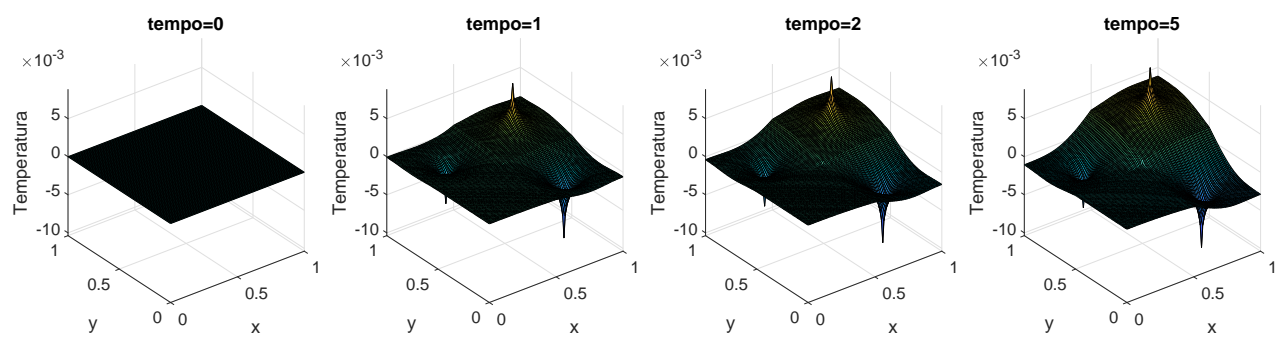

Figura 3.5: Teste 3 (Caso 7)
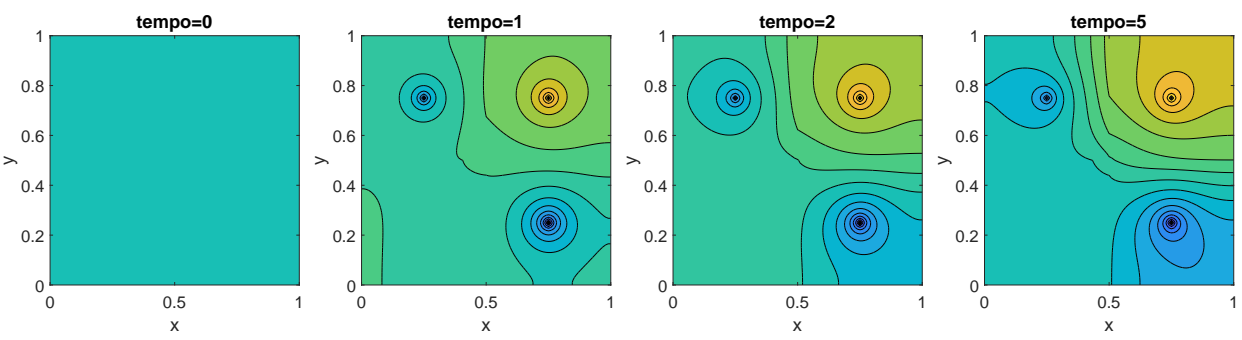

Figura 3.6: Curvas de nível do Teste 3 (Caso 7)

Nesse caso, perceba novamente que as condições de contorno internas na placa fazem com que as regiões interfiram pouco umas nas outras, dado que a região $\Omega_{3}$, que não possui nenhuma fonte de calor, quase não é afetada na solução, como pode ser notado nas Figuras 3.5 e 3.6. A temperatura máxima alcançada pela placa foi 0.0088 e a mínima foi -0.0104 .

Caso 8: Usamos a fonte de calor constante como em (3-14). A Figura 3.7 apresenta a evolução da solução obtida em quatro diferentes tempos, através de um gráfico de temperatura por posição. E a Figura 3.8 ilustra as correspondentes curvas de nível. 

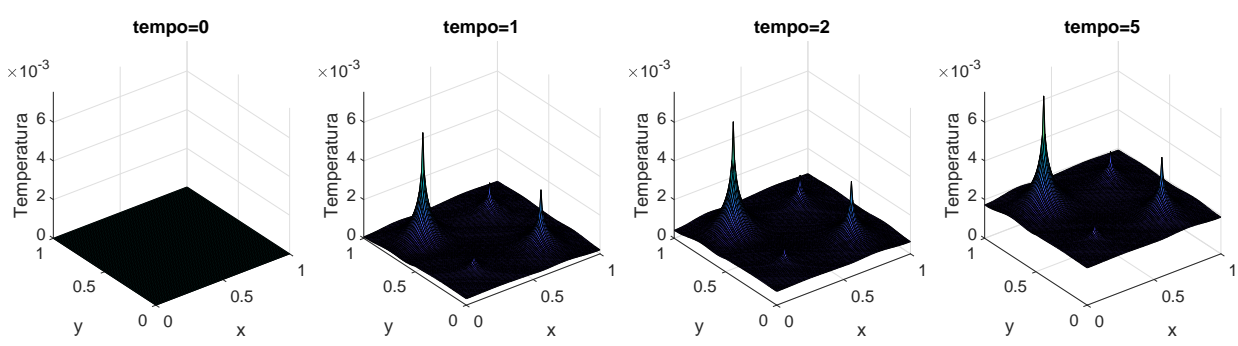

Figura 3.7: Teste 3 (Caso 8)
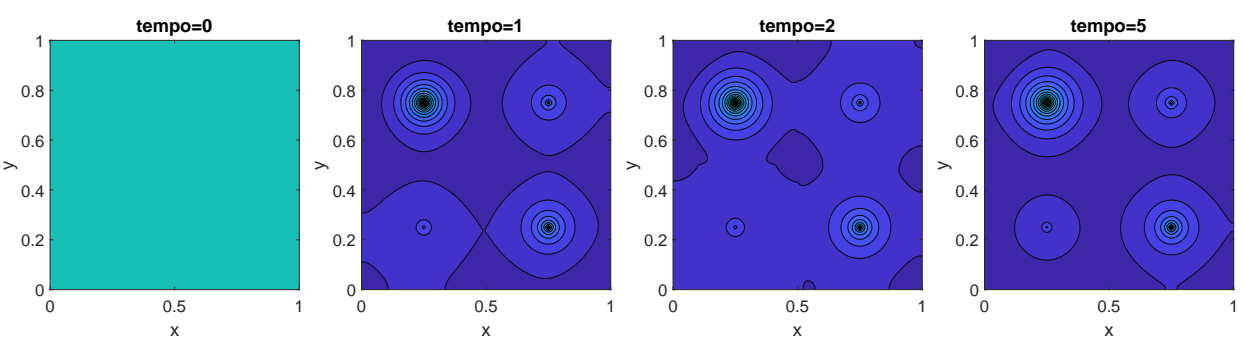

Figura 3.8: Curvas de nível do Teste 3 (Caso 8)

Esse caso mostra como o valor de $\sigma$ de cada região está sendo respeitado pela solução, pois no centro de todas as regiões, estão posicionadas fontes de calor de mesmo valor. Repare na Figura 3.7 como está em ordem crescente os bicos da região $\Omega_{2}, \Omega_{4}, \Omega_{3}$ e $\Omega_{1}$, que é a mesma ordem crescente dos valores de $\sigma$ de cada região. Isso pode ser observado também na Figura 3.8, onde essa mesma ordem crescente ocorre para a quantidade de curvas de nível em cada região. A solução então cresce indifinidamente, tendo um comportamento semelhante ao da solução no caso 1, Teste 1. A temperatura máxima alcançada pela placa foi 0.0075 , e a mínima 0 , como era esperado. Note também que como nesse caso não temos o termo fonte de calor variável $s$, então aparecem os bicos de temperatura na solução, o que não ocorre quando temos $s$ sendo a função seno.

Caso 9: Usamos a fonte de calor constante como em (3-15). A Figura 3.9 apresenta a evolução da solução obtida em quatro diferentes tempos, através de um gráfico de temperatura por posição. E a Figura 3.10 ilustra as correspondentes curvas de nível. 

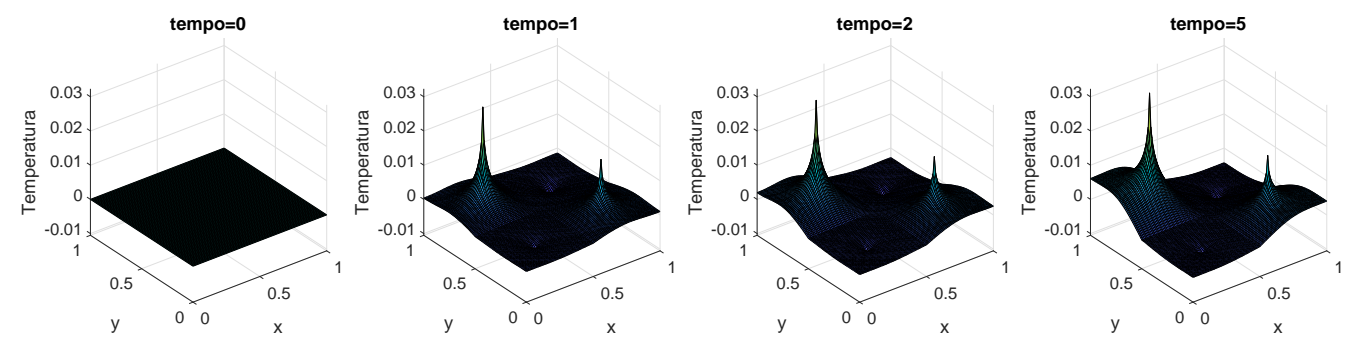

Figura 3.9: Teste 3 (Caso 9)
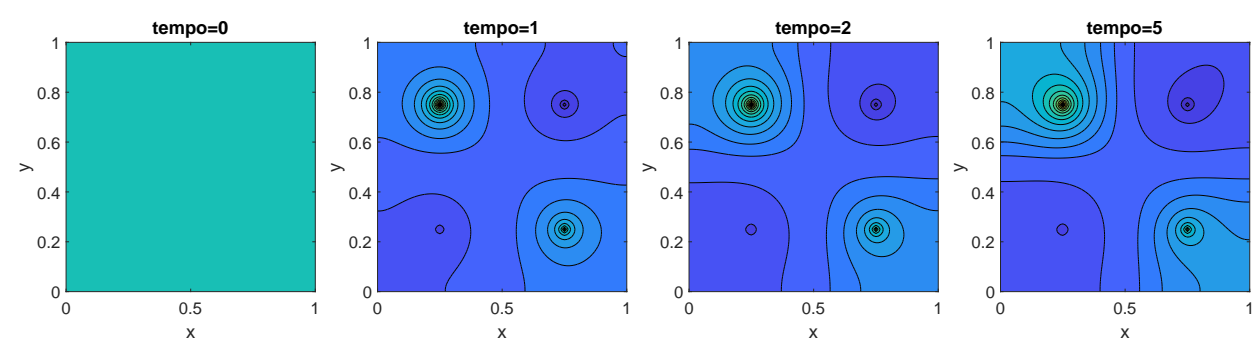

Figura 3.10: Curvas de nível do Teste 3 (Caso 9)

A temperatura máxima alcançada pela placa foi 0.0322 e a mínima -0.0105, como era esperado a temperatura máxima foi maior, em módulo, do que a mínima, dado que as fontes de calor positivas estão nas regiões de maior valor de $\sigma$ e as negativas na de menor valor de $\sigma$. Observe nas Figuras 3.9 e 3.10, como é pouca a interferência de uma região com outra quando temos as condições internas na placa.

\subsection{2}

Teste 4: Equação do Calor não-linear com termo fonte variável e constante na placa heterogênea com condições de contorno internas

Em todos os casos usamos os dados: $L=1, s(U)=\sin (\pi U), f(x, y)=$ $0, \Delta x=0.001, \Delta t=0.025$ e a dimensão do problema é $n^{2}=99^{2}=9801$.

Caso 6: Usamos a fonte de calor constante como em (3-12). A Figura 3.11 apresenta a evolução da solução obtida em quatro diferentes tempos, através de um gráfico de temperatura por posição. A Figura 3.12 ilustra as correspondentes curvas de nível e a Figura 3.13 o gráfico $\|\mathcal{E}(k)\| \times t$ em escala logarítmica. 

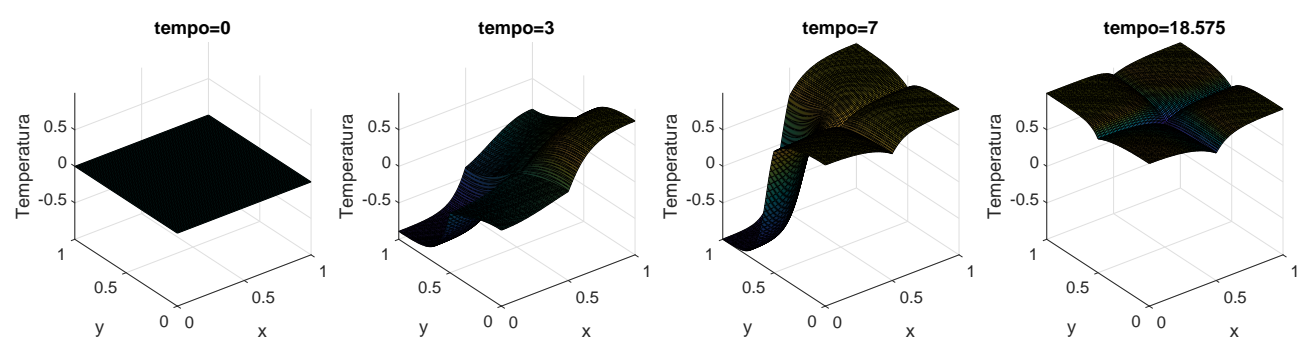

Figura 3.11: Teste 4 (Caso 6)
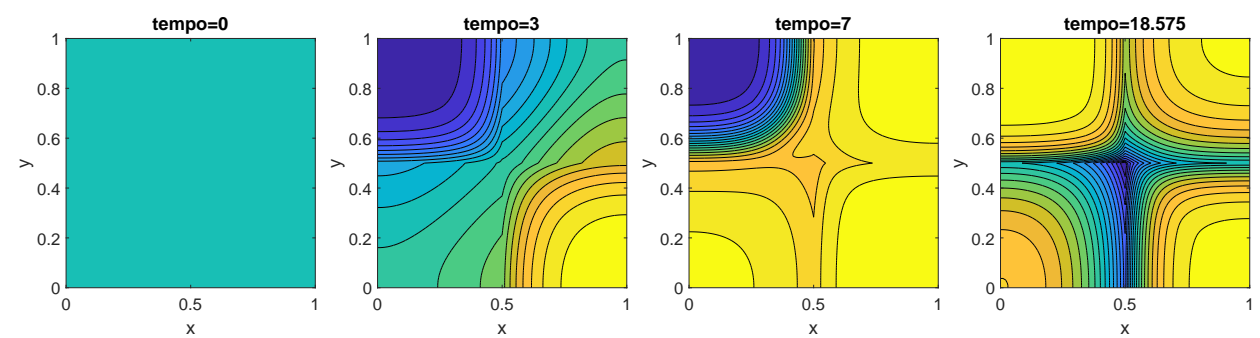

Figura 3.12: Curvas de nível do Teste 4 (Caso 6)

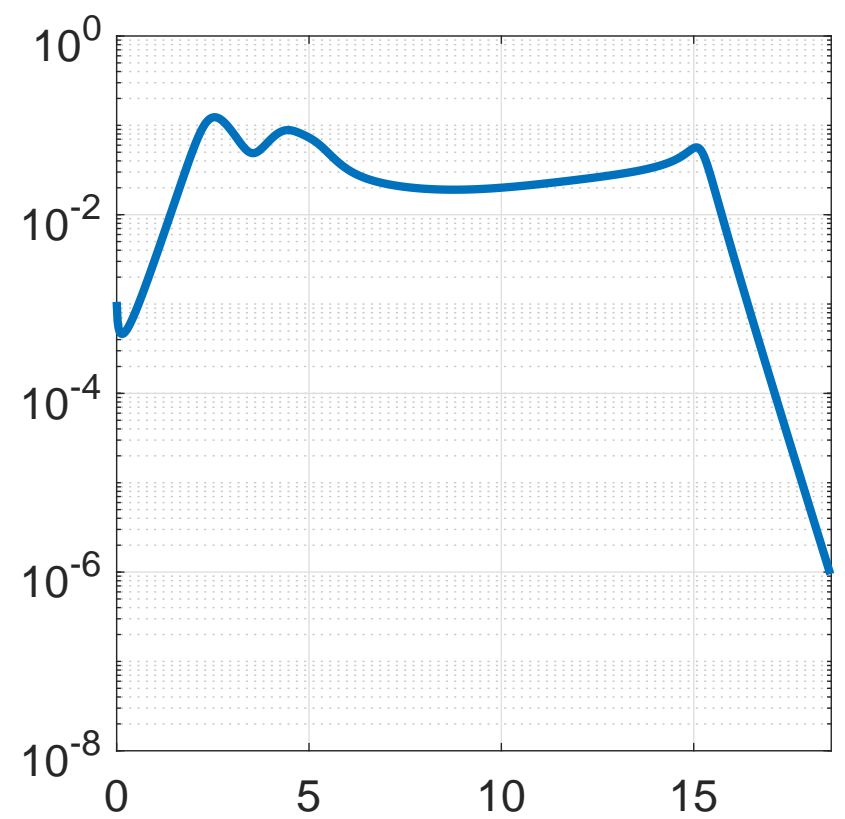

Figura 3.13: Variação $\|\mathcal{E}(k)\|$ do Teste 4 (Caso 6)

Perceba agora que como temos uma fonte de calor variável $s$, e ela tem a função seno em sua definição, que é uma função contínua, então não mais aparecem bicos na solução, como aparecem nesse mesmo caso no Teste 3. Note também que as condições de contorno internas na placa ficam evidentes na solução e em suas curvas de nível, como podemos observar nas Figuras 3.11 e 3.12, fato que também não ocorre nesse mesmo caso no Teste 3 , isso se da por causa da fonte de calor variável $s$. A temperatura máxima alcançada pela 
Capítulo 3. Equação do Calor com Termo Fonte em uma Placa Heterogênea55

placa foi 0.9997 e a mínima -0.9985. A solução chega ao equilíbrio, dado que a variação é decrescente respeitando a tolerância imposta de $10^{-6}$, como pode ser visto na Figura 3.13.

Caso 7: Usamos a fonte de calor constante como em (3-13). A Figura 3.14 apresenta a evolução da solução obtida em quatro diferentes tempos, através de um gráfico de temperatura por posição. A Figura 3.15 ilustra as correspondentes curvas de nível e a Figura 3.16 o gráfico $\|\mathcal{E}(k)\| \times t$ em escala logarítmica.
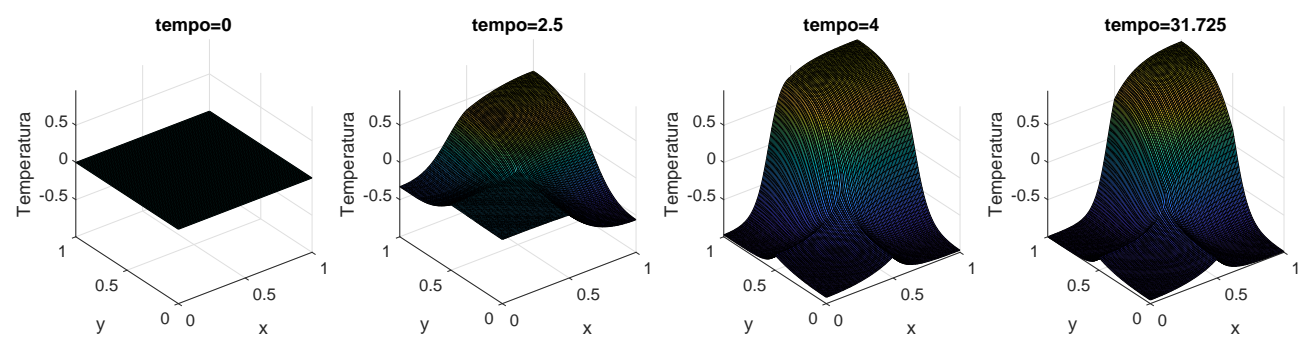

Figura 3.14: Teste 4 (Caso 7)
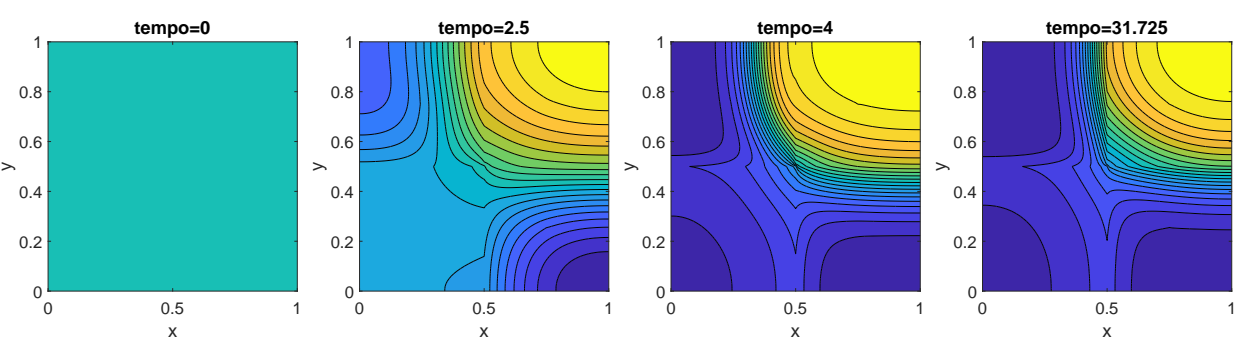

Figura 3.15: Curvas de nível do Teste 4 (Caso 7) 


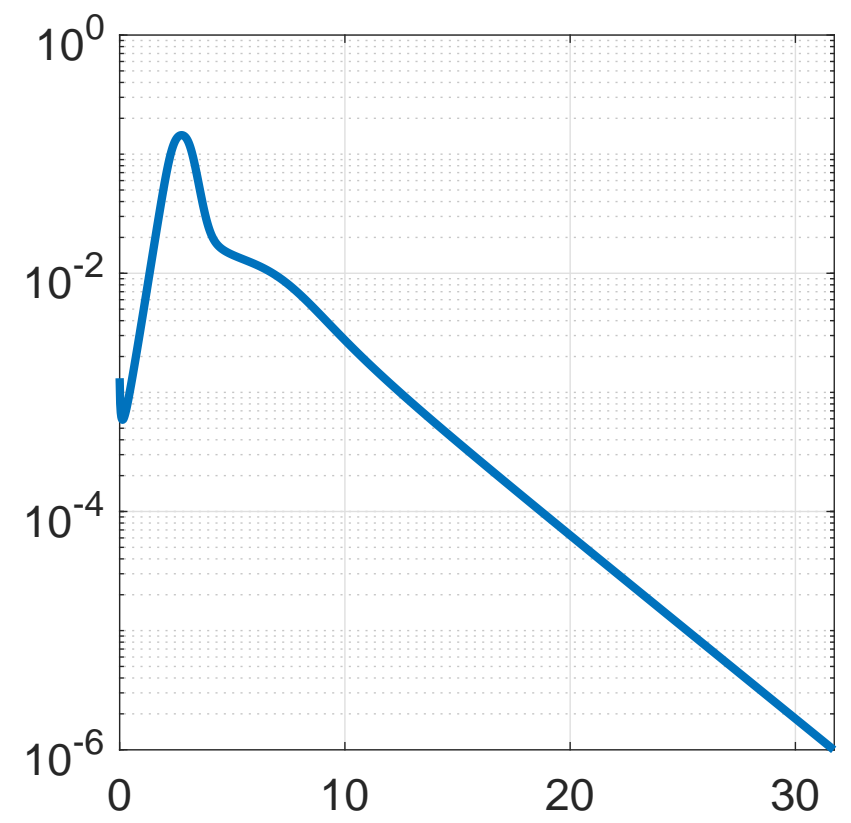

Figura 3.16: Variação $\|\mathcal{E}(k)\|$ do Teste 4 (Caso 7)

Como ocorreu nesse mesmo caso no Teste 3 , a região $\Omega_{2}$ que não possui nenhuma fonte de calor, pouco é afetada pelas outras regiões, todas com fontes de calor, como podemos observar nas Figuras 3.14 e 3.15 isso se da por causa das condições de contorno internas na placa. A temperatura máxima alcançada pela placa foi 0.9623 e a mínima -0.9979 e a solução chega ao equilíbrio como pode ser visto na Figura 3.16, onde a variação decresce.

Caso 8: Usamos a fonte de calor constante como em (3-14). A Figura 3.17 apresenta a evolução da solução obtida em quatro diferentes tempos, através de um gráfico de temperatura por posição. A Figura 3.18 ilustra as correspondentes curvas de nível e a Figura 3.19 o gráfico $\|\mathcal{E}(k)\| \times t$ em escala logarítmica.
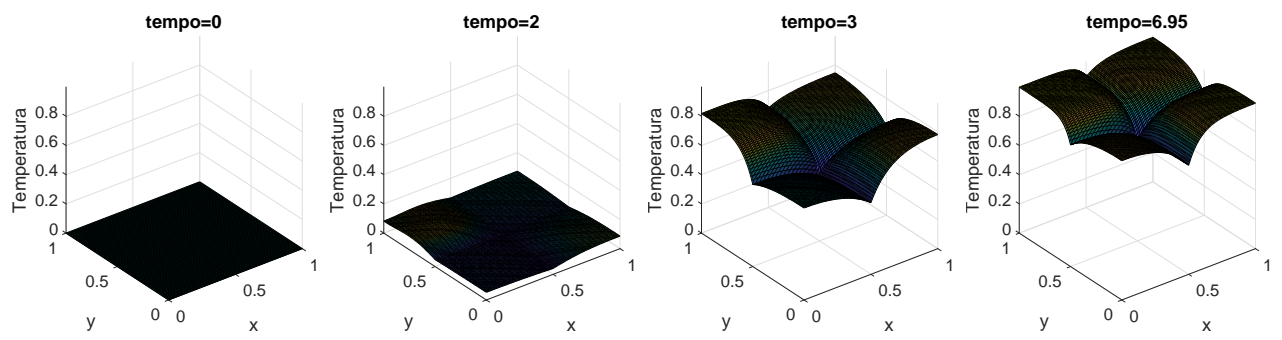

Figura 3.17: Teste 4 (Caso 8) 

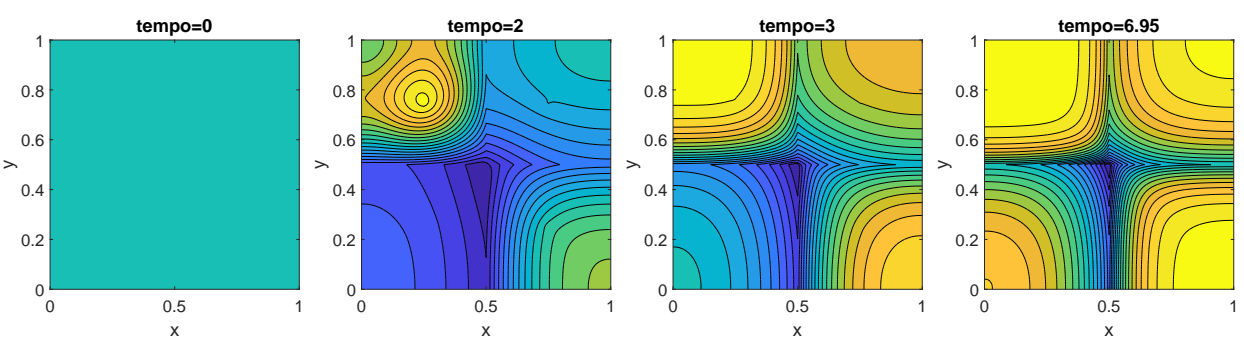

Figura 3.18: Curvas de nível do Teste 4 (Caso 8)

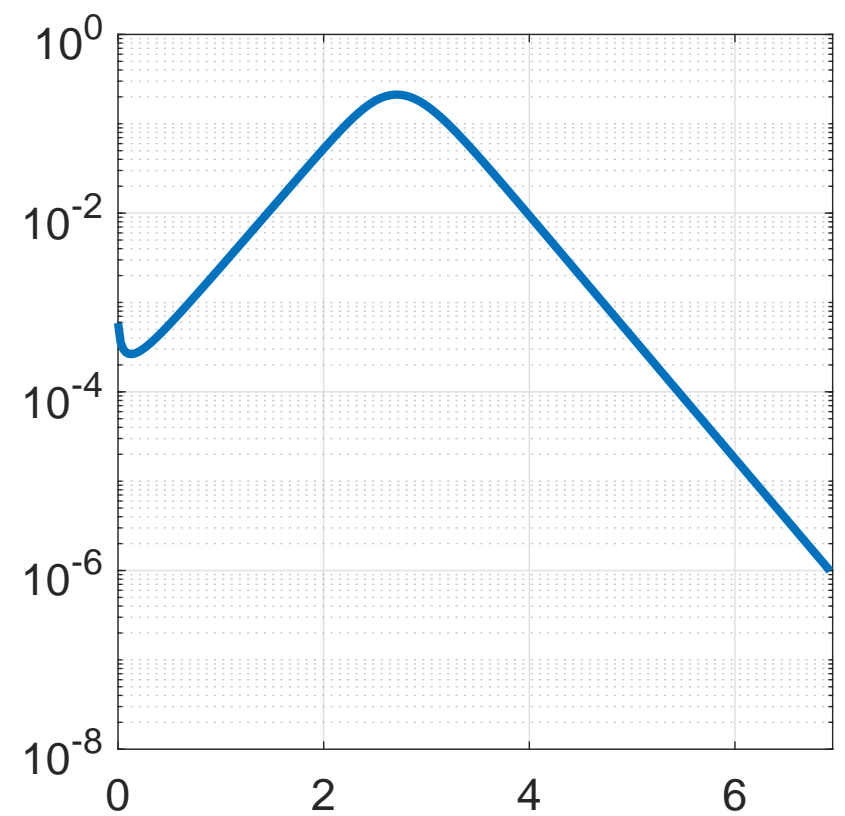

Figura 3.19: Variação $\|\mathcal{E}(k)\|$ do Teste 4 (Caso 8)

Pelo efeito da função seno no termo fonte de calor variável $s$, a solução nesse caso chega ao equilíbrio, como podemos observar na Figura 3.19, fato que não ocorre nesse mesmo caso no Teste 3. Note novamente que as condições de contorno internas na placa ficam evidentes na solução e em suas curvas de nível como pode ser visto nas Figuras 3.17 e 3.18, isso ocorre devido a fonte de calor variável $s$, visto que esse fato não ocorreu em nenhum caso do Teste 3. A temperatura máxima alcançada pela placa foi 0.9998 , maior do que a desse mesmo caso no Teste 3 , e a mínima 0 , ambos valores esperados, dado que a temperatura inicial da placa é zero e a solução chega ao equilíbrio próximo de 1.

Caso 9: Usamos a fonte de calor constante como em (3-15). A Figura 3.20 apresenta a evolução da solução obtida em quatro diferentes tempos, através de um gráfico de temperatura por posição. A Figura 3.21 ilustra as 
correspondentes curvas de nível e a Figura 3.22 o gráfico $\|\mathcal{E}(k)\| \times t$ em escala logarítmica.
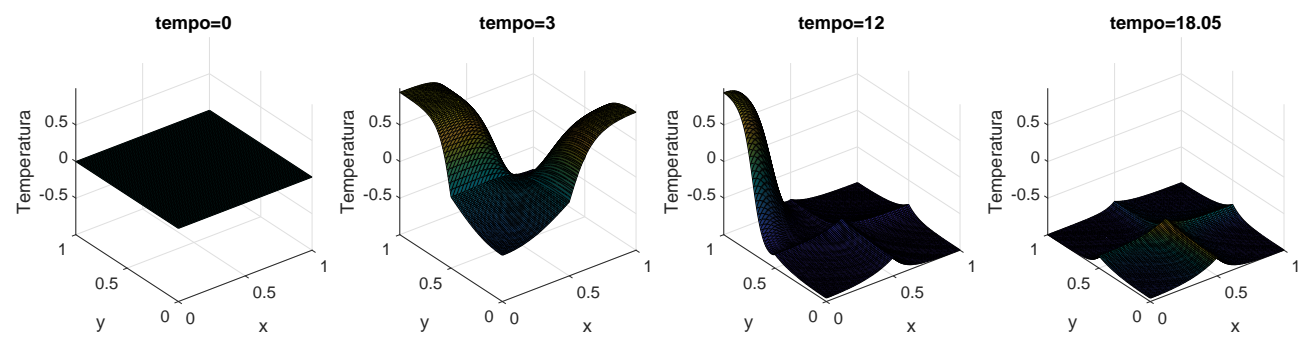

Figura 3.20: Teste 4 (Caso 9)
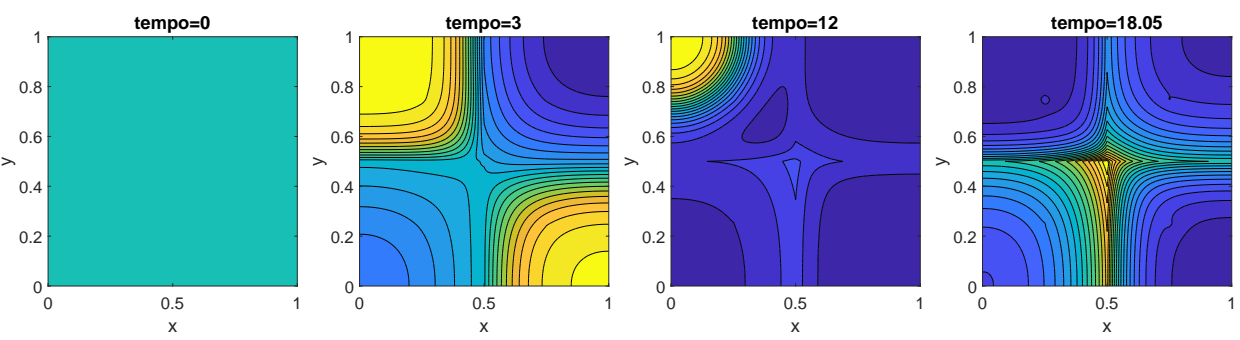

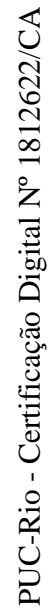

Figura 3.21: Curvas de nível do Teste 4 (Caso 9)

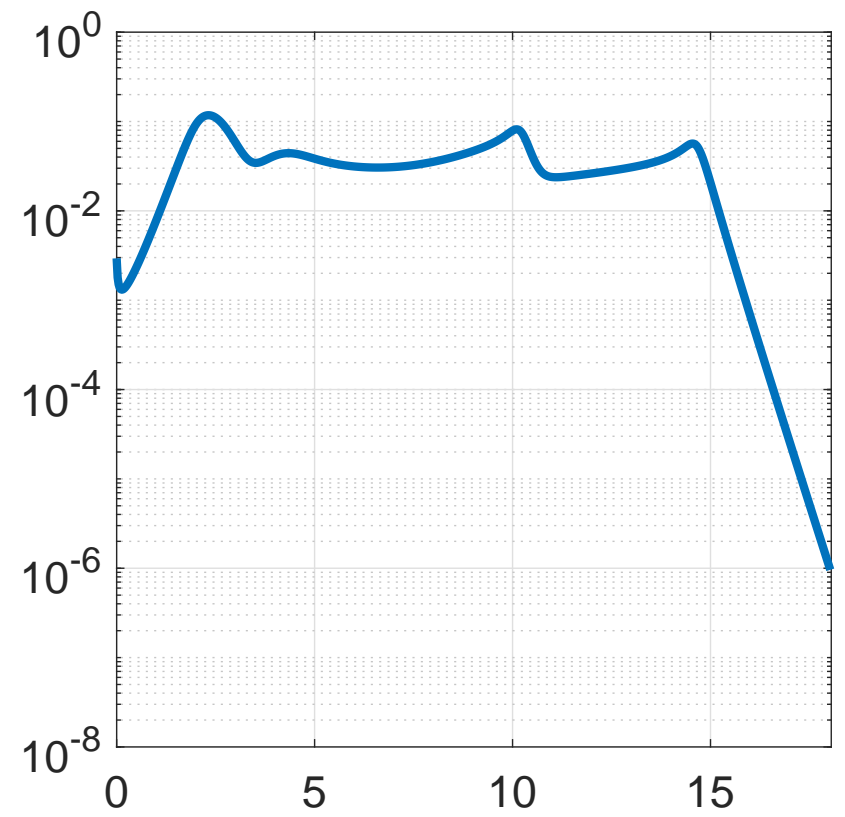

Figura 3.22: Variação $\|\mathcal{E}(k)\|$ do Teste 4 (Caso 9)

Repare que pelo efeito da função seno no termo fonte de calor variável, não há bicos na solução, e podemos perceber nas Figuras 3.20 e 3.21 que as condições de contorno internas na placa ficam evidentes na solução e em suas curvas de nível. Diferentemente desse mesmo caso no teste anterior, a 
Capítulo 3. Equação do Calor com Termo Fonte em uma Placa Heterogênea59

solução chega ao equilíbrio, como pode ser observado na Figura 3.22, visto que a variação decresce respeitando a tolerância de $10^{-6}$ imposta. A temperatura máxima alcançada pela placa foi 0.9966 e a mínima -0.9997. 


\section{4}

\section{Escoamento bifásico de água e óleo}

Nesse capítulo abordaremos a produção de óleo em um reservatório, resultante da injeção de água. Esse processo gera um escoamento imiscível bifásico, conhecido como produção no contexto da recuperação secundária. Escoamentos desse tipo são modelados com sistemas de equações diferenciais parciais não-lineares, muito semelhantes as equações do calor estudadas nos capítulos anteriores.

O objetivo do estudo sobre simuladores computacionais de reservatórios é conhecer informações sobre o comportamento dos fluidos, o que é útil para a indústria do petróleo durante o processo de produção de óleo.

Para realizar uma simulação do escoamento bifásico de fluídos, em reservatórios de petróleo, é preciso que conheçamos as propriedades das rochas, dos fluidos e das interações entre eles, visto que elas serão necessárias para a resolução das equações de balanço usadas na modelagem do escoamento águaóleo.

\section{1}

\section{Equações de conservação}

Como em Ertekin et al. (17), vamos considerar um escoamento bifásico isotérmico de fluidos imiscíveis, ou seja as propriedades não variam conforme a tempertura e não ocorre troca de massa entre água e óleo. As equações abaixo são usadas separadamente para cada fluido, a água e o óleo.

\subsection{1}

\section{Conservação de massa}

O princípio da conservação de massa é dado pela equação da continuidade, Ertekin et al. (17):

$$
\frac{\partial}{\partial t}(\phi \rho S)+\nabla \cdot(\rho v)-q_{m}=0,
$$

onde $\phi$ é a porosidade. A função $\rho$ representa a massa específica, $S$ a saturação, $q_{m}$ o termo fonte e $v$ a velocidade aparente. $\mathrm{O}$ valor de $q_{m}$ é representado como massa por unidade de tempo por unidade de volume e $v$ é a razão entre a vazão de escoamento e a área da seção transversal. 


\subsection{2}

\section{Conservação da quantidade de movimento}

Como estamos tratando de escoamentos multifasícos, a lei de Darcy clássica deve ser modificada, pois precisamos levar em conta a resistência ao escoamento devido à presença de mais fluidos, Ertekin et al. (17):

$$
v=\frac{-k_{r}}{\mu} K(\nabla p-\gamma \nabla Z)
$$

para um meio isotrópico, onde $K$ é o tensor de permeabilidade absoluta do meio poroso, que representa uma medida da facilidade para que um fluido escoe através de seus poros, e aqui será considerado como sendo diagonal, logo tem a forma:

$$
K=\left[\begin{array}{cc}
k_{x} & 0 \\
0 & k_{y}
\end{array}\right]
$$

Para $k_{x}, k_{y}$ sendo a permeabilidade absoluta nas direções $x, y$ e consideraremos que estamos num meio isotrópico, ou seja $k_{x}=k_{y}=k$, assim temos que $K=k$. Para os fluidos (água ou óleo) temos que $k_{r}$ representa a permeabilidade relativa, $\mu$ a viscosidade, $p$ a pressão e $\gamma=\rho g$, onde $g$ é a magnitude da aceleração da gravidade. O termo $\nabla Z$ é o gradiente de profundidade, mas como nossa simulação será em duas dimensões, o desconsideraremos, visto que ele é usado apena para simulações em três dimensões, assim a equação (4-2) se torna:

$$
v=\frac{-k_{r}}{\mu} K \nabla p
$$

\section{2}

\section{Equações de Transporte}

A partir das Equações (4-1) e (4-3), podemos obter uma equação de transporte para cada fluido (água ou óleo):

$$
\frac{\partial}{\partial t}(\phi \rho S)-q_{m}=\nabla \cdot\left(\rho \frac{-k_{r}}{\mu} K \nabla p\right)
$$

Na literatura, a formulação mais encontrada da Equação (4-4) é escrita separadamente para cada fluido, como em Ertekin et al. (17), usaremos o índice de letra $w$ para designar água, e o para óleo:

$$
\begin{gathered}
\frac{\partial}{\partial t}\left[\frac{\phi\left(1-S_{w}\right)}{B_{o}}\right]=\nabla \cdot\left(\frac{k_{r o}}{\mu_{o} B_{o}} K \nabla p_{o}\right)+q_{s c o} \\
\frac{\partial}{\partial t}\left[\frac{\phi S_{w}}{B_{w}}\right]=\nabla \cdot\left[\frac{k_{r w}}{\mu_{w} B_{w}} K\left(\nabla p_{o}-\nabla p_{c}\right)\right]+q_{s c w}
\end{gathered}
$$


Onde o índice $s c$ significa as condições-padrão, $B=\rho_{s c} / \rho$ é o fatorvolume-formação $(\mathrm{FVF}), q_{s c}=q_{m} / \rho_{s c}$, o índice $s c$ indica as condições padrão. Temos que $q_{\text {sco }}$ representa um poço produtor de óleo e $q_{s c w}$ representa um poço injetor de água. $p_{c}=p_{o}-p_{w}$ é a pressão capilar, e consideramos que o meio se encontra saturado, ou seja: $S_{w}+S_{o}=1$.

Em sistemas bifásicos, para se obter uma melhor aproximação de um caso real, as permeabilidades relativas são consideradas como funções da saturação da água $\left(S_{w}\right)$, Ezekwe (18), onde para a permeabilidade relativa da água temos que:

$$
k_{r w}\left(S_{w}\right)=k_{r w_{\max }}\left(\frac{S_{w}-S_{i w}}{1-S_{i w}-S_{\text {orw }}}\right)^{e w},
$$

e para a permeabilidade relativa do óleo:

$$
k_{\text {ro }}\left(S_{w}\right)=k_{\text {romax }_{\max }}\left(\frac{1-S_{w}-S_{\text {orw }}}{1-S_{\text {iw }}-S_{\text {orw }}}\right)^{\text {eow }}
$$

onde $S_{i w}$ representa a saturação irredutível da água e $S_{\text {orw }}$ a saturação residual do óleo. As constantes $k_{r w_{\max }}, k_{r_{o_{\max }}}$ e os expoentes ew, eow são determinados através de medições feitas em laboratórios ou por meio de dados experimentais obtidos para um determinado reservatório.

Também usamos leis de potência para a determinação da pressão capilar, como em Rosa et al. (16):

$$
p_{c}\left(S_{w}\right)=p_{c_{\max }}\left(\frac{1-S_{w}-S_{\text {orw }}}{1-S_{i w}-S_{\text {orw }}}\right)^{e p c}
$$

A constante $p_{c_{\max }}$ e o expoentes epc são determinados a partir de resultados de experimentos laboratoriais ou de dados de campo.

\section{3}

\section{Domínio, condições iniciais e de contorno}

Para solucionarmos o sistema composto pelas equações (4-5) e (4-6), utilizaremos como domínio a região $\Omega=[0, L] \times[0, L] \subset \mathbb{R}^{2}$, que representa nosso reservatório, onde faremos simulações.

Denotaremos a saturação da água e a pressão do óleo no ponto $(x, y) \in \Omega$, no instante de tempo $t$, por $S_{w}((x, y), t)$ e $p_{o}((x, y), t)$ respectivamente, assim $S_{w}, p_{o}: \Omega \times[0, T] \longrightarrow[0, \infty]$, onde $T \in \mathbb{R}, T>0$ representa o tempo final.

Além de definirmos o domínio, precisamos também de condições iniciais e de contorno associadas ao problema de escoamento. Assim, seja a pressão inicial do óleo e a saturação inicial da água dada pelas funções $f(x, y)$ e $g(x, y)$ respectivamente, em todo o domínio $\Omega$. E usaremos as condições de contorno de Dirichlet, para a saturação da água e pressão do óleo, como sendo zero na fronteira de $\Omega$. Assim temos definido o problema: 


$$
\left\{\begin{array}{l}
\frac{\partial}{\partial t}\left[\frac{\phi\left(1-S_{w}\right)}{B_{o}}\right]=\nabla \cdot\left[\frac{k_{r o}}{\mu_{o} B_{o}} K \nabla p_{o}\right]+q_{s c o} \\
\frac{\partial}{\partial t}\left[\frac{\phi S_{w}}{B_{w}}\right]=\nabla \cdot\left[\frac{k_{r w}}{\mu_{w} B_{w}} K\left(\nabla p_{o}-\nabla p_{c}\right)\right]+q_{s c w} \\
p_{o}((x, y), 0)=f(x, y), \quad(x, y) \in \Omega \\
S_{w}((x, y), 0)=g(x, y), \quad(x, y) \in \Omega \\
p_{o}=0, \quad(x, y) \in \partial \Omega, t \in[0, T] \\
S_{w}=0, \quad(x, y) \in \partial \Omega, t \in[0, T]
\end{array}\right.
$$

Utilizaremos aqui a mesma discretização do domínio espacial e temporal feitas no Capítulo 2, e de igual maneira adotaremos a notação $S_{w_{i, j}}^{k}$ e $p_{o_{i, j}}^{k}$, que representa o valor aproximado da solução exata $S_{w}\left(\left(x_{i}, y_{j}\right), t_{k}\right)$ e $p_{o}\left(\left(x_{i}, y_{j}\right), t_{k}\right)$, respectivamente.

\section{4}

\section{Aproximação Numérica}

Vamos resolver o sistema (4-10) pelo método das diferenças finitas, iniciando pela discretização de cada uma de suas equações, para isso iremos considerar constantes as permeabilidades relativas $k_{r o}$ e $k_{r w}$.

Precisaremos da discretização da condição de contorno de Dirichlet, para a pressão do óleo e saturação da água, como nosso domínio $\Omega$ é uma região quadrada, temos que a discretização da condição de contorno $p_{o}=0$ e $S_{w}=0$, em $(x, y) \in \partial \Omega, t \in[0, T]$ significa que os valores dos nós presentes nas extremidades do quadrado são zero, ou seja: para $j=n+1,0 \leq i \leq n+1$ :

$$
\begin{aligned}
& p_{o_{0, n+1}}^{k}=p_{o_{1, n+1}}^{k}=p_{o_{2, n+1}}^{k}=\cdots=p_{o_{n+1, n+1}}^{k}=0 \\
& S_{w_{0, n+1}}^{k}=S_{w_{1, n+1}}^{k}=S_{w_{2, n+1}}^{k}=\cdots=S_{w_{n+1, n+1}}^{k}=0
\end{aligned}
$$

Para $j=0,0 \leq i \leq n+1$ :

$$
\begin{aligned}
& p_{o_{0,0}}^{k}=p_{o_{1,0}}^{k}=p_{o_{2,0}}^{k}=\cdots=p_{o_{n+1,0}}^{k}=0 \\
& S_{w_{0,0}}^{k}=S_{w_{1,0}}^{k}=S_{w_{2,0}}^{k}=\cdots=S_{w_{n+1,0}}^{k}=0
\end{aligned}
$$

Para $i=n+1,0 \leq j \leq n+1$ :

$$
\begin{aligned}
& p_{o_{n+1,0}}^{k}=p_{o_{n+1,1}}^{k}=p_{o_{n+1,2}}^{k}=\cdots=p_{o_{n+1, n+1}}^{k}=0 \\
& S_{w_{n+1,0}}^{k}=S_{w_{n+1,1}}^{k}=S_{w_{n+1,2}}^{k}=\cdots=S_{w_{n+1, n+1}}^{k}=0
\end{aligned}
$$

Para $i=0,0 \leq j \leq n+1$ : 


$$
\begin{aligned}
& p_{o_{0}, 0}^{k}=p_{o_{0,1}}^{k}=p_{o_{0,2}}^{k}=\cdots=p_{o_{0, n+1}}^{k}=0 \\
& S_{w_{0,0}}^{k}=S_{w_{0,1}}^{k}=S_{w_{0,2}}^{k}=\cdots=S_{w_{0, n+1}}^{k}=0
\end{aligned}
$$

Começaremos com a discretização da primeira equação:

$$
\frac{\partial}{\partial t}\left[\frac{\phi\left(1-S_{w}\right)}{B_{o}}\right]=\nabla \cdot\left[\frac{k_{r o}}{\mu_{o} B_{o}} K \nabla p_{o}\right]+q_{s c o}
$$

Ao retirar as constantes das derivadas temos que:

$$
-\frac{\phi}{B_{o}} \frac{\partial S_{w}}{\partial t}=\frac{k_{r o} K}{\mu_{o} B_{o}} \Delta p_{o}+q_{s c o}
$$

Usando como discretização Euler implícito no tempo e diferenças centrais no espaço, obtemos:

$$
-\frac{\phi}{B_{o}} \frac{S_{w_{i, j}}^{k+1}-S_{w_{i, j}}^{k}}{\Delta t}=\frac{k_{r o} K}{\mu_{o} B_{o}} \frac{\left(p_{o_{i-1, j}}^{k}+p_{o_{i, j-1}}^{k}-4 p_{o_{i, j}}^{k}+p_{o_{i+1, j}}^{k}+p_{o_{i, j+1}}^{k}\right)}{\Delta x^{2}}+q_{s c o_{i, j}}
$$

Ao passar as constantes para o lado direito, vem:

$S_{w_{i, j}}^{k+1}-S_{w_{i, j}}^{k}=\frac{-k_{r o} K \Delta t}{\phi \mu_{o} \Delta x^{2}}\left(p_{o_{i-1, j}}^{k}+p_{o_{i, j-1}}^{k}-4 p_{o_{i, j}}^{k}+p_{o_{i+1, j}}^{k}+p_{o_{i, j+1}}^{k}\right)-\frac{q_{s c o_{i, j}} B_{o} \Delta t}{\phi}$

Definindo $\alpha:=\frac{-k_{r o} K \Delta t}{\phi \mu_{o} \Delta x^{2}}$ temos:

$$
S_{w_{i, j}}^{k+1}-S_{w_{i, j}}^{k}=\alpha\left(p_{o_{i-1, j}}^{k}+p_{o_{i, j-1}}^{k}-4 p_{o_{i, j}}^{k}+p_{o_{i+1, j}}^{k}+p_{o_{i, j+1}}^{k}\right)-\frac{q_{s c o_{i, j}} B_{o} \Delta t}{\phi}
$$

Ao fixar $k$, variar $i, j$ e aplicar as equações de contorno discretizadas para a pressão do óleo (4-11), (4-12), (4-13) e (4-14), obtemos a equação:

$$
S_{w}^{k+1}-S_{w}^{k}=\alpha A p_{o}^{k}-\frac{q_{s c o} B_{o} \Delta t}{\phi}
$$

Onde $A \in \mathbb{R}^{n^{2} \times n^{2}}$ é a matriz pentadiagonal que tem a forma:

$$
A=\left[\begin{array}{ccccccccc}
-4 & 1 & & 1 & & & & & \\
1 & -4 & 1 & & 1 & & & & \\
& 1 & -4 & 1 & & 1 & & & \\
1 & & 1 & -4 & 1 & & 1 & & \\
& \ddots & & \ddots & \ddots & \ddots & & \ddots & \\
& & 1 & & 1 & -4 & 1 & & 1 \\
& & & 1 & & 1 & -4 & 1 & \\
& & & & 1 & & 1 & -4 & 1 \\
& & & & & 1 & & 1 & -4
\end{array}\right]
$$

Com $S_{w}^{k+1}, p_{o}^{k}, q_{s c o} \in \mathbb{R}^{n^{2} \times 1}$ sendo as matrizes: 


$$
S_{w}^{k+1}=\left[\begin{array}{c}
S_{w_{1,1}}^{k+1} \\
S_{w_{1,2}}^{k+1} \\
\vdots \\
S_{w_{1, n}}^{k+1} \\
\vdots \\
S_{w_{n, n}}^{k+1}
\end{array}\right], p_{o}^{k}=\left[\begin{array}{c}
p_{o_{1,1}}^{k} \\
p_{o_{1,2}}^{k} \\
\vdots \\
p_{o_{1, n}}^{k} \\
\vdots \\
p_{o_{n, n}}^{k}
\end{array}\right] \quad, \quad q_{s c o}=\left[\begin{array}{c}
q_{s c o_{1,1}} \\
q_{s c o_{1,2}} \\
\vdots \\
q_{s c o_{1, n}} \\
\vdots \\
q_{s c o_{n, n}}
\end{array}\right]
$$

E assim podemos escrever a Equação (4-20) como:

$$
S_{w}^{k+1}=S_{w}^{k}+\alpha A p_{o}^{k}-\frac{q_{s c o_{i, j}} B_{o} \Delta t}{\phi}
$$

Agora, vamos tratar da discretização da segunda equação:

$$
\frac{\partial}{\partial t}\left[\frac{\phi S_{w}}{B_{w}}\right]=\nabla \cdot\left[\frac{k_{r w}}{\mu_{w} B_{w}} K\left(\nabla p_{o}-\nabla p_{c}\right)\right]+q_{s c w}
$$

Retirando as constantes das derivadas obtemos:

$$
\frac{\phi}{B_{w}} \frac{\partial S_{w}}{\partial t}=\frac{k_{r w} K}{\mu_{w} B_{w}}\left(\Delta p_{o}-\Delta p_{c}\right)+q_{s c w}
$$

Vamos usar como discretização, Euler implícito no tempo e diferenças centrais no espaço para a pressão do óleo, mas agora no tempo $k+1$, assim teremos a mesma discretização para $\Delta p_{o}$ obtida na primeira equação. $\mathrm{E}$ também vamos substituir a Equação (4-9) para a pressão capilar, usando o expoente $e p c=1$, assim temos que:

$$
\frac{\phi}{B_{w}} \frac{S_{w_{i, j}}^{k+1}-S_{w_{i, j}}^{k}}{\Delta t}=\frac{k_{r w} K}{\mu_{w} B_{w}}\left[\frac{1}{\Delta x^{2}} A p_{o}^{k+1}-\Delta p_{c_{m a x}}\left(\frac{1-S_{w}-S_{\text {orw }}}{1-S_{i w}-S_{\text {orw }}}\right)\right]+q_{s c w_{i, j}}
$$

Ao passar as constantes do lado esquerdo para o direito e retirar as constantes da derivada, vem que:

$$
S_{w_{i, j}}^{k+1}-S_{w_{i, j}}^{k}=\frac{k_{r w} K \Delta t}{\phi \mu_{w}}\left(\frac{1}{\Delta x^{2}} A p_{o}^{k+1}+\frac{p_{c_{\max }}}{1-S_{i w}-S_{\text {orw }}} \Delta S_{w}\right)+\frac{q_{s c w_{i, j}} B_{w} \Delta t}{\phi}
$$

Da mesma forma que discretizamos o termo $\Delta p_{o}$ na primeira equação, vamos usar diferenças centrais no espaço para discretizar o termo $\Delta S_{w}$, e tomemos $\tau=\frac{p_{c_{\max }}}{1-S_{i w}-S_{\text {orw }}}$, assim:

$$
\begin{aligned}
S_{w_{i, j}}^{k+1}-S_{w_{i, j}}^{k} & =\frac{k_{r w} K \Delta t}{\phi \mu_{w}}\left(\frac{1}{\Delta x^{2}} A p_{o}^{k+1}+\tau \frac{\left(S_{w_{i-1, j}}^{k}+S_{w_{i, j-1}}^{k}-4 S_{w_{i, j}}^{k}+S_{w_{i+1, j}}^{k}+S_{w_{i, j+1}}^{k}\right)}{\Delta x^{2}}\right)+ \\
& +\frac{q_{s c w_{i, j}} B_{w} \Delta t}{\phi}
\end{aligned}
$$


Seja $\beta=\frac{k_{r w} K \Delta t}{\phi \mu_{w} \Delta x^{2}}$ e $\zeta=\beta \tau$, dai:
$S_{w_{i, j}}^{k+1}-S_{w_{i, j}}^{k}=\beta A p_{o}^{k+1}+\zeta S_{w_{i-1, j}}^{k}+\zeta S_{w_{i, j-1}}^{k}-4 \zeta S_{w_{i, j}}^{k}+\zeta S_{w_{i+1, j}}^{k}+\zeta S_{w_{i, j+1}}^{k}+\frac{q_{s c w_{i, j}} B_{w} \Delta t}{\phi}$

Ao passar o termo $S_{w_{i, j}}^{k}$ para o lado direito, vem que:

$S_{w_{i, j}}^{k+1}=\beta A p_{o}^{k+1}+\zeta S_{w_{i-1, j}}^{k}+\zeta S_{w_{i, j-1}}^{k}+(1-4 \zeta) S_{w_{i, j}}^{k}+\zeta S_{w_{i+1, j}}^{k}+\zeta S_{w_{i, j+1}}^{k}+\frac{q_{s c w_{i, j}} B_{w} \Delta t}{\phi}$

Ao fixar $k$, variar $i, j$ e aplicar as equações de contorno discretizadas para a saturação da água (4-11), (4-12), (4-13) e (4-14), obtemos a equação:

$$
S_{w}^{k+1}=\beta A p_{o}^{k+1}+B S_{w}^{k}+\frac{q_{s c w} B_{w} \Delta t}{\phi}
$$

onde $B \in \mathbb{R}^{n^{2} \times n^{2}}$ é a matriz pentadiagonal que tem a forma:

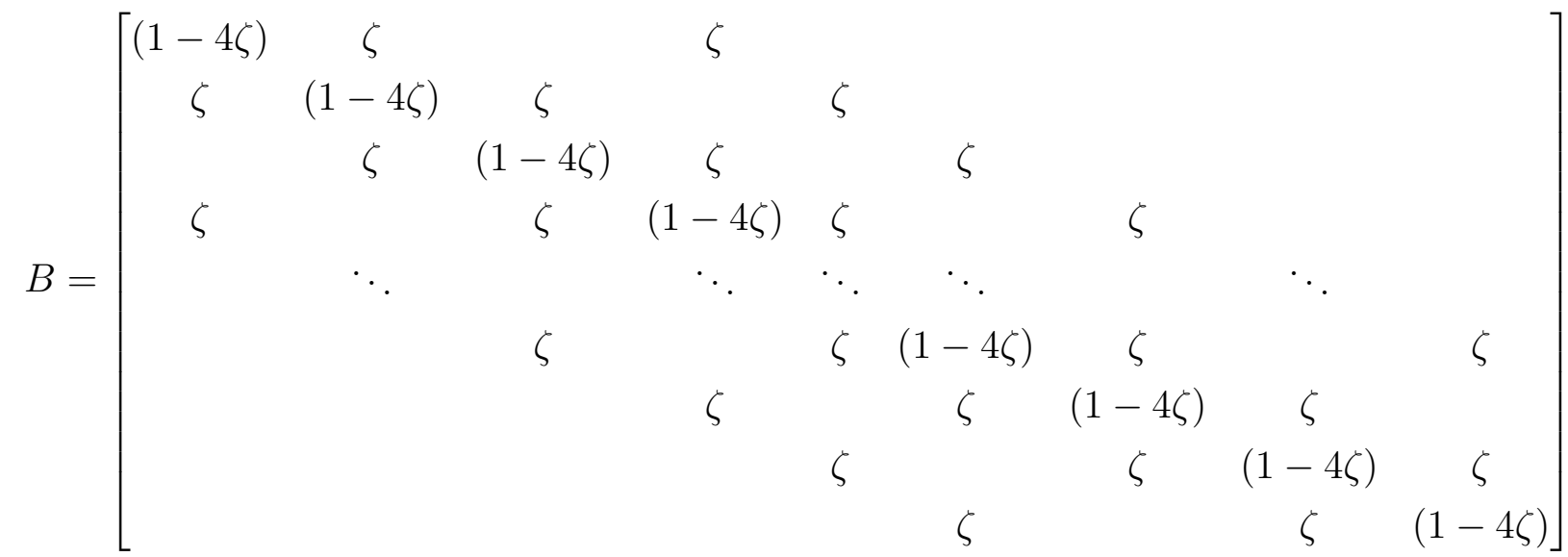

Onde $q_{s c w} \in \mathbb{R}^{n^{2} \times 1}$ é a matriz:

$$
q_{s c w}=\left[\begin{array}{c}
q_{s c w_{1,1}} \\
q_{s c w_{1,2}} \\
\vdots \\
q_{s c w_{1, n}} \\
\vdots \\
q_{s c w_{n, n}}
\end{array}\right]
$$

E assim podemos escrever a equação (4-29) como:

$$
\beta A p_{o}^{k+1}=S_{w}^{k+1}-B S_{w}^{k}-\frac{q_{s c w} B_{w} \Delta t}{\phi}
$$

Portanto nosso problema (4-10) discretizado tem a forma: 


$$
\left\{\begin{array}{l}
S_{w}^{k+1}=S_{w}^{k}+\alpha A p_{o}^{k}-\frac{q_{s c o_{i, j}} B_{o} \Delta t}{\phi} \\
\beta A p_{o}^{k+1}=S_{w}^{k+1}-B S_{w}^{k}-\frac{q_{s c w} B_{w} \Delta t}{\phi} \\
p_{o_{i, j}}^{0}=f\left(x_{i}, y_{j}\right), \quad 0 \leq i, j \leq n+2 \\
S_{w_{i, j}}^{0}=g\left(x_{i}, y_{j}\right), \quad 0 \leq i, j \leq n+2
\end{array}\right.
$$

Para encontrarmos a solução numérica do problema (4-31), vamos usar o método IMPES (Implicit Pressure Explicit Saturation), em Kou e Sun (8), onde tratamos as equações desacopladas, resolvendo implicitamente para a pressão do óleo e explicitamente para a saturação da água, como em Coats (19). Por calcular a saturação da água explicitamente e solucionar separadamente as equações, esse método apresenta um baixo custo computacional por iteração, porém pode apresentar problemas de estabilidade numérica.

\subsection{1}

\section{Experimentos Numéricos}

Vamos realizar experimentos numéricos resolvendo o problema (4-10), utilizando diferentes tipos de termos fontes $q_{s c o}$ e $q_{s c w}$, usamos três casos, são eles:

Caso 10:

$$
\begin{aligned}
q_{\text {sco }}(x, y) & =\left\{\begin{array}{lc}
50, & (x, y)=(0.1,0.1) \\
0, & \text { c.c. }
\end{array}\right. \\
q_{\text {scw }}(x, y) & = \begin{cases}-50, & (x, y)=(0.9,0.9) \\
0, & \text { c.c. }\end{cases}
\end{aligned}
$$

Caso 11:

$$
\begin{gathered}
q_{\text {sco }}(x, y)=\left\{\begin{array}{lc}
40, & (x, y)=(0.5,0.5) \\
0, & \text { c.c. }
\end{array}\right. \\
q_{\text {scw }}(x, y)= \begin{cases}-10, & (x, y)=(0.1,0.9) \\
-10, & (x, y)=(0.1,0.1) \\
-10, & (x, y)=(0.9,0.1) \\
-10, & (x, y)=(0.9,0.9) \\
0, & \text { c.c. }\end{cases}
\end{gathered}
$$

Caso 12:

$$
q_{\text {sco }}(x, y)= \begin{cases}10, & (x, y)=(0.1,0.9) \\ 10, & (x, y)=(0.1,0.1) \\ 10, & (x, y)=(0.9,0.1) \\ 10, & (x, y)=(0.9,0.9) \\ 0, & \text { c.c. }\end{cases}
$$




$$
q_{s c w}(x, y)=\left\{\begin{array}{lc}
-40, & (x, y)=(0.5,0.5) \\
0, & \text { c.c. }
\end{array}\right.
$$

Caso 13:

$$
\begin{aligned}
& q_{\text {sco }}(x, y)=\left\{\begin{array}{lc}
10, & (x, y)=(0.1,0.9) \\
10, & (x, y)=(0.3,0.9) \\
10, & (x, y)=(0.5,0.9) \\
10, & (x, y)=(0.7,0.9) \\
10, & (x, y)=(0.9,0.9) \\
0, & \text { c.c. }
\end{array}\right. \\
& q_{s c w}(x, y)= \begin{cases}-10, & (x, y)=(0.1,0.1) \\
-10, & (x, y)=(0.3,0.1) \\
-10, & (x, y)=(0.5,0.1) \\
-10, & (x, y)=(0.7,0.1) \\
-10, & (x, y)=(0.9,0.1) \\
0, & \text { c.c. }\end{cases}
\end{aligned}
$$

Avaliamos a variação para a pressão do óleo e saturação da água da mesma maneira feita no capítulo dois.

Usamos os dados: $L=1, \Delta x=0.0625, \Delta t=0.0005, K=1 \cdot 10^{-11}$, $S_{i w}=0.1 \cdot 10^{-3}, S_{n r w}=0.25 \cdot 10^{-3}, k_{r n}=0.7 \cdot 10^{-3}, k_{r w}=0.3 \cdot 10^{-3}$, $\phi=0.3 \cdot 10^{-3}, \mu_{n}=2.0 \cdot 10^{-3}, \mu_{w}=0.5 \cdot 10^{-3}, B_{o}=1.5 \cdot 10^{-3}, B_{w}=1 \cdot 10^{-3}$, $p_{c_{\max }}=0.8 \cdot 10^{6}, f(x, y)=10^{7}|\operatorname{sen}(\pi x) \operatorname{sen}(\pi y)|, g(x, y)=\frac{|\operatorname{sen}(\pi x) \operatorname{sen}(\pi y)|}{2} \mathrm{e}$ a dimensão do problema é $n^{2}=15^{2}=225$.

O tempo final para cada caso foi analisado separadamente.

Caso 10: Usamos os termos fontes como em (4-32) e (4-33). As Figuras 4.1 e 4.2 apresentam a evolução da solução obtida para a pressão do óleo e saturação da água em quatro diferentes tempos, através de um gráfico de temperatura por posição.
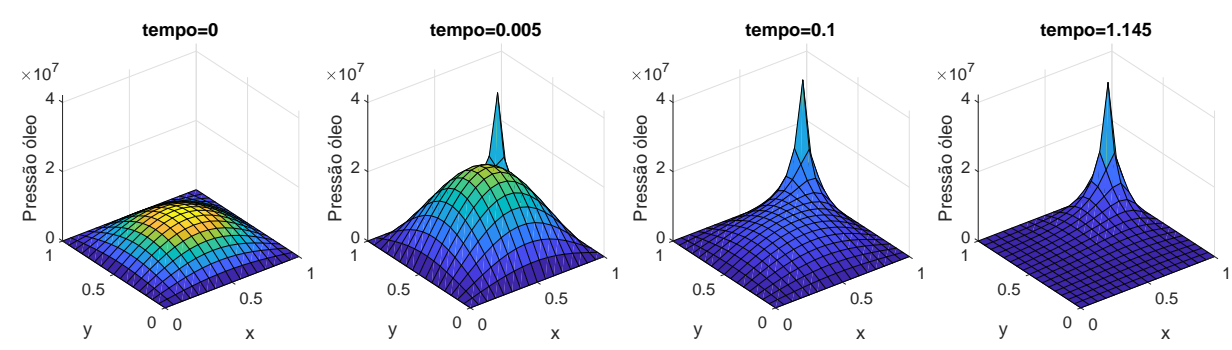

Figura 4.1: Pressão do óleo (Caso 10) 

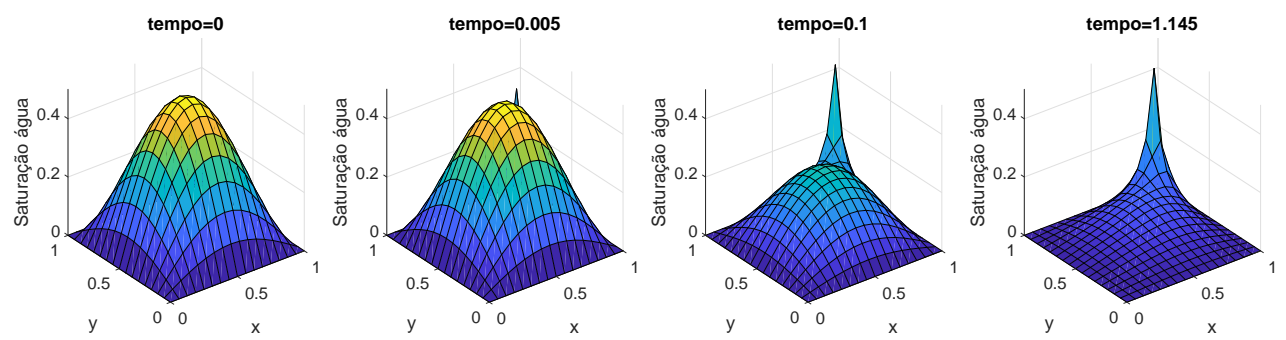

Figura 4.2: Saturação da água (Caso 10)

Nesse caso temos que os termos fontes proporcionam uma injeção de água na extremidade $(0.9,0.9)$ do reservatório, e produção de óleo na extremidade simétrica $(0.1,0.1)$. As soluções que obtivemos nas Figuras 4.1 e 4.2 são resultados esperados, onde com o passar do tempo, tanto a saturação da água quanto a pressão do óleo se concentram na parte do reservatório que está o poço injetor, pois a injeção de água no reservatório em determinado local, faz aumentar a saturação da água na região e consequentemente a pressão do óleo. Obtemos como valor máximo para a pressão do óleo $4.5896 \cdot 10^{7}$ e o mínimo 0 . Para a saturação da água, o valor máximo obtido foi 0.5011 e o mínimo 0. O tempo final obtido foi $T=1.145$.

Caso 11: Usamos os termos fontes como em (4-34) e (4-35). As Figuras 4.3 e 4.4 apresentam a evolução da solução obtida para a pressão do óleo e saturação da água em quatro diferentes tempos, através de um gráfico de temperatura por posição.
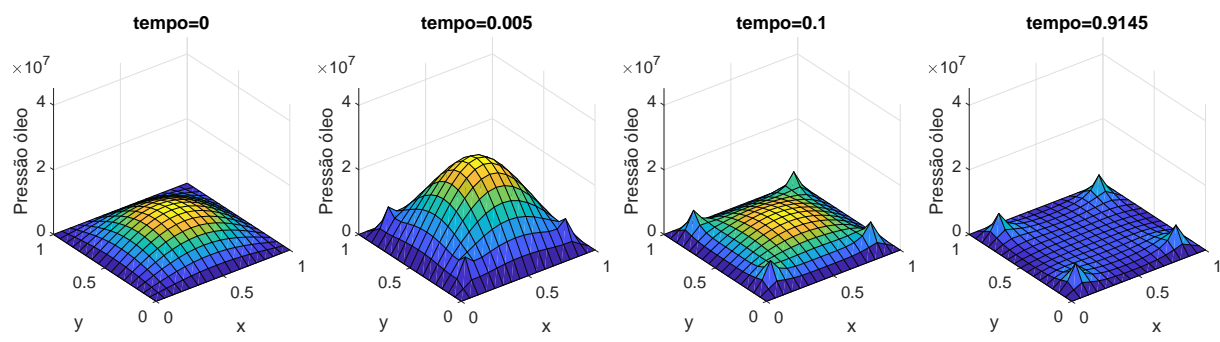

Figura 4.3: Pressão do óleo (Caso 11)
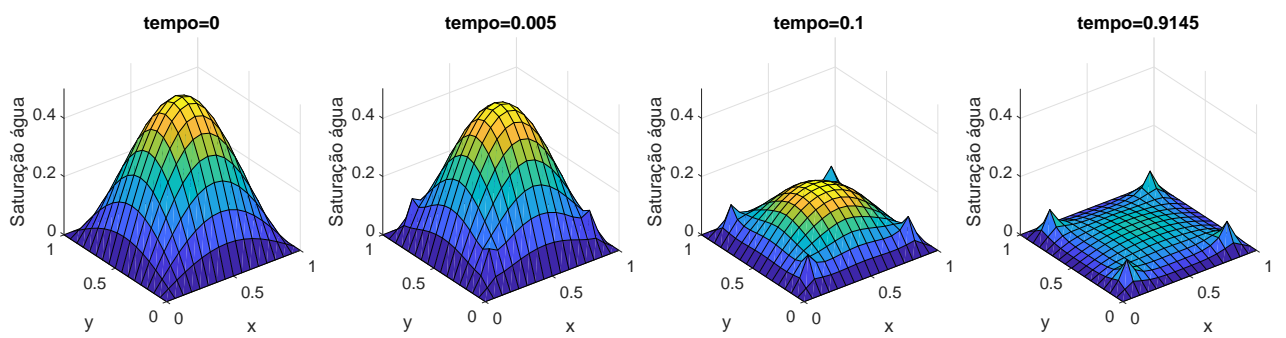

Figura 4.4: Saturação da água (Caso 11) 
Esse é o famoso esquema de produção conhecido como five-spot, onde no centro do reservatório temos um poço produtor e nas quatro extremidades poços injetores, com o passar do tempo, a pressão do óleo e saturação da água são maiores nas proximidades dos poços injetores, como era esperado, e podemos observar isso nas soluções nas Figuras 4.3 e 4.4. A pressão máxima do óleo que obtemos foi $4.5185 \cdot 10^{7}$, e a mínima 0 , para a saturação da água obtemos valor máximo 0.5011 e mínimo 0 . O tempo final obtido foi $T=0.9145$.

Caso 12: Usamos os termos fontes como em (4-37) e (4-36). As Figuras 4.5 e 4.6 apresentam a evolução da solução obtida para a pressão do óleo e saturação da água em quatro diferentes tempos, através de um gráfico de temperatura por posição.
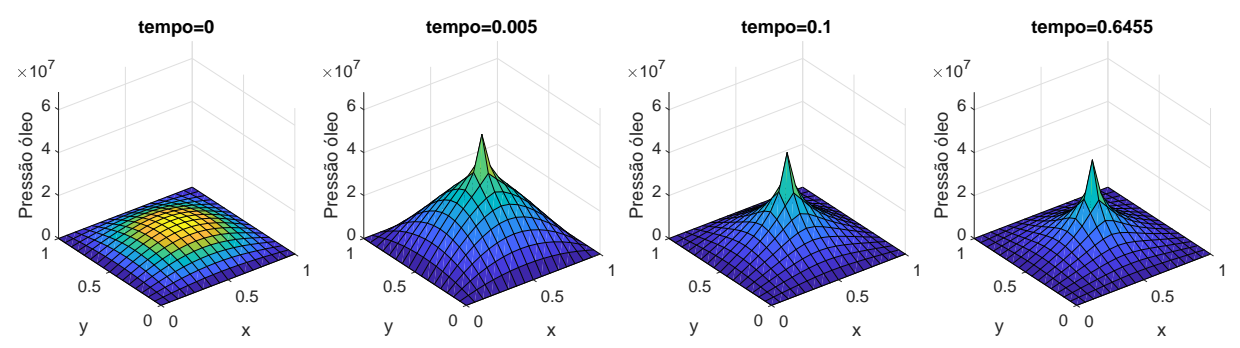

Figura 4.5: Pressão do óleo (Caso 12)
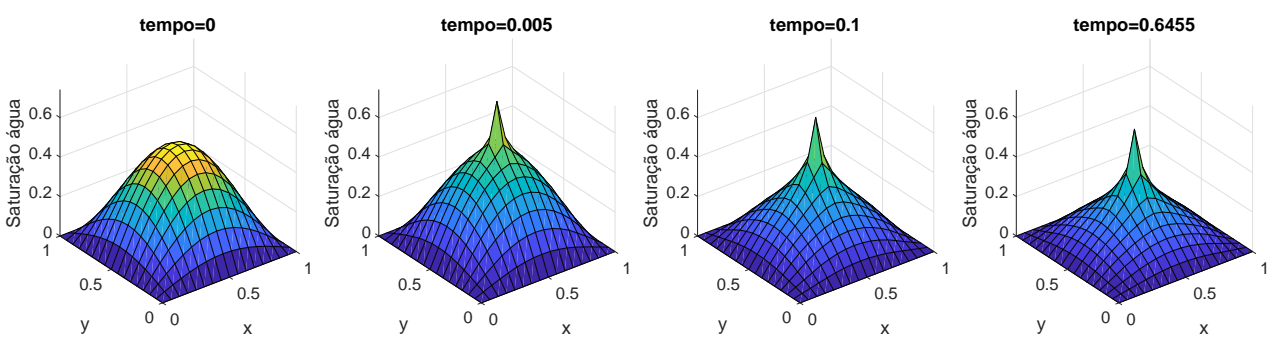

Figura 4.6: Saturação da água (Caso 12)

Muito semelhante ao caso anterior, esse esquema é conhecido como fivespot invertido, porque para obtê-lo basta apenas trocar os poços injetores por produtores e vice-versa, no esquema five-spot. Isso fica claro ao observarmos as soluções nas Figuras 4.5 e 4.6, onde no decorrer do tempo a pressão do óleo e saturação da água se concentram no centro do reservatório, onde está situado o poço injetor. A pressão máxima do óleo obtida foi $6.8022 \cdot 10^{7}$ e a mínima 0. A saturação da água alcançou seu valor máximo em 0.7399 e mínimo 0. O tempo final obtido foi $T=0.6455$.

Caso 13: Usamos os termos fontes como em (4-38) e (4-39). As Figuras 4.7 e 4.8 apresentam a evolução da solução obtida para a pressão do óleo e saturação 
da água em quatro diferentes tempos, através de um gráfico de temperatura por posição.
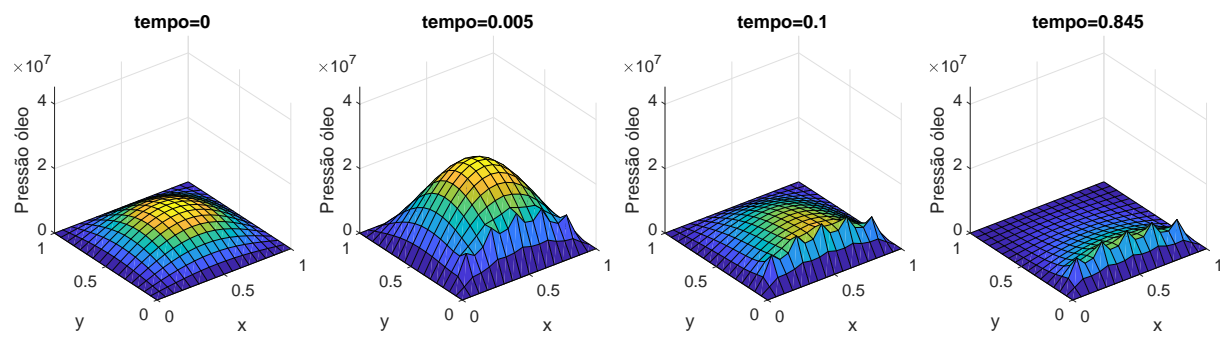

Figura 4.7: Pressão do óleo (Caso 13)
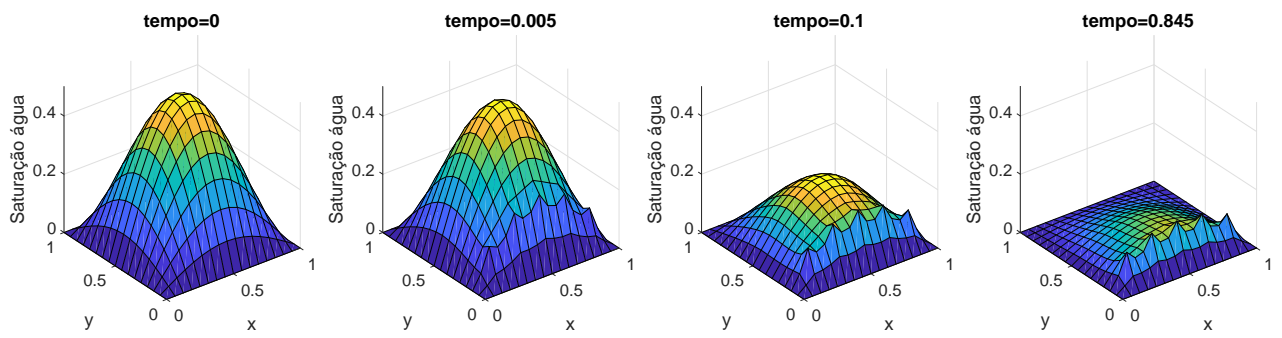

Figura 4.8: Saturação da água (Caso 13)

Esse caso também apresenta um esquema de produção famoso, conhecido como injeção em linha, onde em uma das extremidades do reservatório, nesse caso na extremidade sul, estão os poços injetores, injetando água, e na extremidade oposta, norte, os poços produtores, produzindo óleo, como pode ser observado na solução nas Figuras 4.7 e 4.8, onde notamos também que no decorrer do tempo a pressão do óleo e a saturação da água se comportam como esperado, se concentrando próximas da região onde estão os poços injetores. O valor máximo da pressão do óleo foi $4.5274 \cdot 10^{7}$ e o mínimo 0. Para a saturação da água, o valor máximo foi 0.5011 e o mínimo 0. O tempo final obtido foi $T=0.845$. 


\section{5 \\ Conclusão}

Nosso objetivo era buscar aplicações da equação diferencial parcial do calor na indústria do petróleo. Iniciamos com a resolução numérica dessa equação pelo método das diferenças finitas implícito, para o domínio sendo uma placa quadrada plana homogênea com fontes de calor constantes em diferentes posicionamentos (Teste 1), e depois acrescentamos uma fonte de calor variável (Teste 2). Em seguida resolvemos a mesma equação, mas para o domínio sendo uma placa quadrada plana heterogênea, dividida em quatro regiões com condições internas possuindo fontes de calor constantes em diferentes posicionamentos (Teste 3), e depois acrescentamos uma fonte de calor variável (Teste 4). Resolvemos os problemas nos testes pelo método JFNK - Newton Krylov sem Jacobiano, que é o uso do Método dos Resíduos Mínimos Generalizados (GMRES) para resolver os sistemas lineares advindos do Método de Newton, sem precisarmos calcular a matriz jacobiana, pois usamos uma aproximação para ela. Por fim aplicamos esses conhecimentos para resolver um sistema de equações diferenciais parciais que representa o escoamento bifásico de água e óleo com coeficientes de difusividade constantes, onde as variáveis são a pressão do óleo e a saturação da água. Para isso utilizamos o método IMPES, resolvendo implicitamente para a pressão e explicitamente para a saturação. Sistemas como esse são importantes para a indústria do petróleo, pois concede informações a respeito dos fluidos, o que contribui para a exploração do óleo. Fizemos simulações numéricas de esquemas famosos largamente utilizados, como o five-spot e a injeção em linha, onde alcançamos soluções esperadas, o que mostrou uma boa qualidade nas simulações do nosso trabalho. 


\section{Referências bibliográficas}

[1] FRIEDMAN, A. Mathematics in Industrial Problems. Springer-Verlag, New York, 1st edition, 1988.

[2] FRIEDMAN, A.; LAVERY, J. How to Start an Industrial Mathematics Program in the University. SIAM, Philadelphia, 1st edition, 1993.

[3] ABOU-KASSEM, J. H.; ALI, F. S. M.; ISLAM, R. M. Petroleum Reservoir Simulation: A Basic Approach. Gulf Publishing Company, Houston, Texas, 1st edition, 2006.

[4] LEVEQUE, J. R. Finite Difference Methods for Ordinary and Partial Differential Equations: Steady-State and Time-Dependent Problems. Siam, Philadelphia, 1st edition, 2007.

[5] FAIRES, D. J.; BURDEN, R. L. Numerical Analysis. Cengage Lerning, Massachusetts, 10th edition, 2015.

[6] LIESEN, J.; STRAKOS, Z. Krylov Subspace Methods, Principles and Analysis. Oxford University Press, Oxford, UK, 1st edition, 2013.

[7] KNOLL, D.A.; KEYES, D.E. Jacobian-free newton-krylov methods: a survey of approaches and applications. Journal of Computational Physics, 193:357-397, 2004.

[8] KOU, J.; SUN, S. On iterative impes formulation for two-phase flow with capillarity in heterogeneous porous media. International Journal of Numerical Analysis and Modeling, 1:20-40, 2004.

[9] EVANS, L. C. Partial Differential Equations. AMS, Rhode Island, 1st edition, 1998.

[10] CUMinATO, J. A.; MENEGUETTE JR., M. Discretização de Equações Diferenciais parciais. SBM, Rio de Janeiro, 1st edition, 2013.

[11] HOFFMAN, K.; KUNZE, R. Linear Algebra. Prentice-Hall, New Jersey, 2nd edition, 1971. 
[12] SAAD, Y.; SCHULTZ, M. H. Gmres: A generalized minimal residual algorithm for solving nonsymmetric linear systems. SIAM Journal on Scientific and Statistical Computing, 7:856-869, 1986.

[13] ARNOLDI, W. E. The principle of minimized iterations in the solution of the matrix eigenvalue problem. Quarterly of Applied Mathematics, 9:17-29, 1951.

[14] GOLUB, G.H.; LOAN, C.F.V. Matrix Computations. The Johns Hopkins University Press, Baltimore, 4th edition, 2013.

[15] BROWN, P.N.; SAAD, Y. Convergence theory for nonlinear newton-krylov algorithms. SIAM - Journal on Optimization, 4:297-330, 1994.

[16] ROSA, A. J.; CARVALHO, R. S.; XAVIER, J. A. Engenharia de Reservatórios de Petróleo. Interciência, Rio de Janeiro, 1st edition, 2006.

[17] ERTEKIN, T.; ABOU-KASSEM, J.; KING, G. Basic Applied Reservoir Simulation. Society of Petroleum Engineers, Richardson, Texas, 1st edition, 2001.

[18] EZEKWE, N. Petroleum Reservoir Engineering Practice. PrenticeHall, Westford-USA, 1st edition, 2010.

[19] COATS, K. H. A note on impes and some impes-based simulation models. Society of petroleum engineers SPE, 5:245--251, 2000. 